\title{
The asymmetric Pitx 2 regulates intestinal muscular-lacteal development and protects against fatty liver disease
}

Shing $\mathrm{Hu}^{1}$, Aparna Mahadevan ${ }^{1}$, Isaac F. Elysee ${ }^{1}$, Joseph Choi ${ }^{1}$, Nathan R. Souchet ${ }^{1}$, Gloria H. Bae ${ }^{1}$, Alessandra K. Taboada ${ }^{1}$, Gerald E. Duhamel ${ }^{2}$, Carolyn S. Sevier ${ }^{1}$, Ge $\mathrm{Tao}^{3}$, and Natasza A. Kurpios ${ }^{1, *}$

${ }^{1}$ Department of Molecular Medicine, College of Veterinary Medicine, Cornell University, Ithaca, NY 14853, USA

${ }^{2}$ Department of Biomedical Sciences, College of Veterinary Medicine, Cornell University, Ithaca, NY 14853, USA

${ }^{3}$ Department of Regenerative Medicine and Cell Biology, Medical University of South Carolina, Charleston, SC 29425, USA

*Correspondence and Lead Contact: natasza.kurpios@ cornell.edu

RUNNING TITLE: Pitx $2 c$ regulates gut lymphatic development 


\section{SUMMARY}

Intestinal lacteals are the essential lymphatic channels for absorption and transport of dietary lipids and drive pathogenesis of debilitating metabolic diseases. Yet, organ-specific mechanisms linking lymphatic dysfunction to disease etiology remain largely unknown. In this study, we uncover a novel intestinal lymphatic program that is linked to the left-right (LR) asymmetric transcription factor Pitx2. We show that deletion of the asymmetric Pitx2 enhancer, ASE, alters normal lacteal development through the lacteal-associated contractile smooth muscle lineage. ASE deletion leads to abnormal muscle morphogenesis induced by oxidative stress, resulting in impaired lacteal extension and defective lymphatic-dependent lipid transport. Surprisingly, activation of lymphaticindependent trafficking directs dietary lipids from the gut directly to the liver, causing diet-induced fatty liver disease. In summary, our studies reveal the molecular mechanism linking gut lymphatic development to the earliest symmetry-breaking Pitx2 and highlight the important relationship between intestinal lymphangiogenesis and gut-liver axis.

KEYWORDS: left-right asymmetry; Pitx2; ASE enhancer; embryonic development; gut lymphatic development; lacteal development; lineage tracing; villus-axial smooth muscle; oxidative stress; dietary lipid transport; portal lipid transport; fatty liver disease.

\section{HIGHLIGHTS:}

Gut lymphangiogenesis is linked to Pitx2-driven LR asymmetry

$\sim$ Lacteal-associated smooth muscle requires $A S E$

$\sim A S E$ deletion leads to redox imbalance in intestinal smooth muscle lineage

$\sim A S E$ is required for the normal route of dietary lipid transport

$\sim$ Pitx $2^{A S E / A S E}$ neonates develop diet-induced fatty liver disease 


\section{INTRODUCTION}

Lymphatic vessels are a crucial component of the cardiovascular system and play a central role in several pathogenic processes including edema, hypertension, obesity, diabetes, inflammation, and metastasis [1-9]. In the intestine, the lymphatic vessels are essential for the absorption and transport of fats and fat-soluble nutrients, a function that distinguishes them from all other lymphatic channels. However, the molecular mechanisms governing their specialized functions remain unknown. Knowledge of how gut lymphatic development is regulated at the organ level will provide important insights into the mechanisms underlying these diseases.

The formation of gut lymphatic vessels follows blood vascular development [10]. Specifically, we have previously shown that gut lymphangiogenesis depends on prior establishment of arteries within the left side of the dorsal mesentery, the major conduit for blood and lymphatic vessels in the gut [11]. This process is regulated by the homeodomain transcription factor Pitx2, the major player responsible for the evolutionarily conserved left-right (LR) asymmetry of visceral organs [12-15]. Expression of Pitx2 on the left side of the dorsal mesentery drives gut rotation and the resulting gut chirality. Disruption of this leads to intestinal malrotation and volvulus, a catastrophic strangulation of the gut vasculature [16-18]. In this context, gut rotation must be carefully coordinated with the early positioning of blood and lymphatic vessels to prevent vascular occlusion and to endow lymphatics with their polarized absorptive function once they arise in the intestinal villus. Indeed, gut arterial development is commensurate with the onset of gut rotation and proceeds strictly on the left side of the dorsal mesentery dependent on Cxcl12-Cxcr4 signaling, downstream of Pitx2 [11]. Subsequent gut lymphangiogenesis is also left-sided and depends on prior arteriogenesis [11]. Pit $x 2^{-/-}$mouse embryos have gut arterial patterning defects and fail to initiate gut lymphatic development [11]. Thus, proper gut lymphatic development, like asymmetric gut rotation morphogenesis, depends on Pitx2 to link vessel patterning with the morphogenesis of the parent organ.

The Pitx gene family includes three vertebrate paralogues, Pitx1, Pitx2, and Pitx3, that share an almost identical homeodomain protein sequence, varying mainly in the $\mathrm{N}$ terminal region $[19,20]$. In mice, the Pitx2 gene maps to chromosome 3 [19] and is transcribed into three distinct isoforms: Pitx $2 a$, Pitx $2 b$, and Pitx $2 c$. The Pitx $2 a$ and Pitx $2 b$ splice variants share the same promoter and are expressed bilaterally in the embryo, while Pitx $2 c$, the major gut isoform, is transcribed from a separate promoter and is expressed asymmetrically [21-24]. Importantly, left-specific expression of Pitx $2 c$ is conferred by the evolutionarily conserved asymmetric Pitx2 enhancer, ASE [21, 22]. Pitx $2^{A S E / A S E}$ mutant mice fail to manifest most of the left-sided Pitx $2 c$ expression and exhibit some laterality defects similar to those of Pitx $2^{-/-}$mice [22, 25-27] and mice specifically lacking Pitx2c [28]. Importantly, unlike Pitx $2^{-/-}$embryos, most ASE mutants survive to birth and some reach weaning age, allowing analyses of gut lymphatic function in the absence of $A S E$.

To analyze the consequence of $A S E$ deletion, we first focused on the morphogenesis of lacteals, the absorptive lymphatic capillaries responsible for dietary fat uptake and gut immune surveillance [5, 29]. Fatty nutrients use lacteals as their major transport route, where lipids packaged into lipoprotein particles (chylomicrons) drain into larger mesenteric collecting vessels and ultimately to the systemic blood circulation [9, 30-32]. 
In contrast, non-lipid nutrients enter the portal circulation for primary delivery to the liver [9, 30-32]. Lacteals form around embryonic (E) day 17.5 and are functionally ready to absorb lipids from milk at birth [10]. Signaling via the lymphangiogenic vascular endothelial growth factor C (VEGF-C), the main VEGF receptor, VEGFR-3, and its coreceptor neuropilin 2 (NRP2), plays a key role in driving postnatal lacteal sprouting and lacteal growth $[33,34]$. Although the majority of adult lymphatic vessels are quiescent, intestinal lacteals, similar to intestinal epithelium, are in a constant state of regeneration throughout adulthood, a process dependent on the formation of lacteal filopodia extensions at the lacteal tip [35]. Moreover, whereas most lymphatic capillaries lack smooth muscle coverage, lacteals are surrounded by contractile bundles of axial smooth muscle cells (SMCs) [36], which secrete lymphangiogenic growth factors [37] and facilitate lipid transport by squeezing the lacteal under autonomic nervous system control [38].

Here we show that Pitx2 is required for the development and function of lacteals through a non-cell autonomous pathway that involves lacteal-associated contractile axial SMCs. Loss of asymmetric Pitx 2 expression, induced by ASE deletion, results in abnormal axial SMC morphogenesis caused by oxidative stress, leading to impaired extension of the developing lacteals and defective lymphatic-dependent lipid transport. Unexpectedly, we found that $A S E$ deletion resulted in shunting of dietary lipid transport to the portal circulation resulting in excessive accumulation of lipids within the liver, and severe hepatic lipidosis (fatty liver disease) in Pitx $2^{A S E / A S E}$ neonatal pups. We propose that this alternative lymphatic-independent transport of dietary lipids is active in Pit $x 2^{A S E / A S E}$ pups because lymphatic structure and transport within the intestinal villus is compromised. In summary, our studies reveal a molecular mechanism linking gut lymphatic development and function to the earliest symmetry-breaking events governed by Pitx2 and highlight the important relationship between the intestinal lymphatic vasculature and the gut-liver axis. Moreover, our studies demonstrate how the Pitx2 gene continues to orchestrate postnatal intestinal development and function beyond its well-established roles in early LR asymmetry. 


\section{RESULTS}

\section{Loss of LR asymmetric Pitx2 enhancer ASE results in growth retardation and early postnatal lethality}

The Pitx2 gene encodes three isoforms (Pitx2a, Pitx2b, Pitx2c) (Fig. 1A). Pitx2c, the major isoform in the gut, is expressed asymmetrically via a conserved enhancer, ASE [22]. Pit $x 2^{-/}$ mouse embryos lacking all isoforms (Pitx $2^{\text {hd/hd }}$ ) [25] fail to initiate gut lymphangiogenesis and die by E14.5 precluding analysis of gut lymphatic development [11] (Fig. 1BC). To explore the role of Pitx2 in gut lymphatics, we studied mice lacking ASE (Pitx ${ }^{A S E / A S E}$ ), which fail to manifest left-sided Pitx2c expression but survive to birth [22] (Fig. 1BC).

Whereas most Pitx $2^{A S E / A S E}$ mice die within hours after birth (C57BL/6 x 129 mixed background), we noted that some Pitx $2^{A S E / A S E}$ newborns on the FVB background remain viable for $\sim 10$ days after birth $(21.6 \%$, Fig. $1 \mathrm{C}$ and Fig. S1) while an even smaller subset survive past weaning age $\left(4.7 \%\right.$, Fig. 1C). Collectively, the Pitx $2^{A S E / A S E}$ mouse model allows analyses of gut lymphatic development and function in the absence of ASE.

Intestinal lymphatics are the essential channels for absorption and transport of dietary lipids. Thus, to briefly evaluate intestinal lymphatic function of $A S E$ in dietary lipid transport, we first compared post-feeding weight gain between wild type (WT), Pitx $2^{A S E /+}$ heterozygous, and Pit $x 2^{A S E / A S E}$ homozygous neonates. Despite being born with comparable body weight, Pitx $2^{A S E / A S E}$ homozygous pups had severely retarded growth at 24-48 hours and at postnatal (P) day P9 (Fig. 1D and Fig. S1). Importantly, this was not a consequence of variable food ingestion, as ample milk was seen in all neonatal stomachs analyzed, regardless of genotype (Fig. 1D). Thus, failure to properly gain weight in Pitx $2^{A S E / A S E}$ mutant pups was due to malabsorption rather than insufficient food intake, implicating a role for $A S E$ (and Pitx2c) in lymphatic transport function.

\section{$A S E$ is required for lacteal extension and formation of lacteal filopodia}

Intestinal lipid transport is driven by lacteals at the center of each intestinal villus (Fig. $\mathrm{S} 2 \mathrm{~A})$. We hypothesized that failure to properly gain weight in Pitx $2^{A S E / A S E}$ pups is due to abnormal lacteal development in the absence of $A S E$. Lacteals can be detected as early as E17.5 using the lymphatic endothelial cell marker Lyve-1 [10] (Fig. S2A). We first characterized embryonic and postnatal lacteal development in WT and Pitx $2^{\text {ASE/ASE }}$ mice using Lyve-1 immunofluorescence (IF) on gut slices (Fig. S2B). First, we observed a significant reduction in the number of Lyve-1+ lacteals in Pitx $2^{A S E / A S E}$ embryos at E18.5 (Fig. S2C) and again at P9 (Fig. S2C), suggesting a role for Pitx2 in lacteal development. Next, we noted that lymphatic endothelial cells at the tip of the lacteals extend long filopodia in WT neonatal intestines, consistent with active sprouting and migration (P1.5, Fig. 2A, arrows) [39]. Moreover, extension of long filopodia was largely restricted to the tip cell of the lacteals (Fig. 2A, arrows). We observed that $\sim 73 \%$ of WT lacteals harbor at least one filopodium at P1.5 (Fig. 2A; $72.90 \pm 2.760 \%, n=16$ ), in agreement with prior studies in adulthood [35]. By contrast, we observed that most Pitx $2^{A S E / A S E}$ mutant lacteals are missing filopodia at P1.5 (Fig. 2A, arrowheads; $41.28 \pm 3.545 \%, \mathrm{n}=10, \mathrm{p}=0.0001$ ). Similar results were obtained following isoform-specific deletion of Pitx2c (Fig. 2B; WT: $81.38 \pm 4.660, \mathrm{n}=3 ;$ Pitx $\left.2 c^{-/}, 41.13 \pm 5.604, \mathrm{n}=4 ; \mathrm{p}=0.0034\right)$. Filopodia formation 
remained suppressed during later stages of development (P9), a phenotype that exacerbated with time (Fig. 2C; WT, $49.66 \pm 4.200 \%, \mathrm{n}=8 ;$ Pitx $2^{\text {ASE/ASE }}, 8.543 \pm 2.610 \%$, $\mathrm{n}=3 ; \mathrm{p}=0.0003$ ).

Consistent with filopodia defects, Pitx $2^{A S E / A S E}$ lacteals were significantly shorter than those of control littermates at P1.5 (Fig. 2A; WT, $176.1 \pm 6.401 \mu \mathrm{m}, \mathrm{n}=17$; Pitx2 ${ }^{\text {ASE } / A S E}$, $143.7 \pm 6.392 \mu \mathrm{m}, \mathrm{n}=10, \mathrm{p}=0.0026$ ) and again at P9 (Fig. 2C; WT, $222.7 \pm 8.252 \mu \mathrm{m}, \mathrm{n}=8$; Pitx $\left.2^{\text {ASE/ASE }}, 144.6 \pm 9.518 \mu \mathrm{m}, \mathrm{n}=3, \mathrm{p}=0.0005\right)$. Whereas WT lacteals elongated by $50 \mu \mathrm{m}$ from P1.5 to P9 (Fig. 2AC; P1.5, $176.1 \pm 6.401 \mu \mathrm{m}, \mathrm{n}=17$; P9, $222.7 \pm 8.252 \mu \mathrm{m}$, $\mathrm{n}=8$ ), such lacteal extension was halted in Pitx $2^{\overline{A S E} / A S E}$ mutant pups, despite normal villus length (Fig. 2AC; P1.5, $143.7 \pm 6.392 \mu \mathrm{m}, \mathrm{n}=10 ; P 9,144.6 \pm 9.518 \mu \mathrm{m}, \mathrm{n}=3$ ). In summary, we conclude that during gut lymphatic development, $A S E$ is required for lacteal extension and lacteal filopodia formation.

\section{Pitx2 daughter cells populate lacteal-associated smooth muscle}

Whereas a vascular-specific role for Pitx2 has been documented both in vitro and in vivo [11, 22, 40-42], to our knowledge, endothelial cell-specific expression of Pitx2 has never been detected. To determine whether Pitx2 acts autonomously in lymphatic endothelial cells or in a non-cell autonomous manner during lacteal morphogenesis, we performed Pitx $2^{\text {Cre }}$ (knock-in) lineage tracing to follow Pitx 2 daughter cells in the gut (Fig. S3AA'A"). Pitx $2^{\text {Cre }}$ is a null Pitx2 allele that drives Cre activity in cells that have expressed any Pitx2 isoform throughout embryonic development, including the Pitx2c asymmetric isoform [28] (Fig. S3A). To follow Pitx2 daughter cells, we crossed Pitx $2^{\text {cre }}$ heterozygotes with Rosa26 (R26R-tdTomato) reporter mice (Fig. S3A).

TdTomato-marked Pitx 2 daughter cells were easily detected in the intestine, consistent with the described role of Pitx2 during midgut development (Fig. S3A'). Consistent with prior reports, Pitx2 daughter cells did not populate CD31-positive blood endothelial cells (BECs), or Lyve1-positive lymphatic endothelial cells (LECs) at any time point analyzed (E14.5, E16.5, E18.5, P1.5, P9, 6 months, n=19) (Fig. S3A"). Instead, we found Pitx2 daughter cells among the $\alpha$-smooth muscle actin ( $\alpha \mathrm{SMA})$-positive smooth muscle cells of the intestine, including villus-axial smooth muscle cells (SMCs) that are closely associated with lacteals [36, 43] (Fig. 3A'A"A", white arrowheads and Fig. 3B, WT). We confirmed this observation using ASE-specific lineage tracing with Rosa26 (R26R-EYFP) reporter mice, where the activity of Cre is driven by an $\sim 18 \mathrm{~kb}$ genomic fragment containing ASE and the Pitx2c promoter [44] (Fig. 3A"",, white arrowheads).

In addition to axial SMCs, we found a discrete fraction of TdTomato-marked Pitx2 (Fig. 3A', white arrows) and YFP-marked ASE (Fig. 3A"', white arrows) daughter cells morphologically different from axial SMCs and in close proximity to, but distinct from, the CD31+ blood capillary plexus of the villous lamina propria (Fig. 3A"', white arrows). Based on their location within the villus and morphological appearance these cells may lie upstream in the lineage compared to the more mature axial SMCs and may be involved in muscular regeneration at later stages (Fig. 3A", white arrows, 6 months). Taken together, these findings suggest that Pitx2 regulates lacteal development through a non-cell autonomous pathway, and underscore a role for Pitx2 in smooth muscle patterning of the intestinal lamina propria. 


\section{Loss of ASE impairs lacteal-associated axial smooth muscle development}

A subset of axial SMCs secretes VEGF-C [37], the critical lymphatic morphogen. Loss of VEGF-C-driven activation of VEGFR-3, the main VEGF receptor expressed by lacteals, leads to arrested lacteal growth [37]. Moreover, axial SMC contraction can squeeze the adjacent lacteal to drive lipid transport [38]. Therefore, villus-axial SMCs may provide the principal cues for development of lacteals. We therefore hypothesized that Pitx2 is indirectly required for lacteal morphogenesis via SMC patterning. We first studied the villus smooth muscle histopathological structure in WT and Pitx $2^{\text {ASE/ASE }}$ mice post weaning, at P26 (Fig. S3B). Compared to robust villus smooth muscle coverage in WT mice, we observed a severe reduction in smooth muscle of the lamina propria in Pitx $2^{A S E / A S E}$ mice, consistent with a role of Pitx2 in villus smooth muscle development (Fig. S3B, red arrowheads).

To corroborate these findings and to characterize the muscular-lacteal complex inside the villus at high resolution, we examined WT and Pit $x 2^{A S E / A S E}$ gut slices using confocal microscopy with $\alpha$ SMA (smooth muscle) and Lyve-1 (lacteal) IF. In WT pups at P9, $\alpha \mathrm{SMA}+$ cells were closely intertwined with each other and with Lyve-1+ lacteals, a striking pattern with "closed" muscle bundle morphology, suggesting active muscular contraction squeezing the lacteal (Fig. 3BE). In contrast, age-matched Pitx $2^{A S E / A S E}$ mutants displayed a wide spectrum of muscular-lacteal abnormalities, including misaligned axial SMCs with absent lacteals, reduced axial SMC numbers, loss of direct SMCs-LECs contact, and "open" bundle conformation leaving spaces between individual muscle bundles and lacteals (Fig. 3BE). We quantified a significant increase in open axial smooth muscle bundles within Pitx $2^{A S E / A S E}$ villi, compared with control mice (Fig. 3BC; WT, $33.51 \pm 3.950 \%, \mathrm{n}=6$; Pitx $\left.2^{\text {ASE/ASE }}, 76.12 \pm 7.775 \%, \mathrm{n}=3, \mathrm{p}=0.0009\right)$. Moreover, using immunohistochemistry (IHC) of transverse tissue sections through the villus, we showed that unlike the close association of WT axial SMCs with adjacent lacteals (Fig. 3DE, arrows), Pitx $2^{A S E / A S E}$ axial SMCs and lacteals failed to tightly align (Fig. 3DE, arrowheads). Thus, $A S E$ regulates the morphogenesis of villus axial smooth muscle, which further directs intestinal lymphatic development.

\section{Lacteal-associated axial SMCs arise by ASE-dependent remodeling}

Villus-axial SMCs were first identified in ultrastructural studies in 1909 [45]. The ultrastructure was characterized in the rat and was considered vital to providing structural tension against interstitial pressure while driving villous rhythmical contraction in close relationship with the adjacent fibroblasts $[36,46]$. More recent in vivo imaging in mice has revealed that villus SMCs promote lateral villus contractions, dependent on the autonomic nervous system, and facilitate lipid transport by squeezing the lacteal [38]. Despite the crucial interplay between axial SMCs and lacteal function, the origins and patterning mechanisms of axial SMCs remain unexplored.

To investigate muscle formation alongside lacteals, we assessed the dynamics of villous muscular formation in WT mice from E16.5 to P9 (Fig. 4A and Fig. S4A). Cells expressing low levels of $\alpha \mathrm{SMA}(\alpha \mathrm{SMA}+)$ were first detected in the villus at E16.5, before the emergence of lacteals (Fig. S4A). Morphologically, $\alpha$ SMA+ cells within the villus appeared star-shaped with multiple protrusions (Fig. 4A, inset, 
"star cells"), and aligned closely with the CD31+ blood vascular plexus (Fig. S4A). Interestingly, $\alpha \mathrm{SMA}+$ star cells were reminiscent of TdTomato-marked Pitx2 and YFPmarked ASE daughter cells we previously observed (Fig. 3A'A"', white arrows). Strikingly, coincident with the appearance of lacteals at E18.5, $\alpha \mathrm{SMA}+$ cells underwent a robust transformation to elongated, spindle-like cell types with strong immunoreactivity for $\alpha \mathrm{SMA}(\alpha \mathrm{SMA}++)$, and in close association with lacteals (Fig. 4A, graph). At P1.5, the number of spindle-like $\alpha \mathrm{SMA}++$ cells became predominant at the expense of $\alpha \mathrm{SMA}+$ star cells (Fig. 4A, graph). At P9, all $\alpha \mathrm{SMA}++$ spindle cells were located adjacent to the lacteal, extending radially from the submucosa to the filopodium at the tip of the lacteal, while very few $\alpha \mathrm{SMA}+$ star cells were detected at this time (Fig. 4A and Fig. S4D).

Interestingly, $\alpha \mathrm{SMA}+$ star cells were actively proliferative (Fig. $4 \mathrm{~B}, \sim 10 \%$ ) compared to very few proliferating $\alpha$ SMA++ spindle-like axial SMCs (Fig. 4B), as judged by phospho-histone $\mathrm{H} 3$ ( $\mathrm{pH} 3$ ) immunoreactivity. This agrees with previous observations that only round muscular progenitor cells (but not mature spindle muscles) are proliferative $[47,48]$. Consistent with $\alpha$ SMA++ spindle cells resembling more differentiated muscle cells, they expressed high levels of myosin heavy chain 11 (Myh11), one of the major contractile proteins in SMCs [49] (P9, Fig. S4D). In contrast, (putative progenitor) $\alpha \mathrm{SMA}+$ star cells showed very weak immunoreactivity for Myh11 (P9, Fig. S4D, white arrows). Collectively, these observations suggest that villus-axial smooth muscle development is commensurate with the formation of lacteals and proceeds by a robust spatiotemporal remodeling program whereby $\alpha \mathrm{SMA}+$ precursor star cells proliferate and assemble to create and shape the mature axial SMC network of the lacteal (Fig. 4E). Of note, axial SMCs were largely juxtavascular and this was especially evident for SMCs at the lacteal filopodia (Fig. S4C), highlighting an important reciprocal interaction with the adjacent lymphatic endothelium.

Next, we examined villus-axial SMC dynamics in the absence of $A S E$. As in WT villi, we first detected $\alpha$ SMA+ star cells in the Pit $x 2^{A S E / A S E}$ mutants at E16.5, with no differences observed in the proportion of villi containing $\alpha \mathrm{SMA}+$ star cells among all genotypes tested (data not shown). However, two days later, at E18.5 we found fewer $\alpha$ SMA++ spindle-like axial SMCs in Pitx $2^{A S E / A S E}$ mutants compared to WT littermates (Fig. 4D; WT, $62.98 \pm 7.52 \%, \mathrm{n}=6$; Pit $x 2^{A S E / A S E}, 36.93 \pm 4.41 \%, \mathrm{n}=6, \mathrm{p}=0.0136$ ). Moreover, in contrast to WT neonates, a significant number of $\alpha \mathrm{SMA}+$ star cells remained in the lamina propria of Pitx $2^{A S E / A S E}$ mutants at P1.5 (Fig. 4CD; WT, $12.25 \pm$ $4.917 \%, \mathrm{n}=6$; Pitx $\left.2^{A S E / A S E}, 42.42 \pm 3.510 \%, \mathrm{n}=5, \mathrm{p}=0.0010\right)$. These star cell-retained Pitx $2^{A S E / A S E}$ villi (Fig. 4C, white arrows) had less prominent muscular bundles surrounding the lacteals (Fig. 4C, white arrowheads).

TUNEL staining of WT and Pitx $2^{A S E / A S E}$ mutants at P9 revealed no difference in villous SMC cell death (Fig. S4E). Using IHC and histopathological analyses, apoptotic or necrotic cells were not seen in E18.5, P1.5, and P9 Pitx $2^{A S E / A S E}$ villi, while villous SMC proliferation was similarly unaffected in Pitx $2^{A S E / A S E}$ at E18.5 (data not shown). These observations suggest that neither cell death nor cell cycle arrest at the stages examined contributes to the $A S E$-dependent axial SMC phenotypes. Instead, we propose that $A S E$ functions in villous-axial SMC morphogenesis during their fetal to neonatal transition (Fig. 4E). 


\section{$A S E$ deletion leads to redox imbalance in intestinal smooth muscle}

To explore the cause of muscular-lacteal impairment in Pitx $2^{\text {ASE/ASE }}$ mutant intestines, whole intestine transcriptomics (RNA-seq) of both WT and Pitx $2^{A S E / A S E}$ neonatal tissue at P1.5 was performed. Notably, $\sim 20 \%$ of genes differentially expressed between WT and Pitx $2^{A S E / A S E}$ mutant intestines corresponded to reactive oxygen species (ROS) production, antioxidant scavenging genes, and redox-sensitive signaling pathways (Fig. 5A). Among potential targets were genes that protect the cell from oxidative stress, such as the glutamate-cysteine ligase ( $G c l c$, also known as gamma-glutamylcysteine synthetase), the first rate-limiting enzyme of glutathione synthesis [50-52]. Interestingly, half of the ROSrelated differentially expressed genes are directly bound by Pitx 2 in vivo [51] including the noncoding region of Gclc (Fig. S5A). These data raised the possibility that Pitx2c may directly regulate oxidation-reduction (redox) balance in intestinal smooth muscle.

To investigate whether $A S E$ deletion leads to a redox imbalance in the intestine, we detected and quantified spectrophotometrically protein carbonylation in WT, Pitx $2^{A S E /+}$ heterozygous, and Pitx2 $2^{A S E / A S E}$ neonatal intestines at P1.5. Carbonyl groups (Fig. 5B) are an irreversible product of ROS-mediated protein oxidation and a general biomarker for oxidative stress [52-54]. We observed Pitx $2^{A S E / A S E}$ intestines harbor 2.5-times more protein carbonyl content compared to their WT or Pitx $2^{A S E /+}$ littermates (Fig. 5B'; WT/Het: $2.760 \pm 0.3194 \mathrm{nmol} / \mathrm{mg}, \mathrm{n}=7 ;$ Pitx $2^{\text {ASE/ASE }} 6.833 \pm 0.4567 \mathrm{nmol} / \mathrm{mg}, \mathrm{n}=3$, $\mathrm{p}=0.0001$ ), demonstrating that $A S E$ loss increases irreversible oxidative damage in the neonatal intestine. We also assessed protein carbonylation levels by electrophoresis, after labeling carbonyl groups in protein extracts from WT, Pitx $2^{A S E /+}$, and Pitx $2^{A S E / A S E}$ neonatal intestines at P1.5 with biotin-hydrazine (biotin-HZ). Proteins were SDS-PAGEseparated, and probed on nitrocellulose with streptavidin-conjugated horseradish peroxidase (SA-HRP). Consistent with the spectroscopic measurements (Fig. 5B'), a higher total level of carbonylated proteins (overall darker lane signal) was observed in the Pitx $2^{A S E / A S E}$ intestine lysate relative to controls (Fig. 5C).

Interestingly, a well-defined carbonylated protein band of $\sim 42 \mathrm{kDa}$ was enriched in Pitx $2^{A S E / A S E}$ intestinal extracts versus controls (Fig. 5C). This band is consistent in size with monomeric actin. Probing the same lysates for $\alpha$ SMA showed actin levels were similar among all genotypes (Fig. 5C), suggesting the possibility that levels of oxidized actin were enriched in Pitx $2^{A S E / A S E}$ intestines.

The dynamic actin cytoskeleton is susceptible to oxidation, which regulates cell behavior and contractility pathways [55]. Oxidized actin is linked to decreased actin monomer (G-actin) assembly and actin filament (F-actin) stability [56]. Oxidation of select cysteine and methionine residues in actin causes structural changes, monomer aggregation, decreased actin polymerization and stability, and defective cell contractility [57-60]. Actin carbonylation is associated with even higher oxidant levels than those associated with the modification of critical cysteine and methionine residues, and an accumulation of carbonylated actin has been proposed to indicate severe oxidative stress and functional impairment [61]. Interestingly, we noted discontinuous patterns of $\alpha \mathrm{SMA}$ arrangement in Pitx $2^{A S E / A S E}$ axial SMCs reminiscent of the severed F-actin filaments seen under oxidative stress (Fig. S5B). Altogether these data led us to hypothesize that ASE 
deletion impaired villus-axial smooth muscle morphogenesis due to abnormal accumulation of high levels of ROS in the differentiating smooth muscle.

To test our hypothesis, we directly assessed the oxidation status of smooth muscle actin in WT and Pitx $2^{A S E / A S E}$ neonatal intestines (Fig. 5D-E). Streptavidin-enrichment of biotin-labeled carbonylated proteins confirmed that actin was carbonylated and that Pitx $2^{A S E / A S E}$ yielded the highest amount of carbonylated $\alpha$ SMA (Fig. 5D). Immunoisolation of $\alpha$ SMA from biotin-HZ-labeled lysates similarly confirmed an increased level of carbonylated $\alpha$ SMA in Pitx $2^{A S E / A S E}$ intestine by comparison to WT or Pitx $2^{A S E /+}$ heterozygous littermates (Fig. 5E). These results demonstrate that loss of ASE induced irreversible oxidative damage in $\alpha$ SMA+ cells of the neonatal intestine. Collectively, our data suggest that elevated levels of oxidative stress caused muscularlacteal impairment in Pitx $2^{A S E / A S E}$ intestines, pointing to a crucial role for Pitx2 in the control of ROS during early smooth muscle development.

\section{$A S E$ is required for the normal route of dietary lipid transport}

The intestinal lacteal-lymphatic vasculature network is the major route through which long-chain fatty acids are absorbed as triglycerides into the body [62]. These lipids are packaged into large specialized lipoproteins called chylomicrons, which are secreted by intestinal epithelial cells $[63,64]$. In contrast, non-fatty nutrients and shorter chain fatty acids are able to directly enter the hepatic portal circulation for processing within the liver [62]. This lymphatic-independent portal transport is insignificant compared with the lymphatic route, except under certain pathological conditions where disrupted intestinal circulation leads to lipid accumulation in the liver [65-74].

To assess whether the intestinal lymphatic structural defects caused by ASE deletion impaired gut lymphatic function, we orally administered fluorescent BODIPY C16, a fluorescent long-chain fatty acid tracer, to WT and Pitx $2^{A S E / A S E}$ neonatal mice to follow lipid trafficking (Fig. 6A) [75]. As expected, long-chain BODIPY C16 entered the lumen of the intestine and mesenteric collecting vessels after oral administration (Fig. 6A), with very little staining of hepatic portal circulation in WT pups (Fig. 6B). Strikingly, longchain BODIPY C16 accumulation was found in the hepatic portal vein and liver parenchyma of Pitx $2^{A S E / A S E}$ mutant pups (Fig. 6B; liver, liver section, hepatic portal vein), confirming abnormal lipid trafficking in the absence of ASE. Notably, BODIPY C16 remained detectable in the mesenteric collecting lymph vessels of Pitx $2^{\text {ASE/ASE }}$ pups implying a partial, rather than complete, shift in lipid transport in the absence of ASE (Fig. S6). Collectively, ASE deletion impairs normal long-chain fatty acid lymphatic trafficking resulting in direct lipid entry into the hepatic portal circulation (Fig. 6C).

\section{$P$ Pitx $2^{A S E / A S E}$ mice develop diet-induced fatty liver disease}

Aberrant dietary lipid transport by the hepatic portal venous circulation can accumulate lipid within hepatocytes, resulting in histological features consistent with hepatic lipidosis. Indeed, changes characteristic of lipid accumulation were grossly apparent in Pitx $2^{A S E / A S E}$ mutant livers at P9. Thus, we compared liver lipid content in prenatal and postnatal WT and Pitx $2^{A S E / A S E}$ mice using oil red O, a fat-soluble dye that stains neutral triglycerides and lipids [76] (Fig. 7A). Consistent with our prior BODIPY C16 feeding 
data, increased oil red $\mathrm{O}$ staining in livers of postnatal, but not prenatal (unfed), Pitx $2^{A S E / A S E}$ mice, suggested hepatic lipid accumulation in Pitx $2^{A S E / A S E}$ livers is a consequence of post-partum nursing. Excessive hepatic lipid accumulation was observed as early as P1.5 and in $100 \%(\mathrm{n}=4 / 4)$ of Pitx $2^{A S E / A S E}$ pups analyzed (Fig. 7A). Hepatic lipid accumulation in P1.5 was confirmed based on by ultrastructural examination by transmission electron microscopy (tEM) (Fig. S7A).

At P9-P11, oil red $\mathrm{O}$ staining was even more robust (Fig. 7A). Moreover, H\&E analysis of affected pups at P9 revealed excessive hepatic lipid accumulation in $92 \%$ $(\mathrm{n}=11 / 12)$ of Pitx $2^{A S E / A S E}$ pups (Fig. S7B), with variable parenchymal extinction and multifocal subcapsular mineralization (Fig. 7B). Importantly, no significant changes in hepatic structure, hepatocyte mitochondria morphology, or extramedullary hematopoiesis were observed between Pitx $2^{A S E / A S E}$ and WT littermates (data not shown), ruling out primary liver impairment.

While the lipid content of murine maternal milk is 17-30\% [77], the lipid content in standard mouse chow diet is 6-10 fold lower $(\sim 3 \%)$. We noticed that hepatic lipidosis in Pitx $2^{A S E / A S E}$ suckling pups gradually resolved once these pups were weaned (P21) and transitioned to a dry pellet diet (Fig. 7B). Severe hepatic lipidosis in Pitx $2^{A S E / A S E}$ pups was seen in only $50 \%(\mathrm{n}=2 / 4)$ of pups at P21 (compared to $92 \%$ at $\mathrm{P} 9$ ) and was further reduced to $25 \%(\mathrm{n}=1 / 4)$ at $\mathrm{P} 26$, and $0 \%$ after P30 $(\mathrm{n}=0 / 2)$ (Fig. S7B). Importantly, the intestinal lymphatic lesions caused by $A S E$ deletion did not resolve with age or weaning or a change of diet. This is a strong indication that adult mature mice remain susceptible to lipid accumulation dependent on their diet. These lesions included lacteal filopodia defects (Fig. 7C; WT, $28.81 \pm 7.915 \%$, n=5; Pitx2 ${ }^{A S E / A S E}, 5.833 \pm 3.967 \%, \mathrm{n}=4, \mathrm{p}=$ 0.0012 ), open versus closed axial smooth muscle (Fig. 7C; WT, $13.08 \pm 2.637 \%$, n=5; Pitx2 $2^{A S E / A S E}, 73.85 \pm 9.599 \%, \mathrm{n}=4, \mathrm{p}=0.0003$ ), and severe axial smooth muscle hypoplasia (Fig. S3B). Collectively, these data suggest that high fat diet (in this case maternal milk) drives the pathogenesis of fatty liver in Pitx $2^{A S E / A S E}$ pups, and that Pitx2c/ASE protects against such changes by directing normal villous smooth muscle morphogenesis and the dependent process of gut lymphatic development.

\section{DISCUSSION}

We have leveraged the ASE mouse model to characterize intestinal lymphatics and lipid transport function in the absence of the LR asymmetric transcription factor Pitx2. Our work demonstrates a new role for the LR axis in the development and physiology of intestinal lymphatics, linking gut lymphatic morphogenesis to the earliest LR symmetrybreaking events in the gut. We found that Pitx2 functions during lacteal morphogenesis by regulating cellular redox in the adjacent smooth muscle lineage. We propose that lacteal-associated contractile SMCs are of blood vessel origin and arise during embryonic development by $A S E$-dependent remodeling of villous blood capillary-associated muscle progenitors to support dietary lipid transport soon after birth. ASE deletion, which leads to malformation of the SMC-lacteal complex results in abnormal lipid trafficking, which underscores the important reciprocal interplay between smooth muscle development and lacteal function in dietary lipid transport. Collectively, our studies highlight the critical 
integration of LR patterning signals that asymmetric viscera must execute from early axis specification through to mature organ function.

\section{Pitx2 in intestinal smooth muscle development}

The evolutionarily conserved process of LR asymmetry is a fundamental aspect of the body plan, errors in which form an important class of human birth defects. Whereas the intestine begins as a symmetrical midline tube, it later rotates and loops in a highly conserved, asymmetric pattern necessary for correct packing into the body cavity. Gut asymmetry initiates with a critical leftward tilt driven by molecular and cellular asymmetries within the left and right sides of the dorsal mesentery, which suspends the gut tube. These events are orchestrated by Pitx2 expressed in all cells of the left dorsal mesentery [16]. To avoid strangulation of gut vessels during looping morphogenesis, Pitx2-dependent mechanisms directing initial gut rotation also pattern the emerging gut vasculature, linking the complex steps of vascularization with the morphogenesis of the parent organ $[11,78]$.

In addition to directing asymmetric gut development, the dorsal mesentery is the major source of smooth muscle progenitors of the gut vasculature [79, 80]. This raises the possibility that Pitx2 may also regulate intestinal smooth muscle patterning. Using lineage tracing experiments to follow Pitx2 (and ASE) daughter cells in the gut, we show that Pitx2 descendants populate multiple intestinal smooth muscle layers, including the lacteal axial SMCs that drive lacteal contraction and efficient lipid transport in the postnatal period [38]. Interestingly, not all axial SMC bundles within the villus are descendants of Pitx2 (Fig. 3A"A"'), suggesting an additional source of muscle progenitors within the dorsal mesentery and raising important questions about the overall functional heterogeneity among lacteal-associated axial SMCs. Whereas Pitx2 is the primary determinant in the left dorsal mesentery, the T-box transcription factor Tbx18 is one of the most highly differentially expressed genes on the right side, and its asymmetric expression within the dorsal mesentery correlates with cellular behavior $[16,18]$. In the kidney, Tbx18derived progenitor cells give rise to vascular SMCs that originate from stromal precursors, and stromal cell differentiation requires $T b x 18$ function to form the renal vasculature [81, 82]. Therefore, Tbx18+ cells within the right dorsal mesentery may provide an additional source of axial SMCs, functionally distinct from those on the left. Similar heterogeneity has recently been demonstrated within the villous fibroblast compartment, highlighting the importance of the dynamic paracrine milieu of the lamina propria to the overall integrity and function of intestinal lymphatic vasculature [83].

In addition to populating axial SMCs, Pitx2 daughter cells were also found in close proximity to the villous blood capillary plexus suggesting that they are blood capillaryassociated immature mesenchymal precursors to the more mature muscle (Fig. 3A'A"'"). Pitx2 daughter cells were also found in a subpopulation of the circular and longitudinal visceral smooth muscle layers within the muscularis externa (data not shown), which drives lymph propulsion through gut peristalsis, suggesting that Pitx2 may regulate overall gut motility. Consistent with this idea, Pitx2 serves to modulate the expression of several contractile proteins in the skeletal muscle including myosin heavy chain (MyHC) isoforms and the contractile regulatory proteins troponin I and troponin T [84]. Moreover, during myogenic development, Pitx2 is downstream of Pax3/7 [85, 86] and upstream of 
the myogenic factor genes Myf5, Myf6, and MyoD [85, 86]. Mutations of Pitx1, Pitx2, and Pitx3 result in developmental defects in humans, including muscle disorders such as Facioscapulohumeral Muscular Dystrophy [87], Axenfeld-Rieger syndrome [88], and Anterior Segment Mesenchymal Dysgenesis[89], respectively. Most of what is known about Pitx2 in the molecular control of myogenesis concerns skeletal muscle, derived from paraxial mesoderm. Here, our work provides new insights into the function of Pitx2 in the visceral smooth muscle from splanchnic mesoderm and suggest Pitx2-mediated mechanisms are involved in intestinal SMC morphogenesis. We speculate that the regulation of muscle biology is a common property of Pitx transcription factors at their distinct spatiotemporal sites of expression.

\section{Pitx2-dependent formation of the lacteal-associated axial SMC complex}

Although recent studies have revealed novel insights into the formation of the muscularis externa [90], the origins and mechanisms of lacteal-associated axial SMC formation remain unexplored. Our spatiotemporal characterization of villous muscular formation demonstrate that the cellular origin of axial SMCs does not appear to be a continuous extension from the submucosal lymphatic vasculature, as these vessels are devoid of muscle coverage [29]. Instead, our data suggest that lacteal-associated SMCs arise from villous blood capillary-associated star-like muscle progenitors in a process regulated by $A S E$. In the adult blood vessels, differentiated muscle cells proliferate at extremely low rates, exhibit low synthetic activity, and express a unique repertoire of contractile proteins $[49,91]$. Consistent with axial SMCs resembling a more differentiated muscle cell type, we show that they exhibit a low rate of proliferation, are strongly $\alpha$ SMApositive, and express high levels of Myh11. In contrast, $\alpha \mathrm{SMA}+$ star cells are proliferative and show weak immunoreactivity for $\alpha$ SMA and Myh11. Thus, our data suggest that blood capillary-associated star cells likely represent less differentiated smooth muscle progenitor phenotype and lie upstream of the more mature bundles of axial SMCs. Of note, a small number of $\alpha \mathrm{SMA}+$ star cells remains in WT villi at P9 (Fig. $\mathrm{S} 4 \mathrm{D})$. This raises the possibility that these cells may contribute to further postnatal axial muscular development or regeneration during adult life. It is also conceivable that many more star-like progenitors remain in the villus but have lost $\alpha$ SMA expression akin to SMC phenotypic switching [47, 48]. These cells would be undetectable by smooth muscle markers postnatally.

The timely transition from $\alpha \mathrm{SMA}+$ star cells to elongated spindle-like $\alpha \mathrm{SMA}++$ cell types coincided with the appearance of lacteals (E18.5) implying bidirectional crosstalk between lacteal development and the onset of axial SMC remodeling. Postnatal lacteals were always accompanied by the adjacent axial SMCs and our analysis of WT and Pitx $2^{A S E / A S E}$ intestines failed to detect lacteals without their muscular neighbors. However, we did observe instances of axial SMCs in villi with missing lacteals in Pitx $2^{A S E / A S E}$ intestines (Fig. 3B). Importantly, axial SMCs that formed in the absence of lacteals were always mispatterned with aberrant branches interconnecting the bundles (Fig. 3B). Together, these data suggest that axial SMCs are necessary for lacteal formation. And while lacteals are dispensable for the formation of axial SMCs, they are required for proper muscle bundle organization. Thus, ASE deletion, which leads to malformation of 
the muscular-lacteal complex, reveals the important reciprocal interplay between lacteal development and axial SMC remodeling during the pre- to postnatal transition.

\section{Pitx2-mediated changes in ROS levels in the intestinal muscle}

Previous studies have shown that oxidative stress inhibits mesenteric lymphatic vessel contractility and reduces lymph flow by affecting lymphatic smooth muscles in anesthetized and aging rats [92, 93]. Consistent with the role of ROS in lymphatic function, our studies suggest that elevated levels of oxidative stress caused the muscularlacteal impairment in Pitx $2^{A S E / A S E}$ intestines pointing to a crucial role for Pitx2 in the control of ROS during early development. During normal muscle development, the transition of proliferative muscular progenitor into postmitotic contractile mature muscle involves a glycolytic to oxidative metabolic switch, leading to excessive production of ROS [94, 95]. Whereas this can damage cells, elevated ROS are crucial to normal physiological responses such as differentiation [96, 97]. Therefore, a network of genes counteracting elevated ROS is critical to mitigate cell damage. We propose that Pitx2 is one of those genes in the intestine. First, Pitx $2^{A S E / A S E}$ neonates had significantly more intestinal protein carbonyl content in comparison to their WT or Pitx $2^{A S E /+}$ heterozygous littermates. Second, they had the most carbonylated $\alpha$ SMA of all genotypes tested, demonstrating increased irreversible actin oxidation in the absence of $A S E$. Based on our RNA-seq data, these effects are likely driven by the cumulative effects of disturbed redox homeostasis-related genes downstream of Pitx2, including Gclc [50-52].

Actin carbonylation (indicative of both F- and G-actin oxidation) is indicative of severe functional impairment of the actin cytoskeleton [61]. Importantly, due to the irreversible nature of protein carbonylation, contractile proteins exposed to early oxidative stress are damaged permanently. In other words, an early disruption in actin dynamics may have repercussions that persist at later stages. In that regard, we observed fragmented patterns of $\alpha$ SMA arrangement in Pitx $2^{A S E / A S E}$ axial SMCs at P21 (Fig. S5B) and profound villus smooth muscle hypoplasia at P26 (Fig. S3B). Whereas we were unable to characterize further muscle morphogenesis due to the early postnatal lethality of Pit $x 2^{A S E / A S E}$ mice, our data suggest that Pitx2-mediated control of ROS is a critical early step to maintaining an organized and dynamic actin cytoskeleton during both organogenesis and subsequent contractile muscle function later in life. Consistent with this notion, recent studies found an essential role for Pitx2 and Pitx3 in the management of ROS in differentiating myoblast and satellite stem cells [98]. Furthermore, in the neonatal heart, Pitx $2 c$ was shown to inhibit ROS after cardiac injury to promote heart repair by activating the antioxidant response pathway and ROS scavenger genes [99]. Collectively, these data implicate Pitx 2 as a core rheostat of redox status during muscle development and regeneration and necessitate future studies targeted to defining the specific roles for Pitx $2 c$ in smooth muscle regeneration after intestinal damage.

\section{Pitx2 regulates lacteal development and function in a non-cell autonomous manner}

It is well established that lymphatic homeostasis and function is regulated in part in a non-cell autonomous manner by the adjacent microenvironment [35, 37, 83, 100, 101]. Because ROS can act on surrounding cells with [102, 103] or without [104] diffusion, our 
data support this model and raise the possibility that ROS-generating axial SMCs can influence cell behavior of the adjacent lacteal including the formation of lacteal filopodia extensions. Filopodia are formed by linear polymerization of G-actin-ATP at their barbed-ends, and the lengthening and retraction of filopodia actin bundles are regulated by ROS [105-107]. During intestinal lymphatic development, lacteal filopodia are crucial for lacteal sprouting, extension, and regeneration throughout adulthood, ensuring continuous lacteal function for transport of dietary lipids [33, 35]. During adult lacteal regeneration, filopodia-mediated lacteal migration is regulated by the Notch ligand deltalike 4 (DLL4), downstream of VEGF-C [35]. Genetic inactivation of DLL4 in lymphatic endothelial cells [35] or postnatal deletion of VEGF-C [37] leads to lacteal regression and impaired dietary fat uptake. Moreover, interaction between NRP2, a transmembrane coreceptor for VEGF-C, and VEGFR-3 mediates proper lacteal sprouting in response to VEGF-C [33]. Interestingly, we have previously identified three highly conserved Pitx2 binding regions upstream of $V e g f C$ transcriptional start sites by ChIP-seq analysis and ChIP-qPCR of embryonic intestines and detected reduced VegfC expression in Pitx $2^{A S E / A S E}$ embryos as early as in E10.75 (data not shown). While VEGF-C has been implicated in multiple crucial aspects of lymphangiogenesis including intestinal lymphatics [37], how this signaling is integrated in the context of a developing organ remains unknown and our preliminary data suggest that Pitx2 may provide this context. Collectively, elevated levels of ROS in Pitx $2^{\text {ASE/ASE }}$ intestines and reduced VEGF-CVEGFR3 signaling in the absence of $A S E$ may have damaging effects on filopodiamediated lacteal extension, resulting in shorter lacteals and impaired dietary fat uptake and/or trafficking.

\section{$P i t x 2^{A S E / A S E}$ mice develop diet-induced fatty liver disease}

In viviparous mammals, a functional intestinal lymphatic system is vital for rapid processing of fat-enriched milk at birth, and in lipid absorption through adulthood. Dietary lipids (mostly long-chain fatty acids), cholesterol, and fat-soluble vitamins use lacteals as the major transport route, whereby lipids packaged into lipoprotein particles (chylomicrons) drain into larger mesenteric collecting lymphatic vessels, and ultimately into the systemic blood circulation. In contrast, non-fatty nutrients and shorter chain fatty acids enter the portal vein directly for delivery to the liver [9, 30-32]. This portal transport is insignificant compared with the chylomicron pathway, but can become active during disease where disrupted lymphatic clearance impairs the normal route of lipid transport [71-73, 108, 109]. Importantly, whereas lymphatic-dependent transport distributes dietary lipids to peripheral tissues for direct energy consumption, the lymphatic-independent lipid trafficking directs lipids exclusively to the liver for immediate catabolism by hepatocytes. This greatly reduces the lipid accessibility to peripheral tissues and may be the cause of growth retardation seen in the Pitx $2^{A S E / A S E}$ mice.

In our model, the lymphatic-dependent lipid transport is dominant in WT neonates, directing dietary long-chain fatty acids into the systemic lymphatic circulation. In contrast, muscular-lacteal development and contractions in the absence of $A S E$ are insufficient to support lymphatic-dependent lipid transport. As a consequence, lymphaticindependent lipid trafficking is activated to cargo lipids from the intestine, leading to 
excessive hepatic lipid accumulation and fatty liver in neonatal Pit $x 2^{A S E / A S E}$ mice. Interestingly, the fatty lesions were reversible when Pit $x 2^{A S E / A S E}$ weanlings transitioned to a low fat diet. This suggests that the duration of fat enriched diet is critical to the prognosis of fatty liver disease, where non-alcoholic fatty liver disease (NAFLD) may be resolved if early diet adjustments are made, while extended high fat diet may lead to nonalcoholic steatohepatitis (NASH).

How lipids are shunted to the portal circulation rather than the lymph in the Pitx $2^{A S E / A S E}$ intestine is a critical and fascinating question. A majority of liver perfusion derives from the portal vein and any portal venous cargo strongly impacts liver function (as in first-pass drug metabolism). Dietary long-chain fatty acids along with other nutrients, including shorter chain fatty acids, carbohydrates, and amino acids are absorbed by enterocytes, a function that is broadly zonated along the villus axis: genes associated with chylomicron packaging and lipid transport functions are most highly expressed in the tip-most enterocytes whereas amino acid and carbohydrate transporters are enriched within the middle of intestinal villi [110]. These fascinating data suggest a chylomicron concentration gradient along the villus axis, consistent with prior tEM analysis [111]. Accordingly, taller lacteals contain more chylomicrons than shorter lacteals. Moreover, lacteals are positioned further away from the enterocytes than the venous capillaries, giving priority for small nutrients entry into the portal circulation. Thus, we postulate that shorter lacteals in Pit $x 2^{A S E / A S E}$ mice have a net deficit in chylomicron entry overall, further aggravating lipid transport insufficiency. Fatty liver disease is currently the world's most common chronic liver disease [112]. Here, our studies link this disease to altered gut lymphatic development and transport of fat in the intestine, pointing to a novel role for the Pitx2-driven organ laterality in the regulation of the gut-liver axis. Understanding the gut-liver axis in relation to lipid trafficking through portal versus lymphatic vasculature is critically needed, as it will lead to future discoveries of alternative regulators of fat absorption that may be clinically targeted under disease conditions. Taken together, our findings unravel a previously unknown role for the LR Pitx2 gene during muscular-lacteal morphogenesis and reinforce the importance of the reciprocal interplay between intestinal muscle development and lacteal function in dietary lipid transport.

\section{ACKNOWLEDGMENTS}

We thank all the Kurpios lab members and Dr. D. Gludish for reading the manuscript and excellent suggestions. We thank Drs. H. Hamada, J. F. Martin, and T. Tumbar for reagents described above. We thank T. Bargar and N. Conoan of the Electron Microscopy Core Facility at the University of Nebraska Medical Center for technical assistance, supported by state funds from the Nebraska Research Initiative and the University of Nebraska Foundation, and institutionally by the Office of the Vice Chancellor for Research. We are grateful to Dr. B. Dixon, Dr. T. Cassis, and A. VanDeMark for help with BODIPY feeding of newborn mice, Drs. J. Dela Cruz and R. Williams for imaging expertise, A. Sulpizio for help with lipid quantifications, and Drs. T. Stokol, E. L. Behling-Kelly, T. L. Southard, and S. Center for clinical discussions. We thank Dr. Jen Grenier at the Transcriptional Regulation and Expression Facility and the Biotechnology Resource Center (BRC) of Cornell Institute of Biotechnology for RNA-seq analysis and 
R. Munroe and C. Abratte of the Cornell Stem Cell and Transgenic Core Facility. We are grateful to B. Laslow, R. Slater, and C. Westmiller for technical assistance. Imaging data was acquired through Cornell BRC Imaging Facility, with NYSTEM (C029155) and NIH (S10OD018516) funding for the shared Zeiss LSM880 confocal/multiphoton microscope. NIH-funded Comparative Medicine Training Program T32OD011000 (S.H.), AHAfunded 17SDG33400141 (G.T.), and NIDDK R01 DK107634 and DK092776 (N.A.K.) supported this work.

\section{AUTHOR CONTRIBUTIONS}

Conceptualization, S.H., A.M., and N.A.K.; Methodology, S.H., A.M., C.S.S., and N.A.K.; Investigation, S.H., A.M., I.F.E., J.C., N.R.S., G.H.B., A.K.T., and G.T.; Writing - Original Draft, S.H., Writing - Review \& Editing, S.H. and N.A.K.; Funding Acquisition, S.H. and N.A.K.; Supervision, G.E.D., C.S.S., and N.A.K.

\section{DECLARATION OF INTERESTS}

The authors declare no competing interests

\section{ACCESSION NUMBERS}

The RNA-sequencing data have been deposited under accession number

GEO: GSE160677 


\section{FIGURE LEGENDS}

\section{Figure 1. Pitx $2^{A S E / A S E}$ mice fail to properly gain weight}

(A) The Pitx2 gene structure and differential splicing of three Pitx2 isoforms. E: exon; ATG: start codon; black arrow: transcriptional start site; ASE: asymmetric enhancer.

(B) The genetic organization of Pitx 2 deficient mouse models. Pit $x 2^{H D}$ mouse has homeobox deletion from exon 5 to 6. Pitx $2^{\Delta c}$ (Pitx $2 c$ ) mouse has Pitx $2 c$-specific exon 4 deletion. Pit $x 2^{A S E}$ mouse contains ASE deletion in intron 5.

(C) Survival rates of Pitx $2^{A S E / A S E}$ mice at different stages. Data displayed on Y-axis are represented as incidence of live Pit $x 2^{A S E / A S E}$ mice upon collection. Data calculated from the following pool of mice: 28 at E10.5, 125 at P0, 500 at P1.5, 533 at P9, and 169 at P21 (weaning age). Orange characters mark the survival rate of Pitx $2^{A S E / A S E}$ mice; calculations are based on the number of Pit $x 2^{A S E / A S E}$ live mice divided by the expected number of mice according to Mendelian ratio $(25 \%)$. Black characters mark live birth rate of Pitx $2^{A S E / A S E}$ mice; calculations are based on the number of Pit $x 2^{A S E / A S E}$ live mice divided by number of total live mice.

(D) Pitx $2^{A S E / A S E}$ mice gain weight less efficiently than their WT and heterozygous littermates. Left: Body weights measured at E18.5 and/or at birth are counted as P0. Body weights measured at P8.5 are counted as P9. Middle: A pair of littermates showing significant growth retardation of Pit $x 2^{A S E / A S E}$ versus WT mice at P9. Right: Stomach at collection of P1.5 WT fed, WT unfed, and Pitx $2^{A S E / A S E}$ fed littermates showing comparable food ingestion of mutant and WT mice.

Data displayed on Y-axis in the left side graph are represented as mean \pm SEM. P0 WT $=$ $1.388 \pm 0.03382 \mathrm{~g}, \mathrm{n}=21 ; \mathrm{P} 0$ Pitx $2^{\text {ASE/ASE }}=1.295 \pm 0.03531 \mathrm{~g}, \mathrm{n}=22$. Difference between WT and Pitx2 ${ }^{A S E / A S E}=0.09264 \pm 0.04897 \mathrm{~g}, \mathrm{P}=0.0656$. P1.5 WT $=1.791 \pm$ $0.2251 \mathrm{~g}, \mathrm{n}=41 ; \mathrm{P} 1.5$ Pitx $2^{A S E / A S E}=1.495 \pm 0.1435 \mathrm{~g}, \mathrm{n}=10$. Difference between WT and Pitx2 $2^{A S E / A S E}=-0.2960 \pm 0.07494 \mathrm{~g}, \mathrm{P}=0.0003 * * *$. P9 WT $=5.963 \pm 0.8161 \mathrm{~g}, \mathrm{n}=16$; $\mathrm{P} 9$ Pitx $2^{A S E / A S E}=4.25 \pm 1.211 \mathrm{~g}, \mathrm{n}=7$. Difference between WT and Pitx $2^{A S E / A S E}=-1.713$ $\pm 0.4286 \mathrm{~g}, \mathrm{P}=0.0007 * * *$. Scale bar, $500 \mu \mathrm{m}$. See also Figure S1.

\section{Figure 2. Shortened lacteals with missing filopodia in Pitx $2^{A S E / A S E}$ mice}

(A) Representative images of whole mount lacteals (lyve-1, green) of WT and Pitx $2^{A S E / A S E}$ villi at P1.5. Top right: \% lacteals with filopodia. Bottom right: Average lacteal length. Data are represented as mean \pm SEM. P1.5 WT lacteals with filopodia $=$ $72.90 \pm 2.760 \%, \mathrm{n}=16 ; \mathrm{P} 1.5$ Pitx $2^{\text {ASE/ASE }}$ lacteals with filopodia $=41.28 \pm 3.545 \%, \mathrm{n}=$ 10. Difference between WT and Pitx $2^{A S E / A S E}=-31.62 \pm 4.476 \%$. P < $0.0001 * * * * . \mathrm{P} 1.5$ WT lacteal length $=176.1 \pm 6.401 \mu \mathrm{m}, \mathrm{n}=17 ; \mathrm{P} 1.5$ Pitx $2^{A S E}$ lacteal length $=143.7 \pm$ $6.392 \mu \mathrm{m}, \mathrm{n}=10$. Difference between WT and Pitx $2^{\text {ASE/ASE }}=-32.41 \pm 9.704 \mu \mathrm{m} . \mathrm{P}=$ $0.0026^{* *}$. White characters mark the mean in each group. Scale bars, $30 \mu \mathrm{m}$. 
(B) Representative images of whole mount lacteals (lyve-1, green) of WT and Pitx $2^{\Delta C}$ villi at P1.5. Right: \% lacteals with filopodia. Data are represented as mean \pm SEM. WT $=81.38 \pm 4.660 \%, \mathrm{n}=3 ;$ Pitx $2^{\triangle C}=41.13 \pm 5.604 \%, \mathrm{n}=4$; Difference between WT and Pitx $2^{\Delta C}=-40.25 \pm 7.692 \%, \mathrm{P}=0.0034 * *$. White characters mark the mean in each group. Scale bar, $20 \mu \mathrm{m}$.

(C) Representative images of whole mount lacteals (lyve-1, green) of WT and Pitx $2^{A S E / A S E}$ villi at P9. Left: \% lacteals with filopodia. Right: Average lacteal length. Note the extended filopodium in WT lacteal tips (white arrows) vs. the blunt-ended lacteals (white arrowhead) in mutants.

Data are represented as mean \pm SEM. P9 WT lacteals with filopodia $=49.66 \pm 4.200 \%, \mathrm{n}$ = 8; P9 Pitx ${ }^{A S E / A S E}$ lacteals with filopodia $=8.543 \pm 2.610 \%, \mathrm{n}=3$. Difference between WT and Pitx $2^{A S E / A S E}=-41.12 \pm 7.237 \% . \mathrm{P}=0.0003 * * *$. P9 WT lacteal length $=222.7 \pm$ $8.252 \mu \mathrm{m}, \mathrm{n}=8$; P9 Pitx $2^{A S E / A S E}$ lacteal length $=144.6 \pm 9.518 \mu \mathrm{m}, \mathrm{n}=3$. Difference between WT and Pitx $2^{A S E / A S E}=-78.12 \pm 14.90 \mu \mathrm{m} . \mathrm{P}=0.0005 * * *$. Black characters mark the mean in each group. Scale bars, $30 \mu \mathrm{m}$. See also Figure S2.

\section{Figure 3. Malformation of the muscular-lacteal complex in Pitx $2^{A S E / A S E}$ mice}

(A) Lineage tracing using Pitx $2^{\text {cre }}-$ ROSA $26^{\text {CAG-tdTomato }}$ and ASE $E^{\text {cre }}-$ ROSA26 CAG-EYFP mice. Representative image of whole mount villus from Pitx $2^{\text {cre }}::$ ROSA $26^{\text {CAG-tdTomato }}$ mice at P9 (A', A") and 6 months (A"'). Note the colocalization of $\alpha$ SMA (green) and tdTomato (tdT, red) that marks axial SMCs of Pitx2 descend (white arrowhead) and axial SMC heterogeneity (A"). White arrows depict additional cell types marked by Pitx2 daughter cells (A'). (A'"') Representative images of whole mount villus from $A S E^{\text {cre }}$ ROSA2 $6^{\text {CAG-EYFP }}$ mice at P9. Note the colocalization of $\alpha$ SMA (red) and YFP (green) that marks axial SMCs of $A S E$ descent (white arrowheads). White arrows depict additional cell types marked by $A S E$ daughter cells, distinct from BECs (red). Scale bar, $20 \mu \mathrm{m}$.

(B) Representative images of whole mount muscular-lacteal complexes of WT and Pitx $2^{A S E / A S E}$ mice at P9. Green is lacteal (lyve-1); red is $\alpha$ SMA (smooth muscle). From left to right in the Pitx $2^{A S E / A S E}$ panel: aberrant muscular arrangement with no lacteal (white asterisk); loss of direct contact between axial SMCs from the lacteal; opened axial SMCs with a shorter and dilated lacteal. Scale bar, $40 \mu \mathrm{m}$.

(C) \% lacteals surrounded by "open" axial SMCs based on data represented in (C). An axial muscle structure was characterized by the apical part arrangement. We defined the muscles "opened" if the axial muscles were divergently aligned around the lacteal tip as demonstrated in (F). Data are represented as mean \pm SEM. P9 WT $=33.51 \pm 3.950 \%$, $\mathrm{n}$ $=6 ; \mathrm{P} 9$ Pitx $^{\text {ASE/ASE }}=76.12 \pm 7.775 \%, \mathrm{n}=3$. Difference between $\mathrm{WT}$ and Pitx $2^{\text {ASE } / A S E}=$ $42.61 \pm 7.703 \%, \mathrm{P}=0.0009 * * *$. White characters mark the mean in each group.

(D) Representative images of muscular-lacteal complexes of WT and Pitx $2^{A S E / A S E}$ mice at P9 in transverse sections. Green is lacteal (lyve-1); red is $\alpha$ SMA (smooth muscle); blue is 
DAPI. Note the close (white arrows) vs. distanced (white arrowheads) proximity of red (muscle) and green (lacteal) signals. White stars mark villi with missing lacteals. Scale bar, $20 \mu \mathrm{m}$.

(E) Cartoon model demonstrating muscular-lacteal arrangement of WT and Pitx $2^{\text {ASE/ASE }}$ mice. Green represents lacteal; red is smooth muscle. See also Figure S3.

\section{Figure 4. Lacteal-associated axial SMCs arise by $A S E$-dependent remodeling}

(A) Representative images of whole mount WT villous muscular-lacteal development from E16.5-P9. Green is lacteal (lyve-1), red is aSMA (smooth muscle). Note the interaction of muscle (red) with the developing lacteal (green). Insets: Note the shape difference of cells at E16.5 (star cells) versus at P9 (spindle cell). Scale bar, $40 \mu \mathrm{m}$. Graph: \% villi with $\alpha \mathrm{SMA}+$ star cells (black squares) or $\alpha \mathrm{SMA}++$ spindle cells (gray dots) during development. Note the negative correlation between $\alpha \mathrm{SMA}+$ star cells (dominant in prenatal stages) and $\alpha \mathrm{SMA}++$ spindle cells (dominant postnatally). Data displayed on Y-axis are represented as mean \pm SEM. E16.5 villi with star cells $=90.7 \pm$ $4.6 \%, \mathrm{n}=6$; E16.5 villi with bundles $=0 \pm 0 \%, \mathrm{n}=6 . \mathrm{E} 18.5$ villi with star cells $=48.02$ $\pm 5.9 \%, \mathrm{n}=6$; E18.5 villi with muscle bundles $=62.98 \pm 7.5 \%, \mathrm{n}=6$. P1.5 villi with star cells $=12.25 \pm 4.9 \%, \mathrm{n}=6 ; \mathrm{P} 1.5$ villi with muscle bundles $=83.95 \pm 4.0 \%, \mathrm{n}=6$. $\mathrm{P} 9$ villi with star cells $=9.454 \pm 4.5 \%, \mathrm{n}=8$; P9 villi with muscle bundles $=93.51 \pm 2.5$ $\%, \mathrm{n}=8$.

(B) Star cells, but not spindle cells, are proliferative (E18.5). Representative images of whole mount WT villus; green is $\alpha$ SMA (green), red is phospho-histone 3 (H3P), and blue is DAPI. Note that $\mathrm{pH} 3$ signal colocalized only with star-like but not spindle-like SMCs. Scale bar, $10 \mu \mathrm{m}$.

(C) Representative images of whole mount muscular-lacteal complexes from WT and Pitx $2^{A S E / A S E}$ siblings at P9. Green is lacteal (lyve-1), red is $\alpha$ SMA (smooth muscle). Note the retention of $\mathrm{SMA}^{+}$star cells in Pitx $2^{A S E / A S E}$. Scale bar, $20 \mu \mathrm{m}$.

(D) Graphs demonstrating \% villi with star or spindle cells in WT and Pitx $2^{\text {ASE/ASE }}$ siblings. Left: \% villi with spindle cells in E18.5 embryos. Right: \% villi with star cells in P1.5 pups. Data displayed on Y-axes are represented as mean \pm SEM. E18.5 WT villi with spindles $=62.98 \pm 7.52 \%, \mathrm{n}=6$; E18.5 Pitx $2^{\text {ASE/ASE }}$ villi with spindles $=36.93 \pm$ $4.41 \%, \mathrm{n}=6$. Difference between WT and Pit $x 2^{A S E / A S E}=-26.05 \pm 8.72 \%, \mathrm{P}=0.0136^{*}$. $\mathrm{P} 1.5$ WT villi with stars $=12.25 \pm 4.917 \%, \mathrm{n}=6 ; \mathrm{P} 1.5$ Pitx $2^{A S E}$ villi with stars $=42.42 \pm$ $3.510 \%, \mathrm{n}=5$. Difference between WT and Pitx2 $2^{\text {ASE/ASE }}=30.18 \pm 6.292 \%, \mathrm{P}=$ $0.0010 * * *$.

(E) Cartoon model depicting star-to-spindle smooth muscle transition underlines the formation of axial SMC-lacteal complex. See also Figure S4.

Figure 5. $A S E$ deletion leads to redox imbalance and actin carbonylation in intestinal muscle 
(A) RNA-seq data analysis. Left: Heatmap displaying the genes that were differentially expressed between WT and Pitx $2^{A S E / A S E}$ intestines at P1.5. The relative expression levels were displayed in color code based on the raw counts in each gene from each sample, with the minimum expression depicted in white and the maximum expression in dark red. Differentially expressed genes were identified as described in methods and listed in UCSC gene symbol. Genes bound by Pitx 2 based on prior ChIP-seq were noted with red dots, genes with known function related to cellular redox homeostasis were noted with green dots. Right: Venn diagrams demonstrating the relation of differentially expressed genes bound by Pitx 2 and/or with reported function in cellular redox balance.

(B) Schematic of protein carbonyl detection. 2,4-dinitrophenylhydrazine (DNPH, or hydrazine) reacts with protein carbonyl groups leading to the formation of the stable 2,4dinitrophenylhydrazone (hydrazone) that can be detected and quantified spectrophotometrically (B'). Protein carbonyl concentration measured from WT (blue), Pitx $2^{A S E /+}$ (orange), and Pitx2 $2^{A S E / A S E}$ (black) intestines. Data are represented as mean \pm SEM. Protein carbonyl in WT/ Pitx $2^{A S E /+}$ group $=2.76 \pm 0.3194 \mathrm{nmol} / \mathrm{mg}, \mathrm{n}=7$; protein carbonyl in Pitx $2^{\text {ASE/ASE }}=6.833 \pm 0.4567 \mathrm{nmol} / \mathrm{mg}, \mathrm{n}=3$. Difference between WT/het and Pitx $2^{A S E / A S E}=4.073 \pm 0.5741 \mathrm{nmol} / \mathrm{mg}, \mathrm{P}=0.0001 * * *$.

(C-E) Increased $\alpha$ SMA carbonyl level in Pitx2 $2^{A S E / A S E}$ intestines (P1.5). Representative blots of biotin-hydrazine (biotin-HZ) labeling assay demonstrate increased carbonylated $\alpha$ SMA in Pitx $2^{A S E / A S E}$ intestine. (C) P1.5 intestine protein lysates were labeled with biotin-HZ and separated by SDS-PAGE then transferred to nitrocellulose membrane. Total protein carbonyl was detected by Streptavidin-HRP (SA-HRP) (top blot), while total $\alpha$ SMA expression was detected by $\alpha$ SMA antibody on the same blot (lower blot).

(D) P1.5 intestine protein extracts were incubated with biotin-HZ. Biotinylated proteins were then purified by streptavidin beads, separated by SDS-PAGE, and transferred to nitrocellulose membrane. (Left) $\alpha$ SMA was detected by $\alpha$ SMA antibody. (Right) Total protein carbonyl was detected by SA-HRP on the same blot.

(E) P1.5 intestine protein extracts were labeled with biotin-HZ following $\alpha$ SMA immunoprecipitation (SMA-IP) and separated by SDS-PAGE then transferred to nitrocellulose membrane. Total protein carbonyl was detected by SA-HRP (top blot). SMA-IP efficiency was confirmed by total $\alpha$ SMA expression, detected by $\alpha$ SMA antibody on the same blot. kDa: kilo Dalton. See also Figure S5.

\section{Figure 6. $A S E$ is required for the normal route of dietary lipid transport}

(A) Schematic demonstration of BODIPYTM FL C16 fluorescent lipid tracer feeding assay. Pups were fed with BODIPY ${ }^{\mathrm{TM}}$ FL C16 (long-chain fatty acid, green) then left with the dam for 5 hours before further analyses. Note representative images of mesenteric collecting lymphatic lipid tracer entry in WT neonates validating the feeding assay. Scale bar, $200 \mu \mathrm{m}$.

(B) Hepatic analysis showing BODIPYTM FL C16 accumulation in Pitx2 $2^{\text {ASE/ASE }}$ at P1. 
Left-to-right: Analysis of whole livers, frozen liver sections with DAPI counterstain (blue), and hepatic portal vein (HPV, white arrows) in WT (top) and Pitx2 $2^{A S E / A S E}$ (bottom) neonates. Note enriched green signal in HPV and livers of Pitx $2^{A S E / A S E}$ neonates by comparison to their WT siblings. Scale bar, $1 \mathrm{~mm}$ (left, liver whole organ), $20 \mu \mathrm{m}$ (center, liver section), and $300 \mu \mathrm{m}$ (right, HPV).

(C) Cartoon model of lipid transport pathways in WT and Pitx $2^{\text {ASE/ASE }}$ neonates. Lymphatic-dependent transport (green) of dietary long-chain fatty acids (yellow dots) is dominant in WT mice, while additional activation of lymphatic-independent lipid transport via the hepatic portal vein (light blue) is evident in Pitx $2^{A S E / A S E}$ mice. Star cells and axial SMCs are shown in red. See also Figure S6.

\section{Figure 7. Pitx $2^{A S E / A S E}$ mice develop diet-induced fatty liver disease}

(A) Hematoxylin (blue) and oil red $\mathrm{O}$ (red) staining of frozen liver sections from E18.5, P1.5, and P11 WT (top) and Pitx $2^{A S E / A S E}$ (bottom) mice. Note the enrichment of oil red O staining in postnatal, but not prenatal, Pitx $2^{A S E / A S E}$ livers. Scale bar, $50 \mu \mathrm{m}$.

(B) Histopathology of WT (top) and Pitx $2^{A S E / A S E}$ (bottom) livers isolated from suckling pups (left) and weanlings (right). Note lipid vacuoles and loss of eosinophilic parenchymal stain in the liver of Pitx $2^{A S E / A S E}$ suckling pups, while lesions were resolved in Pitx $2^{A S E / A S E}$ weanlings. Images shown on the right side are selected high magnification fields of the left adjacent image. Scale bar, $50 \mu \mathrm{m}$.

(C) Structural muscular-lacteal defects remain in post-weaning Pitx $2^{A S E / A S E}$ cubs. Left: Representative images of whole mount muscular-lacteal complexes from WT and Pitx $2^{A S E / A S E}$ cubs at P26. Note shorter lacteals (lyve-1, green) and more open muscular arrangement ( $\alpha$ SMA, red) in Pitx $2^{A S E / A S E}$ but not WT weanlings. Right: Bar graphs showing quantifications of \% lacteals with filopodia and with open muscular arrangement for each genotype. Note that the following mice were pooled: $\mathrm{n}=4 \mathrm{WT}$ at P21 with $\mathrm{n}=1$ Pitx $2^{A S E /+}$ at P26; Pit $x 2^{A S E / A S E}$ group consisted of $\mathrm{n}=3$ at $\mathrm{P} 21$ and $\mathrm{n}=1$ at P26. Data displayed on Y-axes are represented as mean \pm SEM. Lacteals with filopodia in WT weanlings $=28.81 \pm 7.915 \%, \mathrm{n}=5$; lacteals with filopodia in Pitx $2^{\text {ASE } / A S E}$ weanlings $=$ $5.833 \pm 3.967 \%, \mathrm{n}=4$. Difference between $\mathrm{WT}$ and Pitx $2^{A S E / A S E}=-22.98 \pm 4.375 \% ; \mathrm{P}=$ $0.0012 * *$. Lacteals with opened axial muscle in WT weanlings $=13.08 \pm 2.637 \%, \mathrm{n}=5$; lacteals with opened axial muscle in Pitx $2^{A S E / A S E}$ weanlings $=73.85 \pm 9.599 \%, \mathrm{n}=4$. Difference between WT and Pitx $2^{A S E / A S E}=60.77 \pm 8.945 \% ; \mathrm{P}=0.0003 * * *$. Black characters represent the mean of each group. Scale bar, $50 \mu \mathrm{m}$. See also Figure S7.

\section{Figure 8. Proposed model for Pitx2 function in gut lymphatics}

WT: Pitx2 (1) maintains redox balance during the development of villous SMCs, (2) supports SMC-dependent lacteal development, and (3) regulates lymphatic-dependent dietary lipid transport driven by villous SMCs. 
$\underline{\text { Pitx } 2^{A S E / A S E}:}$ sublethal Pitx2 loss leads to (1) increased oxidative stress and protein damage in villous SMCs, therefore (2) compromises SMC-dependent lacteal development and (3) lymphatic-dependent lipid transport, while (4) potentially increases oxidative stress in adjacent LECs. This leads to activation of lymphatic-independent lipid transport, where excessive gut-liver lipid entry results in fatty liver disease. 


\section{SUPPLEMENTAL FIGURE LEGENDS}

\section{Figure S1. Pitx $2^{A S E / A S E}$ mice fail to properly gain weight (related to Figure 1)}

(A) Representative image showing a litter of newborn pups from a cross between two Pitx $2^{A S E /+}$ parents. Scale bar, $2 \mathrm{~cm}$.

(B) Pitx $2^{A S E / A S E}$ pup is smaller than littermates (P11), but not excluded from the nursing litter. Note the Pitx $2^{A S E / A S E}$ runt in lower left corner.

\section{Figure S2. Whole mount analysis of small intestinal lacteal (related to Figure 2)}

(A) Cartoon showing the anatomical structure of lacteal and lacteal-filopodium. Green: lacteal endothelial cells; light blue: blood capillaries; teal: villus epithelium; gray: lamina propria.

(B) Whole mount digestive tract at P1.5 with interior of the duodenum and jejunum exposed and intestinal content removed. Subsequent gut slices were generated for IF. Scale bar, $1000 \mu \mathrm{m}$.

(C) Reduced number of villus with lacteals in pre- (left) and post- (right) natal Pitx $2^{A S E / A S E}$ by comparison to their WT littermates. Data displayed on Y-axes are represented as mean \pm SEM \% of villi with lacteal in each mouse. E18.5 WT $=90.49 \pm$ $1.32 \%, \mathrm{n}=14 ; \mathrm{E} 18.5$ Pitx $2^{\text {ASE/ASE }}=79.87 \pm 4.617 \%, \mathrm{n}=11$. Difference between means $=-10.62 \pm 4.335 \%$. P $=0.0223 *$. P9 WT $=92.02 \pm 1.010 \%, \mathrm{n}=8$; P9Pitx $2^{A S E / A S E}=$ $80.24 \pm 6.060 \%, \mathrm{n}=5$. Difference between WT and Pitx $2^{A S E / A S E}=-11.78 \pm 4.836 \% . \mathrm{P}=$ $0.0331 *$

\section{Figure S3 Villous SMCs are dependent on the Pitx2 lineage (related to Figure 3)}

(A) Genetic background of Pitx $2^{\text {cre }}$ and ROSA26 $6^{\text {CAG-tdTomato }}$ mice used in lineage tracing.

(A') The tdTomato signal in a P1.5 Pitx $2^{\text {cre }}::$ ROSA26 $6^{\text {CAG-tdTomatoflfl }}$ mice is restricted to the digestive tract. Scale bar, $2000 \mu \mathrm{m}$.

(A") Representative images of villous whole mount IF in P9 Pitx $2^{\text {cre }}::$ ROSA26 $6^{\text {CAG-tdTomato }}$ mice. Left: Green is lacteal (lyve-1) and red is tdTomato. Right: Green is blood capillary plexus (CD31) and red is tdTomato. Note that the tdTomato signal neither colocalized with lacteal lymphatic endothelial cells (LECs) nor blood endothelial cells (BECs). Scale bar, $20 \mu \mathrm{m}$.

(B) H\&E staining of paraffin-embedded sections reveals villus smooth muscle hypotrophy in Pitx $2^{A S E / A S E}$ proximal small intestine (P26). Note atrophy of eosinophilic stromal cells in Pit $x 2^{A S E / A S E}$ mice marked by red dash lines and red arrowheads. Scale bar, $50 \mu \mathrm{m}$ for low magnification images; $25 \mu \mathrm{m}$ for high magnification images. 
Figure S4 Lacteal-associated axial SMCs arise by $A S E$-dependent remodeling (related to Figure 4).

(A) Villus SMA+ star cells associate with CD31+ vascular plexus during early development. E16.5: Representative images of whole mount WT villous processed for triple IF to demonstrate the close interaction of $\alpha \mathrm{SMA}^{+}$star cells (red) with $\mathrm{CD}^{+} 1^{+}$blood vascular plexus (white) in early lacteal development (lyve-1, green) and at E18.5 (red is $\alpha$ SMA; green is CD31). P1.5: Note the $\alpha \mathrm{SMA}^{+}$star cells (red) seen at E16.5 and E18.5 are no longer seen at P1.5. Instead of star cells, $\alpha \mathrm{SMA}^{++}$spindle cells are observed resembling axial SMCs. Scale bar, $30 \mu \mathrm{m}$.

(B) Star cells, but not spindle cells, are proliferative (E18.5). Representative images of whole mount WT villus; green is $\alpha$ SMA (green), red is phospho-histone 3 (H3P), and blue is DAPI. Note that $\mathrm{pH} 3$ signal colocalized only with star-like but not spindle-like SMCs. Additional panels are provided to show that star-like SMCs enter all four stages of mitosis (prophase, metaphase, anaphase, telophase). Scale bar, $10 \mu \mathrm{m}$.

(C) Representative images of whole mount WT muscular-lacteal complexes at P1.5. Green is lacteal (lyve-1) and red is $\alpha$ SMA (smooth muscle). Note the closely intertwined axial SMCs with lacteal filopodia. Scale bar, $30 \mu \mathrm{m}$.

(D) Representative images of villous whole mount IF at P9 demonstrating expression levels of contractile smooth muscle proteins $\alpha$ SMA (green) and myosin heavy chain 11 (Myh11, white). Note the intensity difference in contractile protein expression between star cells (white arrows) and axial SMC bundles. $\alpha \mathrm{SMA}^{*}$ marks higher exposure image needed to identify star cells. Scale bar, $40 \mu \mathrm{m}$.

(E) ASE deletion does not result in increased cell death of axial SMCs. Left: Representative images of whole mount TUNEL assays on Pitx $2^{\text {ASE/ASE }}$ and WT villus at P9. Green is $\alpha$ SMA, red is TUNEL signal, and blue is DAPI. Right: \% villi with $\mathrm{TUNEL}^{+} / \alpha \mathrm{SMA}^{+}$double-positive cells were quantified for both genotypes. Data displayed on the $\mathrm{Y}$-axis are represented as mean \pm SEM $\%$ of villi with $\mathrm{TUNEL}^{+} / \mathrm{SMA}^{+}$ double positive cells detected. WT $=0.00 \pm 0.00 \%, \mathrm{n}=3 ;$ Pitx $2^{\text {ASE/ASE }}=5.56 \pm 2.78 \%, \mathrm{n}$ $=3$. Difference between WT and Pitx $2^{A S E / A S E}=5.56 \pm 2.78 \%, \mathrm{P}=0.1161$. Scale bar, 30 $\mu \mathrm{m}$.

Figure S5 $A S E$ deletion leads to redox imbalance and actin carbonylation in intestinal muscle (related to Figure 5)

(A) Glutamate cysteine ligase $(G c l c)$ was one of the 33 differentially expressed genes we have identified by RNA-seq of WT and Pitx $2^{A S E / A S E}$ intestines at P1.5. Pitx2 binds to the noncoding region of intron 1 (black box, Chr9-313) of Gclc as demonstrated by previous ChIP-seq. Scale bar, $20 \mathrm{~kb}$ (top) and 200 base pair (bottom). 
(B) Fragmented $\alpha$ SMA expression pattern in Pitx $2^{A S E / A S E}$ adult intestines $(\mathrm{P} 21)$. Representative images of whole mount muscular-lacteal complexes of WT and Pitx $2^{\text {ASE/ASE }}$ littermates; green is lacteal (lyve-1); red is $\alpha$ SMA (smooth muscle). Note the continuous $\alpha$ SMA staining in WT versus fragmented pattern in Pitx $2^{A S E / A S E}$ axial SMCs. Dotted box represents area of higher magnification. Scale bar, $50 \mu \mathrm{m}$.

Figure S6 $A S E$ is required for the normal route of dietary lipid transport (related to Figure 6)

(A) Representative images of BODIPY ${ }^{\mathrm{TM}}$ FL C16 tracer entry into mesenteric collecting lymphatics in Pit $x 2^{A S E / A S E}$ neonates. Images were taken 5 hours after feeding with the tracer. Signal in mesenteric collectors and lymphangions confirms the entry of dietary long-chain fatty acids into the lymphatic-dependent lipid transport pathway. Scale bar, 20 $\mu \mathrm{m}$.

Figure S7. Pitx $2^{A S E / A S E}$ mice develop diet-induced fatty liver disease (related to Figure 7).

(A) Representative images of tEM from WT (left) and Pitx $2^{A S E / A S E}$ (right) livers at P1.5. Note the accumulation of cytoplasmic lipid droplets (circled in red dash lines) in Pitx $2^{A S E / A S E}$ hepatocytes. Scale bar, $10 \mu \mathrm{m}$.

(B) Graph demonstrating the $\%$ of Pit $x 2^{A S E / A S E}$ mice with fatty liver disease lesions at preweaning (P9), weaning (P21), and post-weaning (P26-32). \% prevalence of fatty liver disease is depicted in orange; black numbers depict positive cases of fatty liver disease over total cases examined. Data displayed on the Y-axis are represented as pooled fatty liver disease rate from $n=12(\mathrm{P} 9), \mathrm{n}=4(\mathrm{P} 21), \mathrm{n}=4(\mathrm{P} 26), \mathrm{n}=1(\mathrm{P} 31)$, and $\mathrm{n}=1$ (P32) mice using histopathology examination. 


\section{Methods}

\section{Key Resources Table}

\begin{tabular}{|c|c|c|}
\hline REAGENT or RESOURCE & SOURCE & IDENTIFIER \\
\hline \multicolumn{3}{|l|}{ Antibodies } \\
\hline Rabbit polyclonal Lyve1 antibody & Abcam & $a b 14917$ \\
\hline CD31 Rat anti-Mouse & BD Sciences & 553370 \\
\hline Rabbit anti-Myosin, Smooth Muscle Heavy Chain & Alfa Aesar & BT-563 \\
\hline Anti-Actin, $\alpha-S m o o t h$ Muscle & Sigma & A2547 \\
\hline Anti-Actin, a-Smooth Muscle-FITC & Sigma & F3777 \\
\hline Anti-Actin, $a-S m o o t h$ Muscle - Cуз ${ }^{\mathrm{TM}}$ & Sigma & C6198 \\
\hline Anti-Histone H3 antibody & Abcam & Ab5176 \\
\hline Rabbit Anti-Mouse IgG H\&L (HRP) & Abcam & $\mathrm{ab} 6728$ \\
\hline Alexa Fluor 488 goat anti-rabbit $\lg G(\mathrm{H}+\mathrm{L})$ & Fisher & A11070 \\
\hline $\begin{array}{l}\text { Donkey polyclonal Secondary Antibody to Rabbit IgG - } \\
\text { H\&L (Alexa Fluor }{ }^{\circledR} 647 \text { ) }\end{array}$ & Abcam & ab150075 \\
\hline $\begin{array}{l}\text { Goat anti-Rat IgG }(\mathrm{H}+\mathrm{L}) \text { Cross-Adsorbed, Alexa Fluor } \\
488\end{array}$ & Fisher & A11006 \\
\hline $\begin{array}{l}\text { Goat polyclonal Secondary Antibody to Rat lgG - H\&L } \\
\text { (Alexa Fluor® 594) }\end{array}$ & Abcam & $a b 150160$ \\
\hline Goat anti-rabbit antibody Alexa Fluor 568 & Thermo Fisher & A-11011 \\
\hline $\begin{array}{l}\text { Donkey polyclonal Secondary Antibody to Rat lgG - H\&L } \\
\text { (Alexa Fluor® 647) }\end{array}$ & Abcam & ab150155 \\
\hline \multicolumn{3}{|l|}{ Chemicals, Peptides, and Recombinant Proteins } \\
\hline Dapi & ThermoFisher & D1306 \\
\hline Prolong Gold antifade reagent $10 \mathrm{~mL}$ without DAPI & Invitrogen & P36930 \\
\hline FocusClearTM & Celexplorer & FC-101 \\
\hline EZ-Link ${ }^{\mathrm{TM}}$ Hydrazide-Biotin & Thermo Scientific & 21339 \\
\hline Peroxidase Streptavidin & Jackson Immuno & 016030084 \\
\hline Pierce $^{\mathrm{TM}}$ High Capacity Streptavidin Agarose & Thermo Scientific & 20357 \\
\hline Protein G Sepharose beads & Abcam & $a b 193259$ \\
\hline Western Lightning Plus-ECL & PerkinElmer Inc. & NEL104001EA \\
\hline BODIPYTM FL C16 & ThermoFisher & D3821 \\
\hline Oil red O & Abcam & ab150678 \\
\hline MOWIOL $^{\circledast}$ 4-88 Reagent, Gelvatol & EMD Millipore & EM475904 \\
\hline Hematoxylin (Modified Mayer's) & Abcam & Ab220365 \\
\hline Halt ${ }^{\mathrm{TM}}$ Protease and Phosphatase Inhibitor Cocktail & Thermo & 78336 \\
\hline Pierce $^{\mathrm{TM}}$ DTT (Dithiothreitol), No-Weigh ${ }^{\mathrm{TM}}$ Format & Thermo & A39255 \\
\hline Intralipid & Sigma & $\mid 141$ \\
\hline Glutaraldehyde $25 \%$ in aqueous solution, EM grade & $\begin{array}{l}\text { Electron Microscopy } \\
\text { Sciences }\end{array}$ & 16220 \\
\hline $\begin{array}{l}16 \% \text { Paraformaldehyde (formaldehyde) aqueous } \\
\text { solution }\end{array}$ & $\begin{array}{l}\text { Electron Microscopy } \\
\text { Sciences }\end{array}$ & 15710 \\
\hline Sorensen's Phosphate Buffer, 0.2M, pH 7.2 & $\begin{array}{l}\text { Electron Microscopy } \\
\text { Sciences }\end{array}$ & $11600-10$ \\
\hline \multicolumn{3}{|l|}{ Critical Commercial Assays } \\
\hline Protein Carbonyl Colorimetric Assay Kit & Cayman & $75816-674$ \\
\hline
\end{tabular}




\begin{tabular}{|c|c|c|}
\hline In Situ Cell Death Detection Kit, TMR red & Sigma & $45-12156792910$ \\
\hline PAXgene Tissue FIX & Qiagen & 765312,765512 \\
\hline \multicolumn{3}{|l|}{ Deposited Data } \\
\hline P1.5 Whole gut ASE RNAseq & Cornell University & GSE160677 \\
\hline \multicolumn{3}{|l|}{ Experimental Models: Organisms/Strains } \\
\hline Pitx2 $^{\text {ASE }}$ & Osaka University & \\
\hline Pitx $2^{4 C}$ & $\begin{array}{l}\text { Baylor College of } \\
\text { Medicine }\end{array}$ & \\
\hline Pitx2 ${ }^{\text {cre }}$ & $\begin{array}{l}\text { Baylor College of } \\
\text { Medicine }\end{array}$ & \\
\hline ASE $^{\text {cre }}$ (referred to as "Pitx2 ${ }^{\text {Cre" }}$ in Shiratori (2006) & Riken & \\
\hline ROSA26 $6^{\text {CAG-Idomato }}$ & Jacksons lab & Jax 007905 \\
\hline ROSA26-EYFP & Jacksons lab & Jax 006148 \\
\hline \multicolumn{3}{|l|}{ Oligonucleotides } \\
\hline Primers for mouse genotyping & $\begin{array}{l}\text { See Supplemental } \\
\text { TABLE }\end{array}$ & \\
\hline \multicolumn{3}{|l|}{ Software and Algorithms } \\
\hline FIJI & $\begin{array}{l}\text { National Institutes of } \\
\text { Health }\end{array}$ & $\begin{array}{l}\text { http://fiii.sC; } \\
\text { RRID: SCR } 002285\end{array}$ \\
\hline Prism 8 & GraphPad & $\begin{array}{l}\text { http://www.graphpad } \\
\text {.com/; } \\
\text { RRID: SCR_002798 }\end{array}$ \\
\hline Imaris 9.5 & Bitplane & $\begin{array}{l}\text { https://imaris.oxinst. } \\
\text { com/; } \\
\text { RRID:SCR_007370 }\end{array}$ \\
\hline ZEN & Zeiss & $\begin{array}{l}\text { https://www.zeiss.co } \\
\text { m/microscopy/us/pro } \\
\text { ducts/microscope- } \\
\text { software/zen.html\#in } \\
\text { troduction; } \\
\text { RRID:SCR_013672 }\end{array}$ \\
\hline
\end{tabular}

\section{Resource Availability}

\section{Lead contact}

Further information and requests for resources and reagents should be directed to and will be fulfilled by the Lead Contact, Natasza A. Kurpios (natasza.kurpios@cornell.edu).

\section{Materials Availability}

This study did not generate new unique reagents.

Data and Code Availability

The RNAseq database generated during this study is available at GEO: GSE160677 
Experimental Model and Subject Details

\section{Mice}

All experiments adhered to guidelines of the Institutional Animal Care and Use Committee of Cornell University, under the Animal Welfare Assurance on file with the Office of Laboratory Animal Welfare. Pitx2 ${ }^{\mathrm{ASE} / \mathrm{ASE}}$, Pitx2 ${ }^{\Delta C}$, Pit $\times 2^{\mathrm{cre}}, \mathrm{ASE}^{\mathrm{cre}}$, ROSA26 ${ }^{\text {CAG-tdTomato }}$, and ROSA26-EYFP mice were previously described [22, 23, $28,113,114]$. All strains of mice in these studies were maintained in a specified pathogen-free barrier facility under a 12-hour light cycle with free access to standard chow pellets and water unless specified. All mice used for mating were between 2-6 months old. For timed pregnancies, dams and studs were housed separately until the scheduled mating. Time mated breeding pairs were separated upon the morning when vaginal plugs were found and staged as E0.5. Postnatal stages are defined upon birth as postnatal day 0 (P0). Each mouse used was numbered by toe clip and genotyped by PCR amplification at the age between 7-10 days. Embryos and pups under 9 days were genotyped after isolation. For full list of genotyping primers, see Supplemental Table. Each group of comparison contained at least three mice from representative genotypes at the specified developmental stages. Mice of different genotypes were randomly chosen and sorted into different procedures and measurements. When possible, littermates of different genotypes were sorted into the same procedure and measurements as pairs.

\section{Method Details}

\section{Mouse tissue collection, fixation, processing}

For sectioning, tissues were dissected in ice-cold 1X PBS, immediately followed by PBS washes and fixed overnight at $4^{\circ} \mathrm{C}$ in $4 \%$ paraformaldehyde (PFA)/PBS, ice-cold $100 \% \mathrm{MeOH}$, or PAXgene ${ }^{\circledR}$ fixative. For tissues fixed in PFA, tissues were thoroughly washed with PBS, then preserved in $4^{\circ} \mathrm{C}$ until use. Tissues fixed in $\mathrm{MeOH}$ were stored in $-20^{\circ} \mathrm{C}$ until further use. Tissues fixed with PAXgene $\AA$ fixative were processed following manufacturer's instructions. For intestinal tissue that proceeded to frozen sections, tissues were dehydrated in gradient sucrose/PBS solution, then embedded in Tissue-Tek* OCT. Compound and stored in $-80^{\circ} \mathrm{C}$ until sectioning. Hepatic tissue for frozen sections following oil red $\mathrm{O}$ stain was embedded in $100 \%$ OCT immediately after dissection. Tissues intended for histology analyses were processed with standard paraffin embedding protocol in the Animal Health Diagnosis Center, Cornell University College of Veterinary Medicine. All frozen sections were $15 \mu \mathrm{m}$ thick; paraffin sections were $5 \mu \mathrm{m}$ thick.

\section{Section and whole mount immunofluorescence}

Embryos were processed for immunofluorescence (IF) on sections or whole mount (tissue slice). For section IF, frozen sections were permeabilized with $0.1 \%$ TritonX-100/PBS for 45 min, blocked in 3\% BSA in PBS for 3 hours at room temperature, and incubated with 100X diluted primary antibodies/blocking 
overnight at room temperature. 500X diluted secondary antibodies were coincubated with 1000x diluted DAPI for nuclear labeling at room temperature for 1 hour. Samples were mounted in ProLong ${ }^{\mathrm{TM}}$ Gold Antifade Mountant (P36930, Thermo Fisher) and preserved in room temperature until imaging. For whole mount IF staining, the protocol was adapted from [43]. In brief, tissue was blocked in BSA, serum, and $0.3 \%$ TritonX-100 in PBS in $4^{\circ} \mathrm{C}$ for 3 hours, then incubated with primary antibodies overnight at $4^{\circ} \mathrm{C}$. Tissues were thoroughly washed in $0.3 \%$ TritonX-100/PBS for 5 hours with hourly buffer changes, then incubated with secondary antibody overnight at $4^{\circ} \mathrm{C}$. Tissue was thoroughly washed in $0.3 \%$ TritonX-100/PBS for 5 hours with buffer changes every half hour, then fixed in $4 \%$ PFA/PBS for two overnights at $4^{\circ} \mathrm{C}$. For confocal imaging, tissue was washed with PBS and properly sliced to $100-200 \mu \mathrm{m}$ with spring scissors before mounted in ProLong ${ }^{\mathrm{TM}}$ Gold Antifade Mountant. Primary antibodies are listed below: GFP (ab290, Abcam), CD31 (PECAM-1, 553371, BD Bioscience), Lyve-1 (Ab14917, Abcam), aSMA (F3777, C6198, A2547, Sigma-Aldrich), and Myh11 (BT-563, Alfa Aesar). Secondary antibodies used are listed below: AlexaFluor anti-goat, anti-mouse or anti-rabbit 568, and anti-rabbit 488 (source).

\section{Liver oil red $O$ stain}

Oil red $O$ stain was performed to detect liver neutral lipids as previously described [76]. In brief, tissue sections were processed as described in the previous section. Slides with paired tissues from WT and Pitx $2^{A S E / A S E}$ littermates collected on the same slide were equivalate to room temperature from $-80^{\circ} \mathrm{C}$ when stored, following oil red $\mathrm{O}$ and hematoxylin incubation. Slides were rinsed in water before mounted in $\mathrm{MOWIOL}^{\circledR}$ 4-88 Reagent (EM475904, EMD Millipore).

\section{In vivo lipid tracer feeding assay}

BODIPY ${ }^{\mathrm{TM}}$ FL C16 (Thermo Fisher D3821) was added to a warmed Intralipid (20\% emulsion, Sigma 1141) solubilizing agent to make final concentration at $0.4 \mu \mathrm{g} / \mu \mathrm{l} .50 \mu \mathrm{L}$ of $37^{\circ} \mathrm{C}$ reconstituted Bodipy ${ }^{\mathrm{TM}} / \mathrm{Intralipid}$ solution was fed to each pup through 24-gauge reusable feeding needles (Fine Science Tools 18061-24). To maintain proper body temperature and hydration, the pups were left with the dam for 5 hours (milk ad lib) before imaging and tissue collection. Images were taken under a Zeiss dissection microscope immediately after sacrifice by decapitation. Images were taken from liver tissue flash frozen in liquid nitrogen, then cryo-sectioned at $20 \mu \mathrm{m}$ and mounted in ProLong ${ }^{\mathrm{TM}}$ Gold Antifade Mountant.

\section{Tissue carbonyl assay detection}

Protein Carbonyl Colorimetric Assay Kit (Cayman 10005020) was adapted for intestinal protein carbonyl measurement. In brief, small intestines were collected from animals euthanized by hypothermia followed by PBS perfusion. Intestine contents were removed by gentle swirling in ice-cold PBS after exposing the interior. Liquids were removed as much as possible before flash freezing the tissue in liquid nitrogen. $150 \mathrm{mg}$ of tissue was homogenized in $50 \mathrm{mM}$ phosphate buffer $\mathrm{pH} 6.7$ then centrifuged at $10,000 \times \mathrm{g}$ for $15 \mathrm{~min}$ at $4^{\circ} \mathrm{C}$. Supernatants were collected and incubated with $1 \%$ streptomycin sulfate in $50 \mathrm{mM}$ potassium 
phosphate $\mathrm{pH} 7.2$ at room temperature following centrifugation at $6,000 \times \mathrm{g}$ for 10 min at $4^{\circ} \mathrm{C}$ to remove excessive nucleic acids. Supernatants were collected and stored in $-80^{\circ} \mathrm{C}$ until further use. The tissue carbonyl assay was then performed and analyzed following manual instruction.

\section{Carbonylated total protein and smooth muscle actin-alpha measurement}

EZ-link hydrazine-biotin was used to label protein carbonyl as previously described [115, 116]. Small intestines were collected in ice-cold PBS following removal of intestinal contents. Tissues were stored in $-80^{\circ} \mathrm{C}$ until further processed. In brief, tissues were homogenized in ice-cold homogenous buffer (pH5.5-100mM sodium acetate, $20 \mathrm{mM} \mathrm{NaCl}, 0.1 \mathrm{mM}$ EDTA with protease and phosphatase inhibitor cocktail). Supernatant was incubated with $2 \%$ SDS in homogenous buffer in $65^{\circ} \mathrm{C}$ for $5 \mathrm{~min}$ after centrifugation at $1200 \mathrm{rpm}$ for $10 \mathrm{~min}$ in $4{ }^{\circ} \mathrm{C}$. Samples were further centrifuged at $13,000 \mathrm{~g}$ for 1 hour in $4^{\circ} \mathrm{C}$. Supernatant was collected for protein concentration measurement and 100-150 $\mu \mathrm{g}$ of protein samples were then incubated with EZ-link hydrazine-biotin at $125 \mathrm{uM}$ for 2 hours at room temperature with constant mixing. Hydrazine-labeled samples were then dialyzed into PBS for streptavidin pulldown or $\alpha$ SMA IP. Specific bands of hydrazine-labeled proteins and $\alpha$ SMA were detected by western blot as previously described (REF or above).

\section{Transmission electron microscopy}

Tissues were isolated in ice-cold PBS and gently agitated to remove blood. Liver tissues were cut into approximately $1 \mathrm{~mm}$ size cubes and fixed in $2 \%$ Glutaraldehyde, 2\% Paraformaldehyde in $0.1 \mathrm{M}$ Sorensen's Phosphate Buffer overnight in $4^{\circ} \mathrm{C}$ then washed in ice-cold PBS 3 times. Tissues were then post fixed in 1\% Osmium Tetroxide aqueous for 1 hour before they were dehydrated in graded ethanol series following Propylene Oxide washes and immersed in Araldite/Propylene Oxide 1:1 solution overnight. The samples were then soaked in fresh Araldite for 4 hours before final embedding and heated to polymerize in silicon rubber molds. Thin sections $(60-90 \mathrm{~nm})$ were cut on a Leica EM UC6 Ultramicrotome. Sections were collected onto 200 mesh copper grids and stained with $2 \%$ Uranyl Acetate and Reynold's Lead Citrate before examined on the FEI Tecnai G2 Spirit Transmission Electron Microscope operated at $80 \mathrm{Kv}$.

\section{RNA-sequencing}

$4 \mathrm{WT}$ and 3 Pitx $2^{A S E / A S E} \mathrm{P} 1.5$ small intestines were included in the analysis. Total RNA was isolated with Trizol, with an extra chloroform extraction to remove residual phenol and addition of glyco-blue as a carrier to promote RNA precipitation. RNA concentration was determined on a Nanodrop. TruSeqbarcoded RNA libraries were generated with the NEBNext Ultra II Directional RNA Library Prep Kit (New England Biolabs) with polyA+ enrichment using $1 \mu \mathrm{g}$ total RNA as input. The libraries were sequenced on a NextSeq500 with singleend $85 \mathrm{nt}$ reads. Illumina pipeline software v1.8 was used for base calling. Trim_galore was used to trim and filter reads (--nextseq 20 --length 50). STAR was used to map reads to the Mus musculus mm10 reference using Ensembl 
gene annotations and output raw counts (--quantMode GeneCounts). Differential gene expression was defined by false discovery rate (FDR, adjusted $p$ value for multiple tests) $<=0.05$ from raw counts between WT and Pitx $2^{\text {ASE/ASE }}$.

Quantification and Statistical analysis

\section{Imaging and quantifications}

Microscopic images were acquired using a Zeiss Observer.Z1/Apotome. Confocal images were taken on Zeiss LSM880 confocal microscopes. To capture the entire lacteal and villus in whole mount immunofluorescent stain, multiple adjacent fields of images were taken under a 40X lens then stitched on Zen before exporting for further analyses. Imaris 9.5 was used for image processing, filtering, background subtraction, confocal image stacking, and quantifications. Measurements (lacteal length, filopodia counts etc.) were done on Imaris 9.5 or Fiji. Z stack images were all analyzed on Imaris 9.5.

\section{Statistics}

Statistical analyses were performed in GraphPad Prism 8 (La Jolla, CA). Comparison between different genotypes were tested by unpaired, two tailed Student's t test. All data were first analyzed as mean values of measurements (lacteal length, filopodia number, etc.) from multiple villi in multiple fields across the proximal small intestine for each animal. Lacteal filopodium was defined as cell protrusion longer than or equal to $6 \mu \mathrm{m}$. The mean values from all animals were then plotted in groups based on genotype and developmental stages. Almost all data were expressed as mean of the means from each mouse \pm standard error of mean (SEM). 


\section{Supplemental Table}

\begin{tabular}{|c|c|c|}
\hline MOUSE GENOTYPING PRIMERS & SOURCE & IDENTIFIER \\
\hline \multicolumn{3}{|l|}{ Oligonucleotides } \\
\hline Pitx2 ${ }^{\text {ASE }}$ F: 5'-TCACTGAAATCCCTGGGGAGA-3' & [22] & $\mathrm{N} / \mathrm{A}$ \\
\hline Pitx2 ${ }^{\text {ASE }}$ R1: 5'-AGAAGCAAGCCTCACGCACTT-3' & {$[22]$} & $\mathrm{N} / \mathrm{A}$ \\
\hline Pitx2 $^{\text {ASE }}$ R2: 5'-AGCCACAGAAGCCATCAACTT-3' & [22] & $\mathrm{N} / \mathrm{A}$ \\
\hline Pitx2 ${ }^{\Delta C}$ F: 5'-CTAATATCAGCTACCTGTCCCTGTCACTC-3' & [28] & $\mathrm{N} / \mathrm{A}$ \\
\hline Pitx ${ }^{\Delta C}$ R: 5'-ACTGAAGGAAGGCCAAGGTAGACTCGG-3' & [28] & $\mathrm{N} / \mathrm{A}$ \\
\hline Pitx2 $^{\text {cre }}$ F1: 5'-GGCTTCTGAGGCGGAAAGAACC-3' & [28] & $\mathrm{N} / \mathrm{A}$ \\
\hline Pitx2 ${ }^{\text {cre }}$ F2: 5'-ACCCACACTTTCACCGCTCACC-3' & [28] & $\mathrm{N} / \mathrm{A}$ \\
\hline Pitx2 $2^{\text {cre }}$ R: 5'-AGGCTCTGATTCTTGGCAAGGC-3' & [28] & $\mathrm{N} / \mathrm{A}$ \\
\hline ASE $^{\text {cre }}$ F1: 5'-GGTGTTAGTTGAGAACTGTGGAG-3' & [44] & $\mathrm{N} / \mathrm{A}$ \\
\hline ASE $^{\text {cre }}$ F2: 5'-AGTGGCCTCTTCCAGAAATG-3' & [44] & $\mathrm{N} / \mathrm{A}$ \\
\hline ASE $^{\text {cre }}$ R1: 5'-ACATGTCCATCAGGTTCTTGC-3' & [44] & $\mathrm{N} / \mathrm{A}$ \\
\hline ASE $^{\text {Cre }}$ R2: 5'-TGCGACTGTGTCTGATTTCC-3' & {$[44]$} & $\mathrm{N} / \mathrm{A}$ \\
\hline ROSA26 ${ }^{\text {CAG-Id Iomato }}$ WT F: 5'-AAGGGAGCTGCAGTGGAGTA-3' & JAX Protocol & olMR9020 \\
\hline ROSA26 ${ }^{\text {CAG-IdIomato }}$ WT R: 5'-CCGAAAATCTGTGGGAAGTC-3' & JAX Protocol & olMR9021 \\
\hline ROSA26 ${ }^{\text {CAG-tdomato }}$ Mut F: 5'-CTGTTCCTGTACGGCATGG-3' & JAX Protocol & olMR9105 \\
\hline ROSA26 ${ }^{\text {CAG-Id Iomato }}$ Mut R: 5'-GGCATTAAAGCAGCGTATCC-3' & JAX Protocol & olMR9103 \\
\hline ROSA26-EYFP WT F: 5’-CTG GCT TCT GAG GAC CG-3' & JAX Protocol & 21306 \\
\hline ROSA26-EYFP WT R: 5'-CAG GAC AAC GCC CAC ACA-3' & JAX Protocol & 24500 \\
\hline ROSA26-EYFP Mut F: 5’-AGG GCG AGG AGC TGT TCA-3' & JAX Protocol & 24951 \\
\hline ROSA26-EYFP Mut R: 5'-TGA AGT CGA TGC CCT TCA G-3' & JAX Protocol & 24952 \\
\hline
\end{tabular}




\section{REFERENCES}

1. Cueni, L.N. and M. Detmar, The lymphatic system in health and disease. Lymphat Res Biol, 2008. 6(3-4): p. 109-22.

2. Alitalo, K., T. Tammela, and T.V. Petrova, Lymphangiogenesis in development and human disease. Nature, 2005. 438(7070): p. 946-53.

3. Alitalo, K., The lymphatic vasculature in disease. Nat Med, 2011.17(11): p. 1371-80.

4. Betterman, K.L. and N.L. Harvey, The lymphatic vasculature: development and role in shaping immunity. Immunol Rev, 2016. 271(1): p. 276-92.

5. Cifarelli, V. and A. Eichmann, The Intestinal Lymphatic System: Functions and Metabolic Implications. Cell Mol Gastroenterol Hepatol, 2019. 7(3): p. 503513.

6. Alexander, J.S., et al., Emerging roles of lymphatics in inflammatory bowel disease. Ann N Y Acad Sci, 2010.1207 Suppl 1: p. E75-85.

7. Alexander, J.S., et al., Gastrointestinal lymphatics in health and disease. Pathophysiology, 2010. 17(4): p. 315-35.

8. Zhang, F., et al., Lacteal junction zippering protects against diet-induced obesity. Science, 2018. 361(6402): p. 599-603.

9. Bernier-Latmani, J. and T.V. Petrova, Intestinal lymphatic vasculature: structure, mechanisms and functions. Nat Rev Gastroenterol Hepatol, 2017. 14(9): p. 510-526.

10. Kim, K.E., H.K. Sung, and G.Y. Koh, Lymphatic development in mouse small intestine. Dev Dyn, 2007. 236(7): p. 2020-5.

11. Mahadevan, A., et al., The left-right pitx2 pathway drives organ-specific arterial and lymphatic development in the intestine. Dev Cell, 2014. 31(6): p. 690-706.

12. Campione, M., et al., The homeobox gene Pitx2: mediator of asymmetric leftright signaling in vertebrate heart and gut looping. Development, 1999. 126(6): p. 1225-34.

13. Logan, M., et al., The transcription factor Pitx2 mediates situs-specific morphogenesis in response to left-right asymmetric signals. Cell, 1998. 94(3): p. 307-17.

14. Ryan, A.K., et al., Pitx2 determines left-right asymmetry of internal organs in vertebrates. Nature, 1998. 394(6693): p. 545-51.

15. Yoshioka, H., et al., Pitx2, a bicoid-type homeobox gene, is involved in a leftysignaling pathway in determination of left-right asymmetry. Cell, 1998. 94(3): p. 299-305.

16. Davis, N.M., et al., The chirality of gut rotation derives from left-right asymmetric changes in the architecture of the dorsal mesentery. Dev Cell, 2008. 15(1): p. 134-45.

17. Kurpios, N.A., et al., The direction of gut looping is established by changes in the extracellular matrix and in cell:cell adhesion. Proc Natl Acad Sci U S A, 2008. 105(25): p. 8499-506. 
18. Welsh, I.C., et al., Integration of Left-Right Pitx2 Transcription and Wht Signaling Drives Asymmetric Gut Morphogenesis via Daam2. Dev Cell, 2013. 26(6): p. 629-44.

19. Gage, P.J. and S.A. Camper, Pituitary homeobox 2, a novel member of the bicoidrelated family of homeobox genes, is a potential regulator of anterior structure formation. Hum Mol Genet, 1997. 6(3): p. 457-64.

20. Gage, P.J., H. Suh, and S.A. Camper, The bicoid-related Pitx gene family in development. Mamm Genome, 1999.10(2): p. 197-200.

21. Shiratori, H., et al., Two-step regulation of left-right asymmetric expression of Pitx2: initiation by nodal signaling and maintenance by Nkx2. Mol Cell, 2001. 7(1): p. 137-49.

22. Shiratori, H., et al., Conserved regulation and role of Pitx2 in situs-specific morphogenesis of visceral organs. Development, 2006. 133(15): p. 3015-25.

23. Liu, C., et al., Regulation of left-right asymmetry by thresholds of Pitx $2 \mathrm{c}$ activity. Development, 2001. 128(11): p. 2039-48.

24. Schweickert, A., et al., Pitx2 isoforms: involvement of Pitx2c but not Pitx2a or Pitx2b in vertebrate left-right asymmetry. Mech Dev, 2000. 90(1): p. 41-51.

25. Lu, M.F., et al., Function of Rieger syndrome gene in left-right asymmetry and craniofacial development. Nature, 1999. 401(6750): p. 276-8.

26. Kitamura, K., et al., Mouse Pitx2 deficiency leads to anomalies of the ventral body wall, heart, extra- and periocular mesoderm and right pulmonary isomerism. Development, 1999. 126(24): p. 5749-58.

27. Lin, C.R., et al., Pitx2 regulates lung asymmetry, cardiac positioning and pituitary and tooth morphogenesis. Nature, 1999. 401(6750): p. 279-82.

28. Liu, C., et al., Pitx $2 c$ patterns anterior myocardium and aortic arch vessels and is required for local cell movement into atrioventricular cushions.

Development, 2002.129(21): p. 5081-91.

29. Miller, M.J., J.R. McDole, and R.D. Newberry, Microanatomy of the intestinal lymphatic system. Ann N Y Acad Sci, 2010.1207 Suppl 1: p. E21-8.

30. Wang, T.Y., et al., New insights into the molecular mechanism of intestinal fatty acid absorption. Eur J Clin Invest, 2013. 43(11): p. 1203-23.

31. Ko, C.W., et al., Regulation of intestinal lipid metabolism: current concepts and relevance to disease. Nat Rev Gastroenterol Hepatol, 2020. 17(3): p. 169-183.

32. Dixon, J.B., Mechanisms of chylomicron uptake into lacteals. Ann N Y Acad Sci, 2010.1207 Suppl 1: p. E52-7.

33. Xu, Y., et al., Neuropilin-2 mediates VEGF-C-induced lymphatic sprouting together with VEGFR3. J Cell Biol, 2010. 188(1): p. 115-30.

34. Tammela, T., et al., Blocking VEGFR-3 suppresses angiogenic sprouting and vascular network formation. Nature, 2008. 454(7204): p. 656-60.

35. Bernier-Latmani, J., et al., DLL4 promotes continuous adult intestinal lacteal regeneration and dietary fat transport. J Clin Invest, 2015. 125(12): p. 457286.

36. Hosoyamada, Y. and T. Sakai, Mechanical components of rat intestinal villi as revealed by ultrastructural analysis with special reference to the axial smooth muscle cells in the villi. Arch Histol Cytol, 2007. 70(2): p. 107-16. 
37. Nurmi, H., et al., VEGF-C is required for intestinal lymphatic vessel maintenance and lipid absorption. EMBO molecular medicine, 2015. 7(11): p. 1418-25.

38. Choe, K., et al., Intravital imaging of intestinal lacteals unveils lipid drainage through contractility. J Clin Invest, 2015. 125(11): p. 4042-52.

39. Adams, R.H. and K. Alitalo, Molecular regulation of angiogenesis and lymphangiogenesis. Nat Rev Mol Cell Biol, 2007. 8(6): p. 464-78.

40. Yashiro, K., H. Shiratori, and H. Hamada, Haemodynamics determined by a genetic programme govern asymmetric development of the aortic arch. Nature, 2007. 450(7167): p. 285-8.

41. Hecksher-Sorensen, J., et al., The splanchnic mesodermal plate directs spleen and pancreatic laterality, and is regulated by Bapx1/Nkx3.2. Development, 2004.131(19): p. 4665-75.

42. Shang, Y., et al., Pitx2 is functionally important in the early stages of vascular smooth muscle cell differentiation. J Cell Biol, 2008. 181(3): p. 461-73.

43. Bernier-Latmani, J. and T.V. Petrova, High-resolution 3D analysis of mouse small-intestinal stroma. Nat Protoc, 2016. 11(9): p. 1617-29.

44. Shiratori, H., et al., Self-regulated left-right asymmetric expression of Pitx2c in the developing mouse limb. Dev Biol, 2014. 395(2): p. 331-41.

45. Trautman, A., Die Muskulatur in den Dunndarmzotten der Haustiere. Anat Anz, 1909. 34(113-125).

46. Guldner, F.H., J.R. Wolff, and D.G. Keyserlingk, Fibroblasts as a part of the contractile system in duodenal villi of rat. Z Zellforsch Mikrosk Anat, 1972. 135(3): p. 349-60.

47. Owens, G.K., M.S. Kumar, and B.R. Wamhoff, Molecular regulation of vascular smooth muscle cell differentiation in development and disease. Physiol Rev, 2004. 84(3): p. 767-801.

48. Owens, G.K., Regulation of differentiation of vascular smooth muscle cells. Physiol Rev, 1995. 75(3): p. 487-517.

49. Gomez, D., P. Swiatlowska, and G.K. Owens, Epigenetic Control of Smooth Muscle Cell Identity and Lineage Memory. Arterioscler Thromb Vasc Biol, 2015. 35(12): p. 2508-16.

50. Lu, S.C., Glutathione synthesis. Biochim Biophys Acta, 2013. 1830(5): p. 314353.

51. Wang, J., et al., Pitx2-microRNA pathway that delimits sinoatrial node development and inhibits predisposition to atrial fibrillation. Proc Natl Acad Sci U S A, 2014. 111(25): p. 9181-6.

52. Fedorova, M., R.C. Bollineni, and R. Hoffmann, Protein carbonylation as a major hallmark of oxidative damage: update of analytical strategies. Mass Spectrom Rev, 2014. 33(2): p. 79-97.

53. Dalle-Donne, I., et al., Protein carbonyl groups as biomarkers of oxidative stress. Clin Chim Acta, 2003. 329(1-2): p. 23-38.

54. Chevion, M., E. Berenshtein, and E.R. Stadtman, Human studies related to protein oxidation: protein carbonyl content as a marker of damage. Free Radic Res, 2000. 33 Suppl: p. S99-108.

55. $\mathrm{Xu}, \mathrm{Q}$, et al., Redox regulation of the actin cytoskeleton and its role in the vascular system. Free Radic Biol Med, 2017. 109: p. 84-107. 
56. Wilson, C. and C. Gonzalez-Billault, Regulation of cytoskeletal dynamics by redox signaling and oxidative stress: implications for neuronal development and trafficking. Front Cell Neurosci, 2015. 9: p. 381.

57. Dalle-Donne, I., et al., Reversible S-glutathionylation of Cys 374 regulates actin filament formation by inducing structural changes in the actin molecule. Free Radic Biol Med, 2003. 34(1): p. 23-32.

58. Dalle-Donne, I., et al., Methionine oxidation as a major cause of the functional impairment of oxidized actin. Free Radic Biol Med, 2002. 32(9): p. 927-37.

59. Hung, R.J., C.W. Pak, and J.R. Terman, Direct redox regulation of F-actin assembly and disassembly by Mical. Science, 2011. 334(6063): p. 1710-3.

60. Hung, R.J., et al., SelR reverses Mical-mediated oxidation of actin to regulate Factin dynamics. Nat Cell Biol, 2013. 15(12): p. 1445-54.

61. Dalle-Donne, I., et al., Actin carbonylation: from a simple marker of protein oxidation to relevant signs of severe functional impairment. Free Radic Biol Med, 2001. 31(9): p. 1075-83.

62. Zhou, A., et al., The Role of Interstitial Matrix and the Lymphatic System in Gastrointestinal Lipid and Lipoprotein Metabolism. Front Physiol, 2020. 11: p. 4.

63. Tso, P. and J.A. Balint, Formation and transport of chylomicrons by enterocytes to the lymphatics. Am J Physiol, 1986. 250(6 Pt 1): p. G715-26.

64. Kindel, T., D.M. Lee, and P. Tso, The mechanism of the formation and secretion of chylomicrons. Atheroscler Suppl, 2010.11(1): p. 11-6.

65. Hussain, M.M., Intestinal lipid absorption and lipoprotein formation. Curr Opin Lipidol, 2014. 25(3): p. 200-6.

66. Anwar, K., J. Iqbal, and M.M. Hussain, Mechanisms involved in vitamin $E$ transport by primary enterocytes and in vivo absorption. J Lipid Res, 2007. 48(9): p. 2028-38.

67. Young, S.G., et al., A genetic model for absent chylomicron formation: mice producing apolipoprotein $B$ in the liver, but not in the intestine. J Clin Invest, 1995. 96(6): p. 2932-46.

68. McDonald, G.B., et al., Portal venous transport of long-chain fatty acids absorbed from rat intestine. Am J Physiol, 1980. 239(3): p. G141-50.

69. Kurtel, H., et al., Ischemia-reperfusion-induced mucosal dysfunction: role of neutrophils. Am J Physiol, 1991. 261(3 Pt 1): p. G490-6.

70. Fujimoto, K., et al., Effect of ischemia-reperfusion on lipid digestion and absorption in rat intestine. Am J Physiol, 1991. 260(4 Pt 1): p. G595-602.

71. Courtney, C.M. and B.W. Warner, Pediatric intestinal failure-associated liver disease. Curr Opin Pediatr, 2017. 29(3): p. 363-370.

72. Onufer, E.J., et al., Lymphatic network remodeling after small bowel resection. J Pediatr Surg, 2019. 54(6): p. 1239-1244.

73. Cabre, E., et al., Absorption and transport of dietary long-chain fatty acids in cirrhosis: a stable-isotope-tracing study. Am J Clin Nutr, 2005. 81(3): p. 692701.

74. Ee, L.C., et al., Lymphatic absorption of fatty acids and cholesterol in the neonatal rat. Am J Physiol Gastrointest Liver Physiol, 2000. 279(2): p. G32531. 
75. Dixon, J.B., S. Raghunathan, and M.A. Swartz, A tissue-engineered model of the intestinal lacteal for evaluating lipid transport by lymphatics. Biotechnol Bioeng, 2009. 103(6): p. 1224-35.

76. Mehlem, A., et al., Imaging of neutral lipids by oil red 0 for analyzing the metabolic status in health and disease. Nat Protoc, 2013. 8(6): p. 1149-54.

77. Gors, S., et al., Technical note: Milk composition in mice--methodological aspects and effects of mouse strain and lactation day. J Dairy Sci, 2009. 92(2): p. 632-7.

78. Sivakumar, A., et al., Midgut Laterality Is Driven by Hyaluronan on the Right. Dev Cell, 2018. 46(5): p. 533-551 e5.

79. Wilm, B., et al., The serosal mesothelium is a major source of smooth muscle cells of the gut vasculature. Development, 2005. 132(23): p. 5317-28.

80. Winters, N.I., A.M. Williams, and D.M. Bader, Resident progenitors, not exogenous migratory cells, generate the majority of visceral mesothelium in organogenesis. Dev Biol, 2014. 391(2): p. 125-32.

81. Xu, J., et al., Tbx18 is essential for normal development of vasculature network and glomerular mesangium in the mammalian kidney. Dev Biol, 2014. 391(1): p. 17-31.

82. Airik, R., et al., Tbx18 regulates the development of the ureteral mesenchyme. J Clin Invest, 2006. 116(3): p. 663-74.

83. Hong, S.P., et al., Distinct fibroblast subsets regulate lacteal integrity through YAP/TAZ-induced VEGF-C in intestinal villi. Nat Commun, 2020.11(1): p. 4102.

84. Zhou, Y., D. Liu, and H.J. Kaminski, Pitx2 regulates myosin heavy chain isoform expression and multi-innervation in extraocular muscle. J Physiol, 2011. 589(Pt 18): p. 4601-14.

85. Lagha, M., et al., Transcriptome analyses based on genetic screens for Pax3 myogenic targets in the mouse embryo. BMC Genomics, 2010.11: p. 696.

86. L'Honore, A., et al., Pitx2 defines alternate pathways acting through MyoD during limb and somitic myogenesis. Development, 2010.137(22): p. 384756.

87. Dixit, M., et al., DUX4, a candidate gene of facioscapulohumeral muscular dystrophy, encodes a transcriptional activator of PITX1. Proc Natl Acad Sci U S A, 2007. 104(46): p. 18157-62.

88. Semina, E.V., et al., Cloning and characterization of a novel bicoid-related homeobox transcription factor gene, RIEG, involved in Rieger syndrome. Nat Genet, 1996. 14(4): p. 392-9.

89. Semina, E.V., et al., A novel homeobox gene PITX3 is mutated in families with autosomal-dominant cataracts and ASMD. Nat Genet, 1998. 19(2): p. 167-70.

90. Huycke, T.R., et al., Genetic and Mechanical Regulation of Intestinal Smooth Muscle Development. Cell, 2019. 179(1): p. 90-105 e21.

91. Wang, G., et al., Origin and differentiation of vascular smooth muscle cells. J Physiol, 2015. 593(14): p. 3013-30.

92. Zawieja, D.C., et al., Reactive oxygen metabolites inhibit spontaneous lymphatic contractions. Am J Physiol, 1991. 260(6 Pt 2): p. H1935-43. 
93. Thangaswamy, S., E.A. Bridenbaugh, and A.A. Gashev, Evidence of increased oxidative stress in aged mesenteric lymphatic vessels. Lymphat Res Biol, 2012. 10(2): p. 53-62.

94. Remels, A.H., et al., Regulation of mitochondrial biogenesis during myogenesis. Mol Cell Endocrinol, 2010. 315(1-2): p. 113-20.

95. Blanchet, E., et al., E2F transcription factor-1 regulates oxidative metabolism. Nat Cell Biol, 2011.13(9): p. 1146-52.

96. Schieber, M. and N.S. Chandel, ROS function in redox signaling and oxidative stress. Curr Biol, 2014. 24(10): p. R453-62.

97. Mittler, R., ROS Are Good. Trends Plant Sci, 2017. 22(1): p. 11-19.

98. L'Honore, A., et al., Redox regulation by Pitx2 and Pitx3 is critical for fetal myogenesis. Dev Cell, 2014. 29(4): p. 392-405.

99. Tao, G., et al., Pitx2 promotes heart repair by activating the antioxidant response after cardiac injury. Nature, 2016. 534(7605): p. 119-23.

100. Davis, R.B., et al., Lymphatic deletion of calcitonin receptor-like receptor exacerbates intestinal inflammation. JCI Insight, 2017. 2(6): p. e92465.

101. Petrova, T.V. and G.Y. Koh, Organ-specific lymphatic vasculature: From development to pathophysiology. J Exp Med, 2018. 215(1): p. 35-49.

102. Niethammer, P., et al., A tissue-scale gradient of hydrogen peroxide mediates rapid wound detection in zebrafish. Nature, 2009. 459(7249): p. 996-9.

103. Yoo, S.K., et al., Lyn is a redox sensor that mediates leukocyte wound attraction in vivo. Nature, 2011.480(7375): p. 109-12.

104. Lim, H.Y., et al., ROS regulate cardiac function via a distinct paracrine mechanism. Cell Rep, 2014. 7(1): p. 35-44.

105. Mattila, P.K. and P. Lappalainen, Filopodia: molecular architecture and cellular functions. Nat Rev Mol Cell Biol, 2008. 9(6): p. 446-54.

106. Shneyer, B.I., et al., ROS induced distribution of mitochondria to filopodia by Myo19 depends on a class specific tryptophan in the motor domain. Sci Rep, 2017. 7(1): p. 11577.

107. Munnamalai, V. and D.M. Suter, Reactive oxygen species regulate F-actin dynamics in neuronal growth cones and neurite outgrowth. J Neurochem, 2009. 108(3): p. 644-61.

108. Kurtel, H., et al., Ischemia-reperfusion-induced mucosal dysfunction: role of neutrophils. The American journal of physiology, 1991. 261(3 Pt 1): p. G4906.

109. Fujimoto, K., et al., Effect of ischemia-reperfusion on lipid digestion and absorption in rat intestine. The American journal of physiology, 1991. 260(4 Pt 1): p. G595-602.

110. Moor, A.E., et al., Spatial Reconstruction of Single Enterocytes Uncovers Broad Zonation along the Intestinal Villus Axis. Cell, 2018. 175(4): p. 1156-1167 e15.

111. Takahara, E., et al., Ultrastructural demonstration of the absorption and transportation of minute chylomicrons by subepithelial blood capillaries in rat jejunal villi. J Vet Med Sci, 2013. 75(12): p. 1563-9.

112. Tesfay, M., W.J. Goldkamp, and B.A. Neuschwander-Tetri, NASH: The Emerging Most Common Form of Chronic Liver Disease. Mo Med, 2018.

115(3): p. 225-229. 
113. Madisen, L., et al., A robust and high-throughput Cre reporting and characterization system for the whole mouse brain. Nat Neurosci, 2010.13(1): p. 133-40.

114. Srinivas, S., et al., Cre reporter strains produced by targeted insertion of EYFP and ECFP into the ROSA26 locus. BMC Dev Biol, 2001. 1: p. 4.

115. Grimsrud, P.A., et al., Carbonylation of adipose proteins in obesity and insulin resistance: identification of adipocyte fatty acid-binding protein as a cellular target of 4-hydroxynonenal. Mol Cell Proteomics, 2007. 6(4): p. 624-37.

116. Xu, Q., W.S. Hahn, and D.A. Bernlohr, Detecting protein carbonylation in adipose tissue and in cultured adipocytes. Methods Enzymol, 2014. 538: p. 249-61. 
bioRxiv preprint doi: https://doi.org/10.1101/2021.06.11.447753; this version posted June 11, 2021. The copyright holder for this preprint (which was not certified by peer review) is the author/funder, who has granted bioRxiv a license to display the preprint in perpetuity. It is made available under aCC-BY 4.0 International license.

\section{GRAPHICAL ABSTRACT}

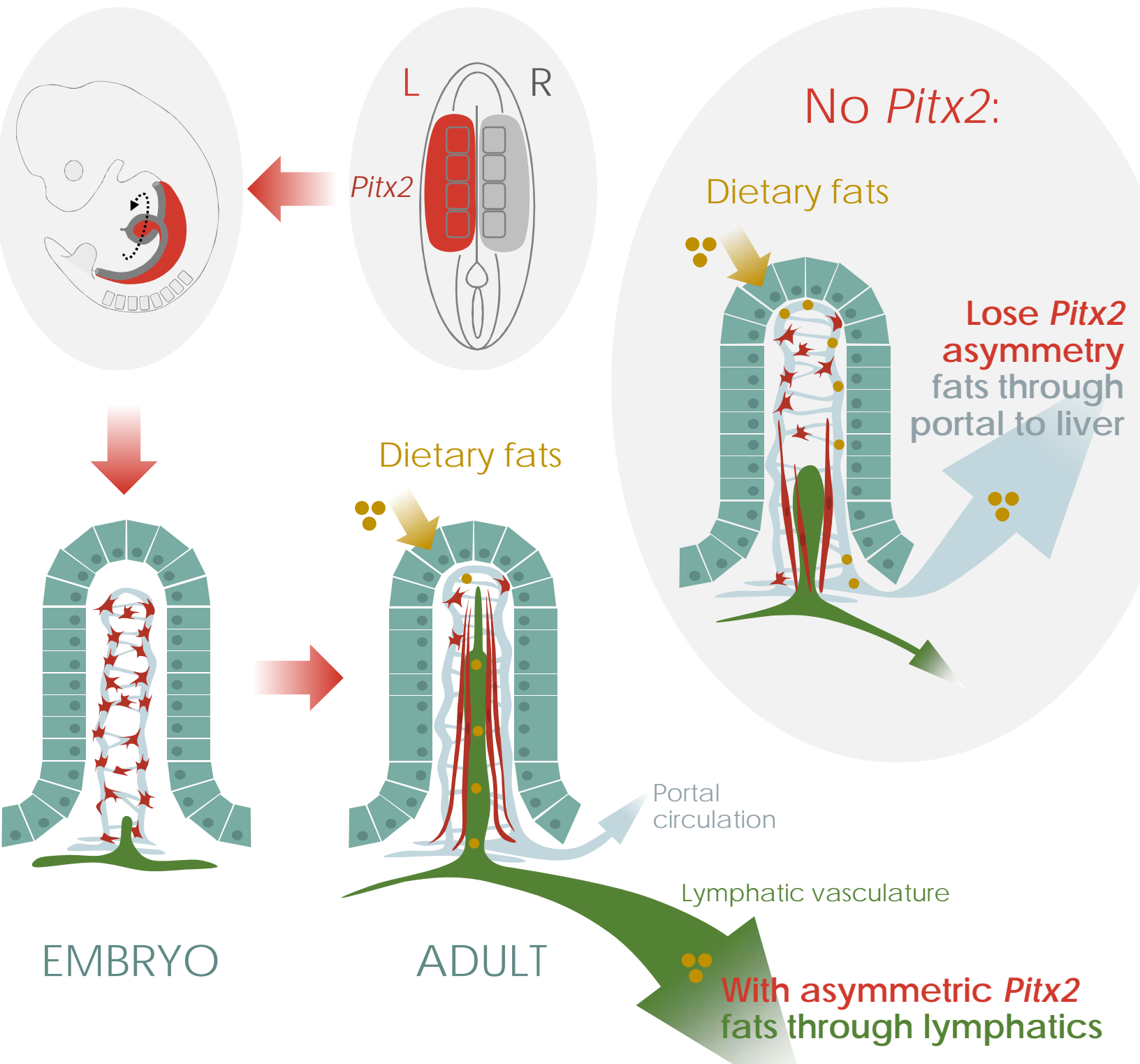




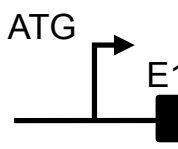

E1

Pitx2a

Pitx2b

Pitx2c

B

Pitx2 $2^{H D}$

Pitx $^{4 C}$

Pitx2 $2^{A S E}$
Genomic organization of the Pitx2 deficient mouse models
C

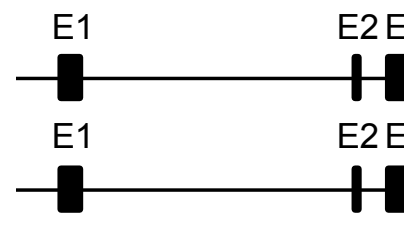

\% survival of Pitx2 deficient mouse models
Pitx2HD

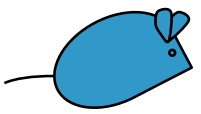

E10.5

Survival: $(100 \%)$

E14.5

$(0 \%)$

\section{Pitx2 ${ }^{\text {ASE }} /$ ASE}

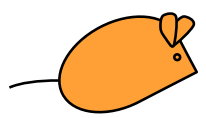

E10.5

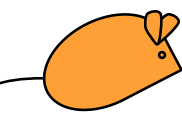

$\mathrm{E} 14.5$ $(100 \%)$

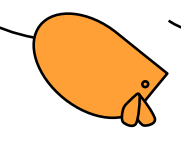

$\mathrm{PO}$

$(70 \%)$

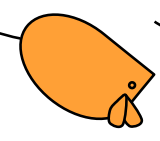

P1.5

$(23 \%)$

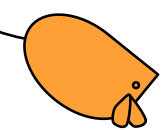

Weaning $(4.7 \%)$
ATG

E5 E6

$\mathrm{E} 4 \mathrm{E} 5 \quad \mathrm{E} 6$
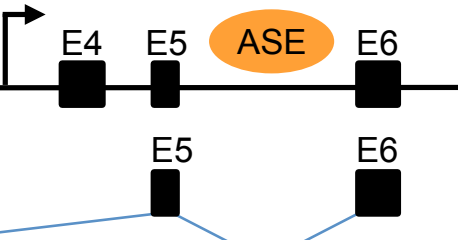

Survival: $(100 \%)$

D

Pitx2 $2^{\text {ASE/ASE }}$ mice fail to properly gain weight
Body weight of Pitx $2^{\text {ASE/ASE }}$ mice

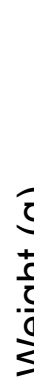

n.s

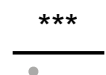

WT

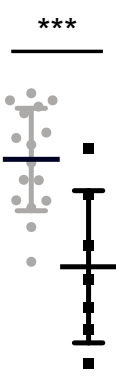

Pitx $2^{A S E} / A S E$

2
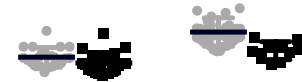

PO

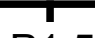

P1.5

Pg
$\%$ survival of Pitx2 $2^{\text {ASE/ASE }}$ mice (\%)

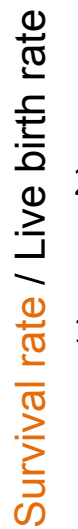

E4

IoxP E5 ASE E6

E4 E5 loxP E6 
A' $\quad$ aSMA/tdT (P9) A" aSMA/tdT (P9) A'”, $\quad$ ASMA/tdT
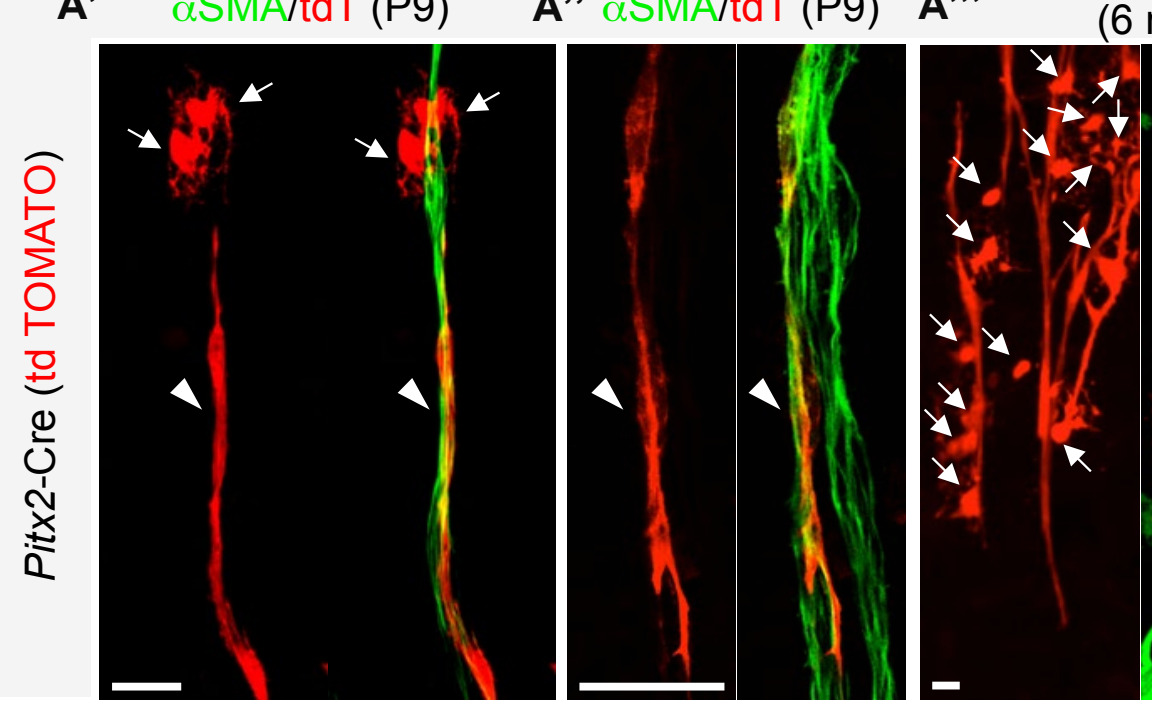

(6 months)

B

Abnormal morphology of axial SMCs in Pitx2 $2^{\text {ASE/ASE }}$ pups (P9)

\section{A'"' $\alpha$ SMAYYFP}

CD31/YFP
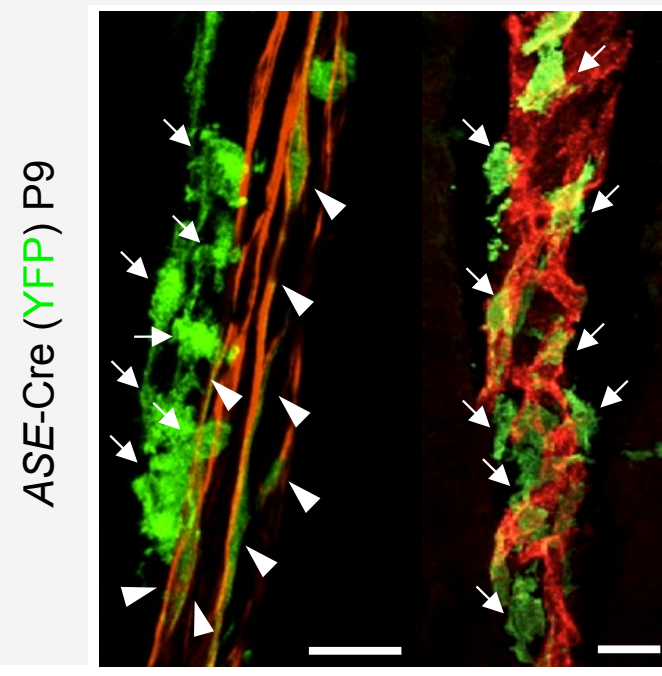

Pitx 2 ASE/ASE villi have
open SMC bundles (P9)

$\%$ lacteals with open SMCs
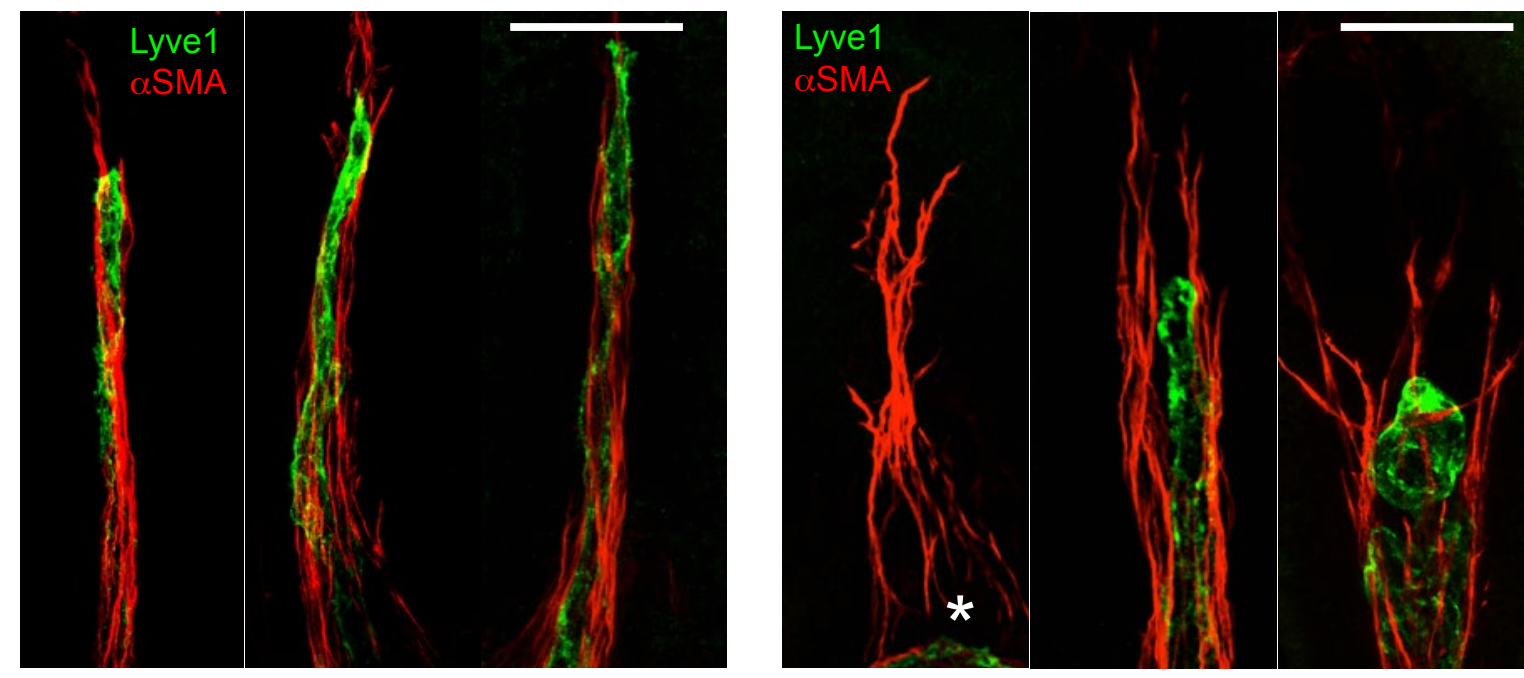

E

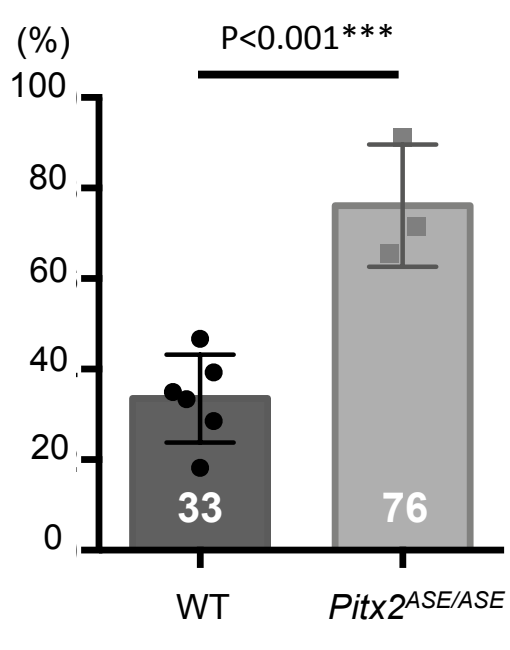

Model

D Pitx2 $2^{\text {ASE/ASE }}$ villi have open SMC bundles (P9, cross section)

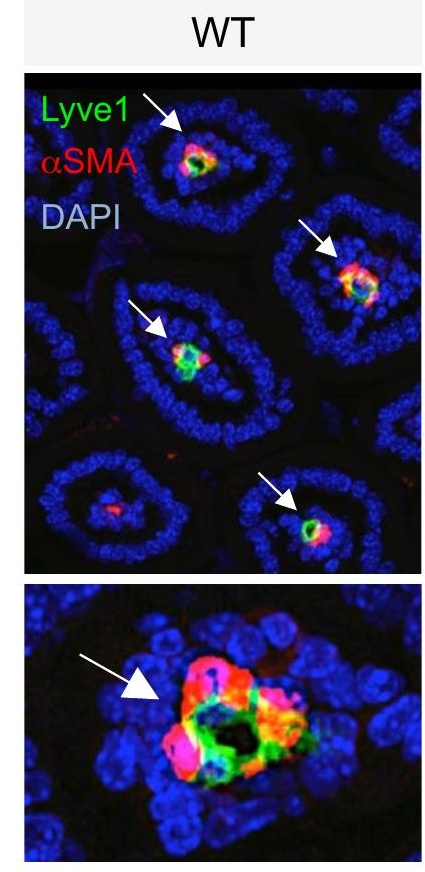

\section{Pitx2 ASE/ASE}

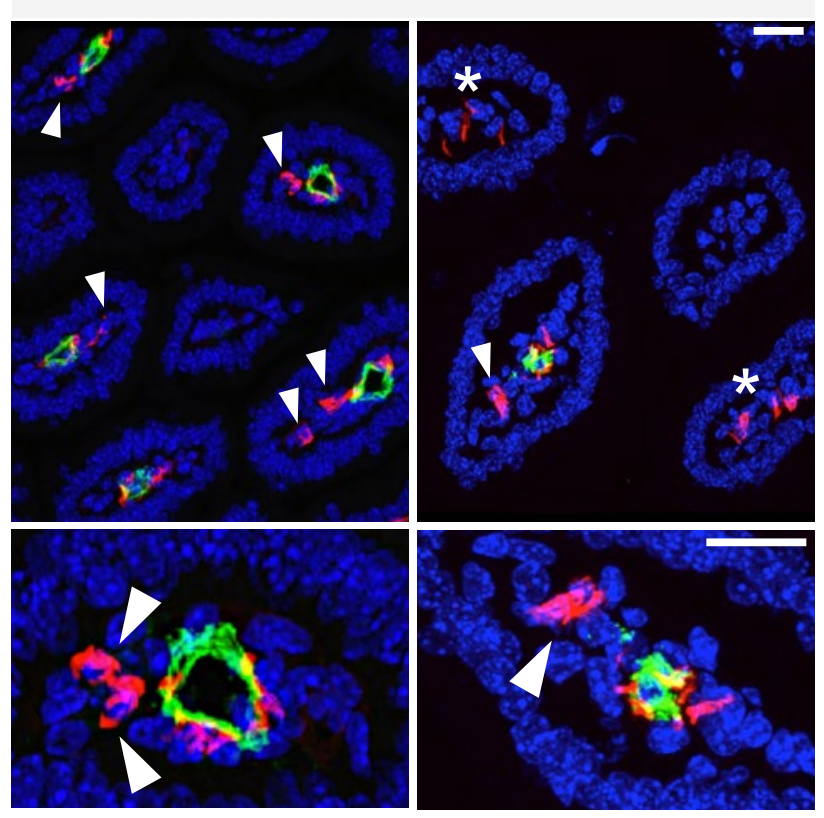

WT

"Closed"

SMC

bundles

Cross

section:

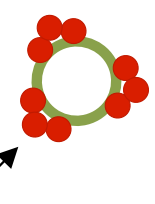

Pitx2 $2^{\text {ASE/ASE }}$

"Open"

SMC

bundles

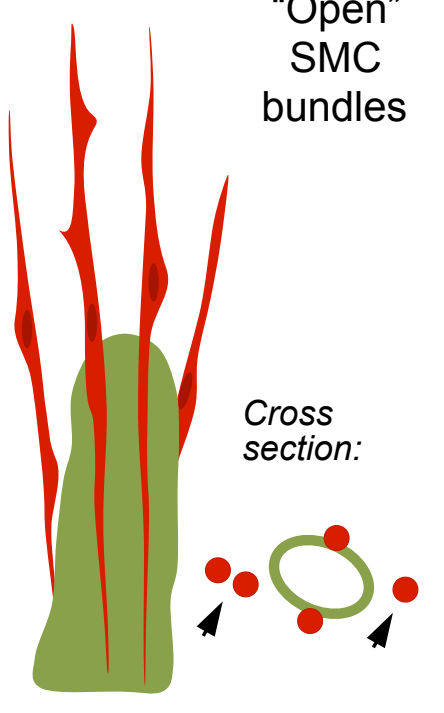




\begin{tabular}{|c|c|c|}
\hline Pitx $2^{\text {ASE/ASE }}$ & WT & Max \\
\hline & & Slc10a2 \\
\hline & & Il1rl1 \\
\hline & & Ereg \\
\hline & & Gclc \\
\hline & & Tifa \\
\hline & & Rfx2 \\
\hline & & Ap1ar \\
\hline & & Abce1 \\
\hline & & Plk3 \\
\hline & & Myo19 \\
\hline & & Camk2d \\
\hline & & Tnfrsf9 \\
\hline & & Alas2 \\
\hline & & Ankrd37 \\
\hline & & Gjb1 \\
\hline & & Pfkl \\
\hline & & Acer2 \\
\hline & & Dao \\
\hline & & Pf4 \\
\hline & & Tsc22d3 \\
\hline & & 4930481A15Rik \\
\hline & & Zgrf1 \\
\hline & & Ddit4 \\
\hline & & Bnip3 \\
\hline & & Hbp1 \\
\hline & & Edn1 \\
\hline & & Pdcd4 \\
\hline & & Capg \\
\hline & & Abtb1 \\
\hline & & Rnf103 \\
\hline & & Tbc1d17 \\
\hline & & Nbl1 \\
\hline & & Psap \\
\hline
\end{tabular}

B' Increased protein carbonylation in the Pitx2 ${ }^{\text {ASE/ASE }}$ pups (P1.5)

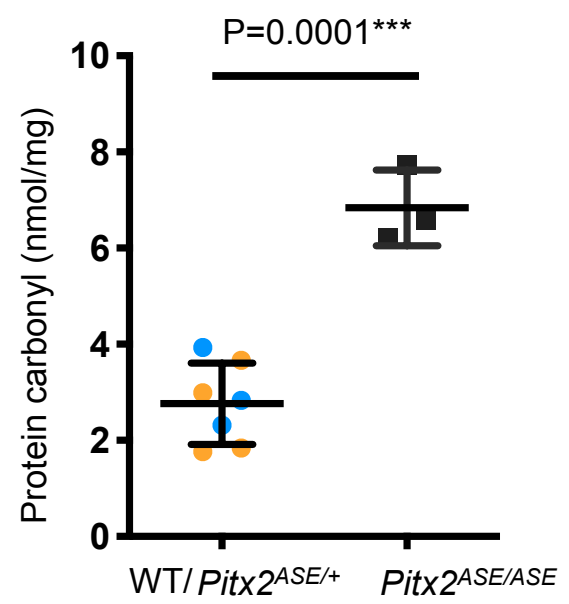

Pitx2 Redox 17/33 genes are bound by Pitx2 binding related

\section{6}

6/33 genes are redox related

6

27

3/6 redox genes are Pitx2 bound

$$
1433
$$

\section{B Carbonylation schematic}
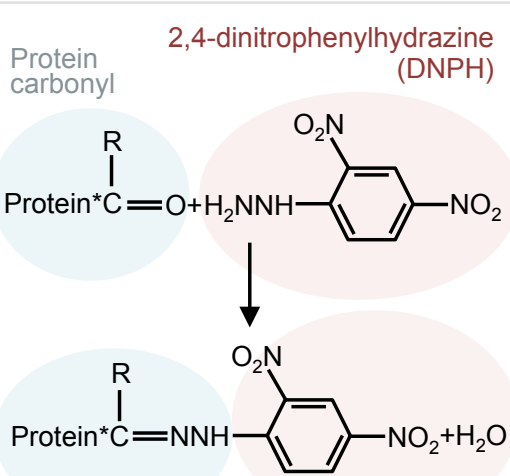

2,4-dinitrophenylhydrazone (Hydrazone)
D Protein carbonyl in SA pulldown

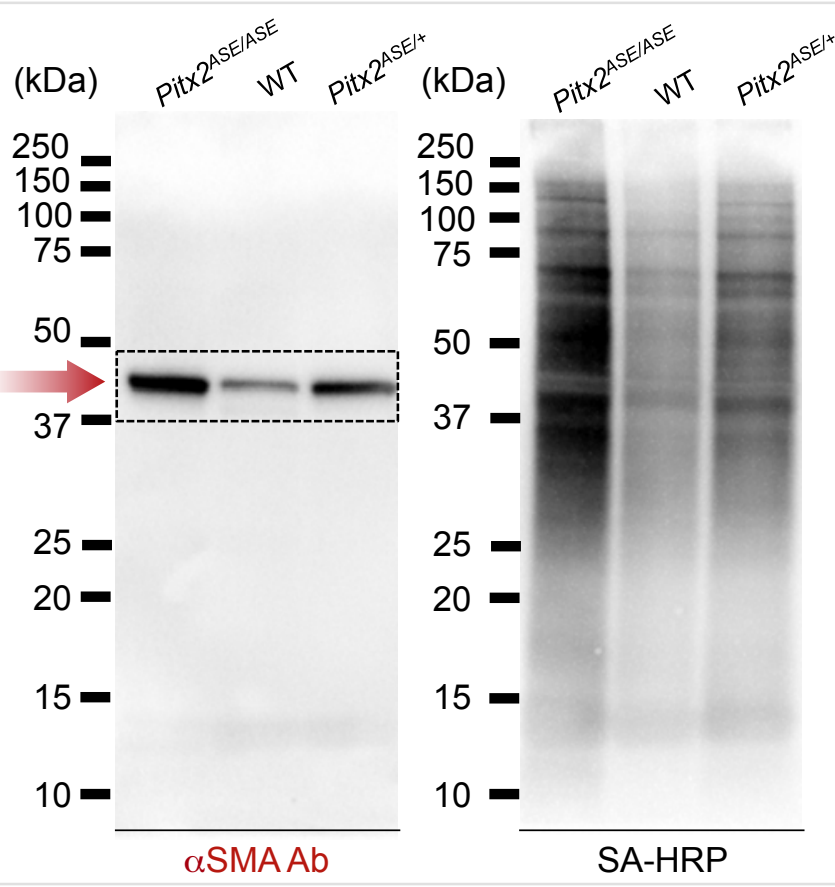

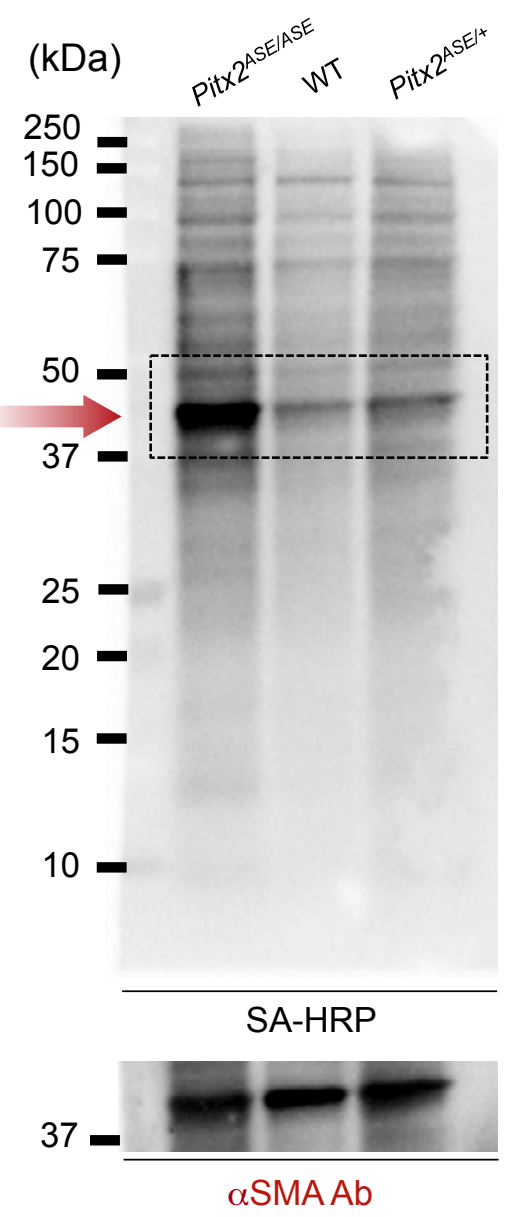

E Protein carbonyl: $\alpha$ SMA-IP

(kDa)

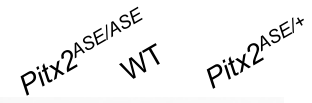

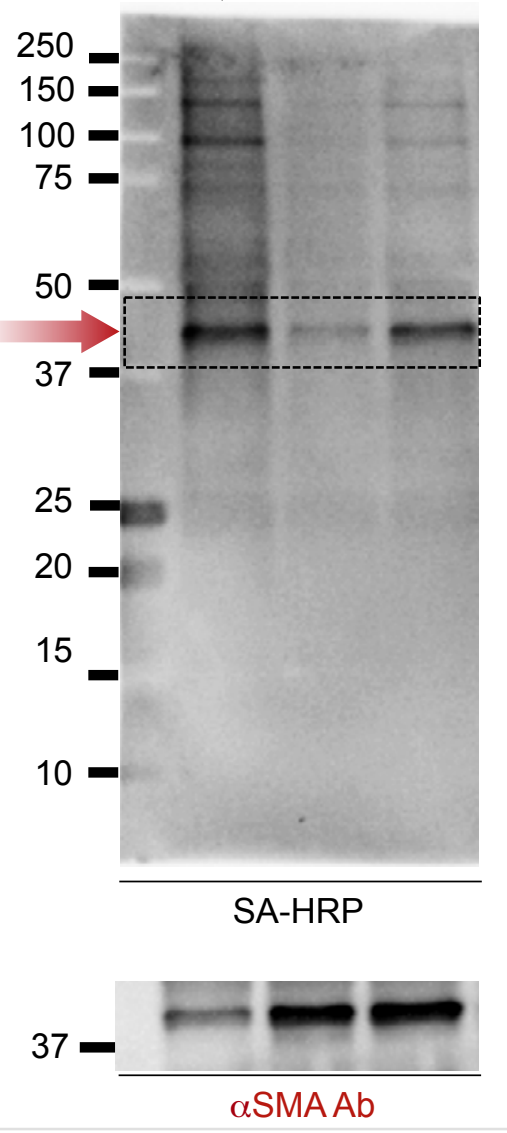




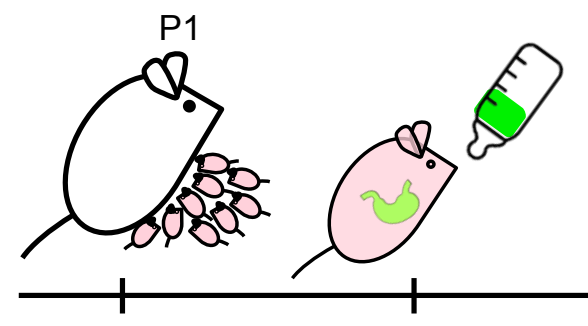

0-hours feeding

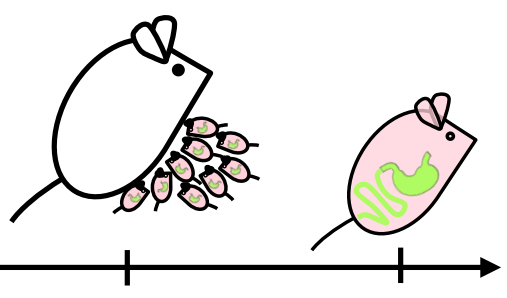

5-hours analysis

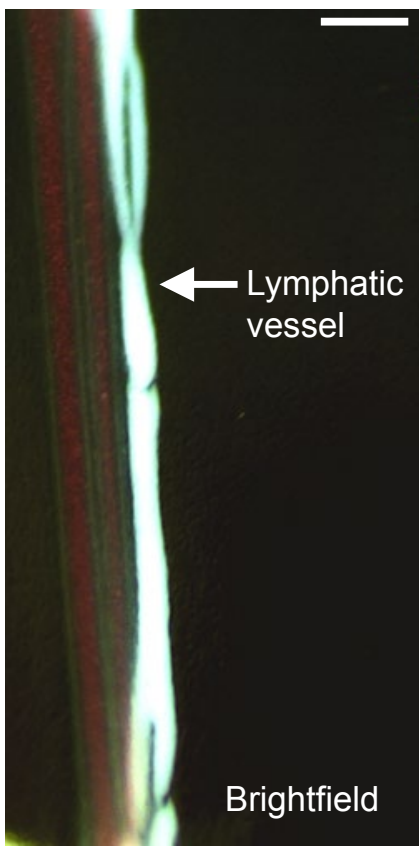

Intestine 5 hrs

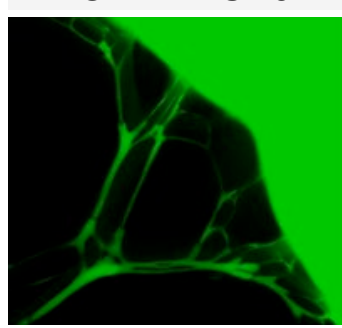

Mesenteric collecting vessels $5 \mathrm{hrs}$

Feeding 0 hrs

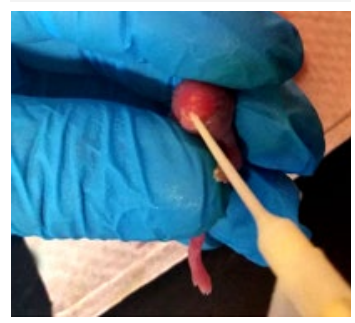

B
Intestine 5hrs Brightfield

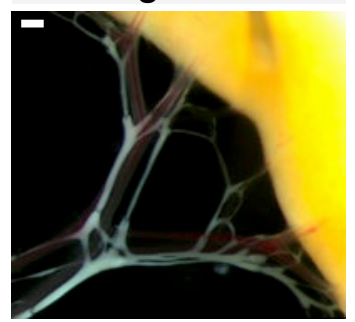

Abnormal BODIPY C16 gut-liver entry in Pitx2 ASE/ASE P1 neonates

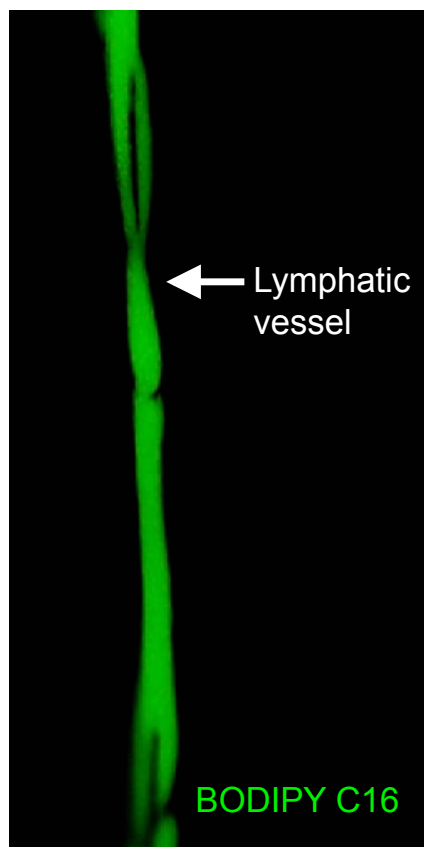

\section{BODIPY C16}

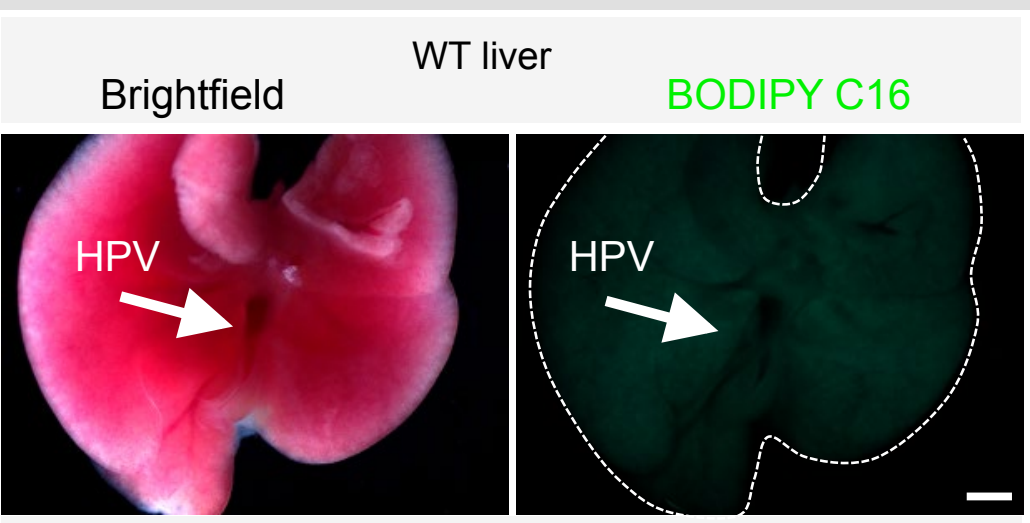

Pitx2 $2^{\text {ASE/ASE }}$ liver

Brightfield

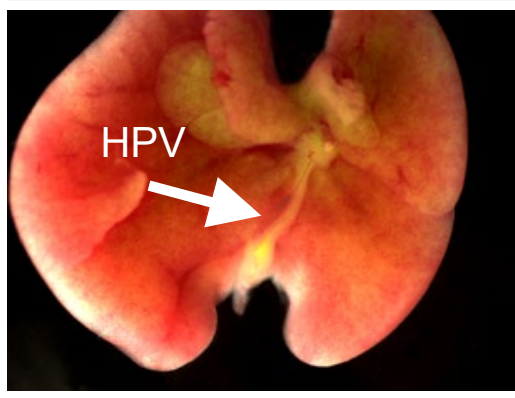

BODIP C16

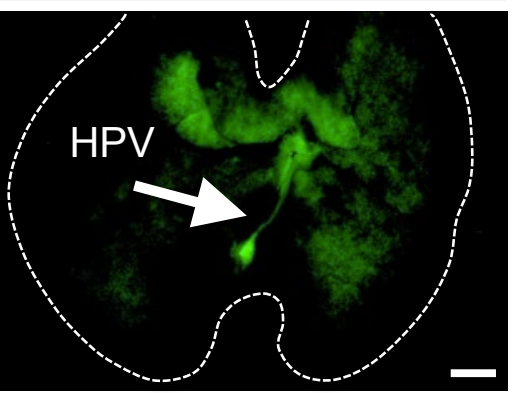

WT Liver section

BODIPY C16

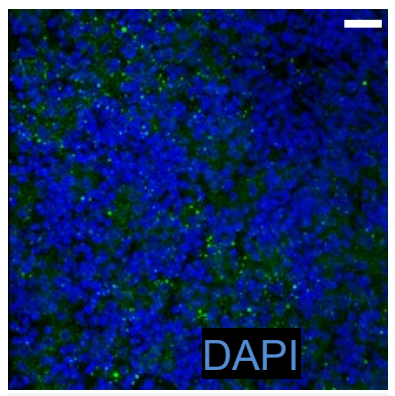

Pitx2 ${ }^{\text {ASE } / A S E}$ liver section BODIPY C-16

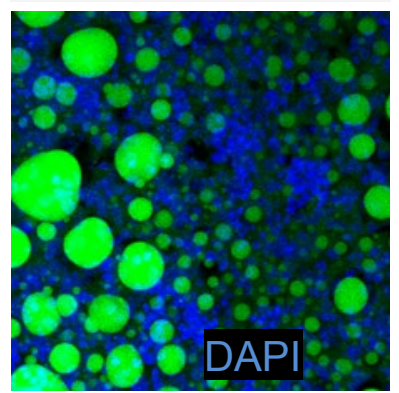

WT portal vein

Brightfield

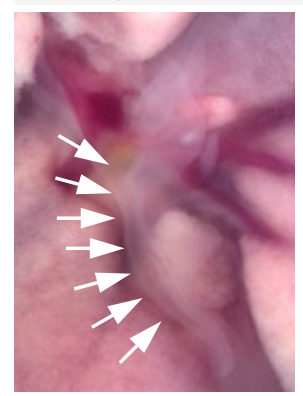

BODIPY C16

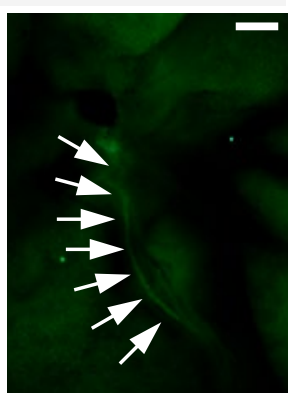

Pitx2 $2^{\text {ASE/ASE }}$ portal vein

Brightfield

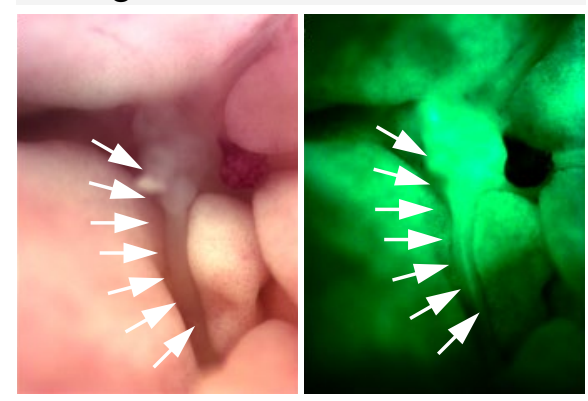

C

Model demonstrating altered lipid transport route in Pitx2 $2^{\text {ASE/ASE }}$ pups

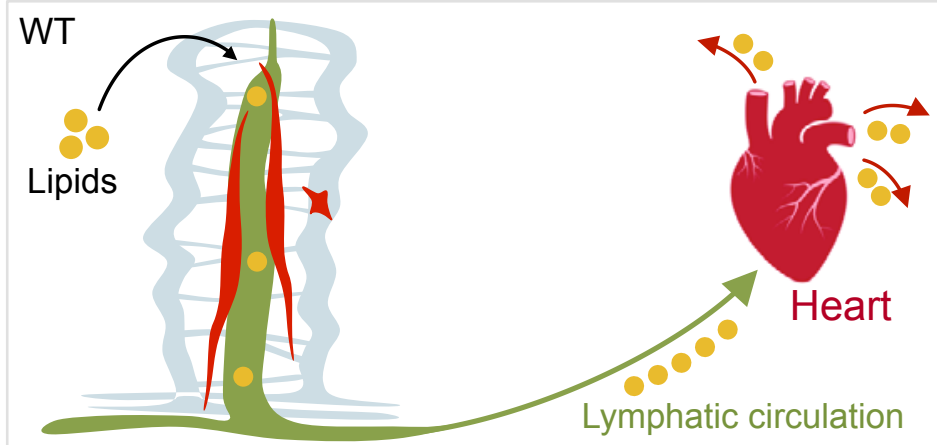

Pitx2 $2^{A S E} / A S E$

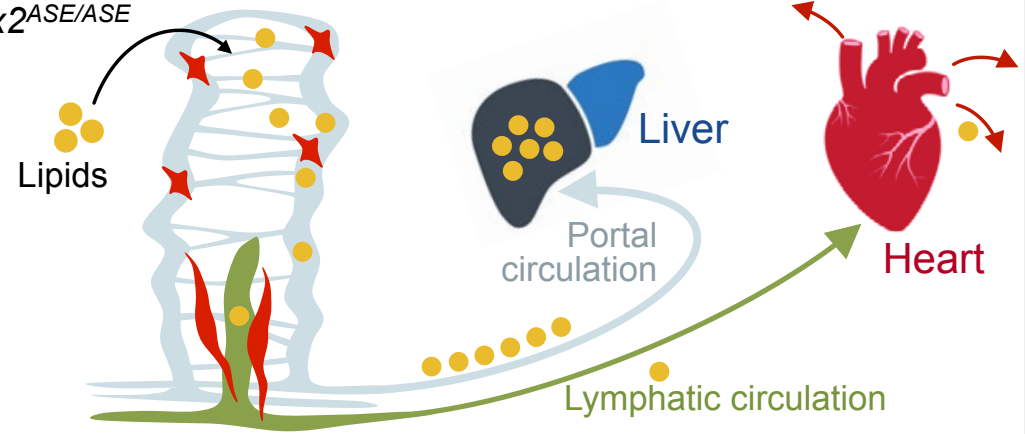


E18.5

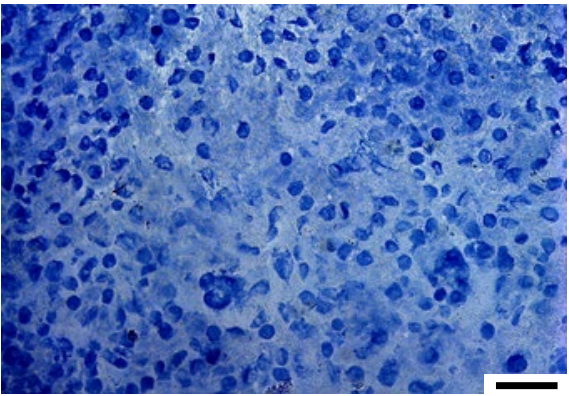

PItx2ASE/ASE liver

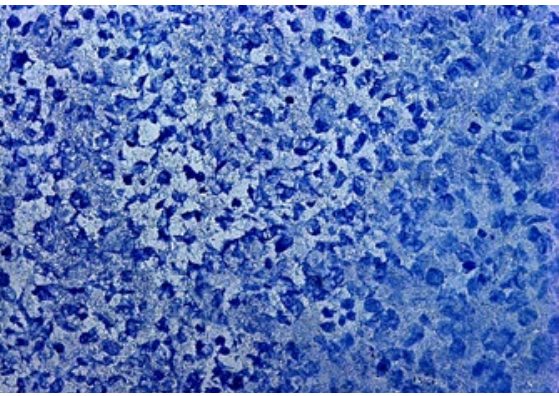

P1.5
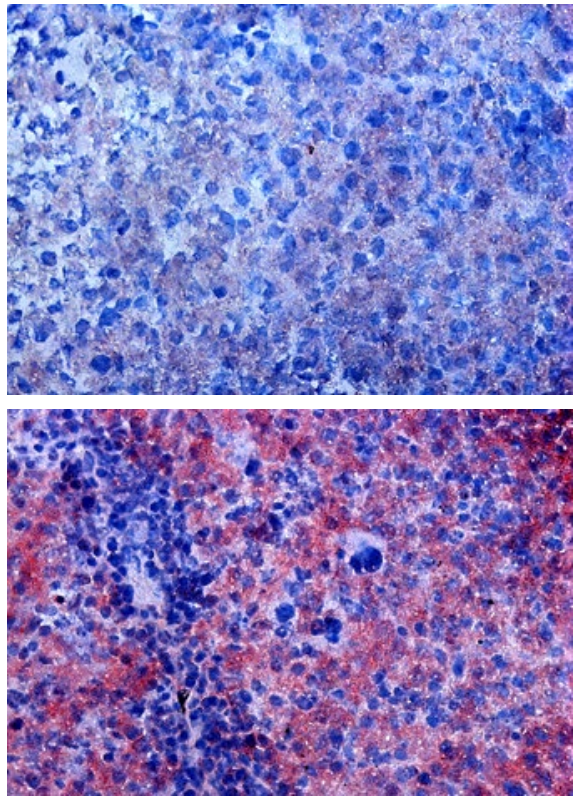

P11
B

Pre-weaning pups P9-P21

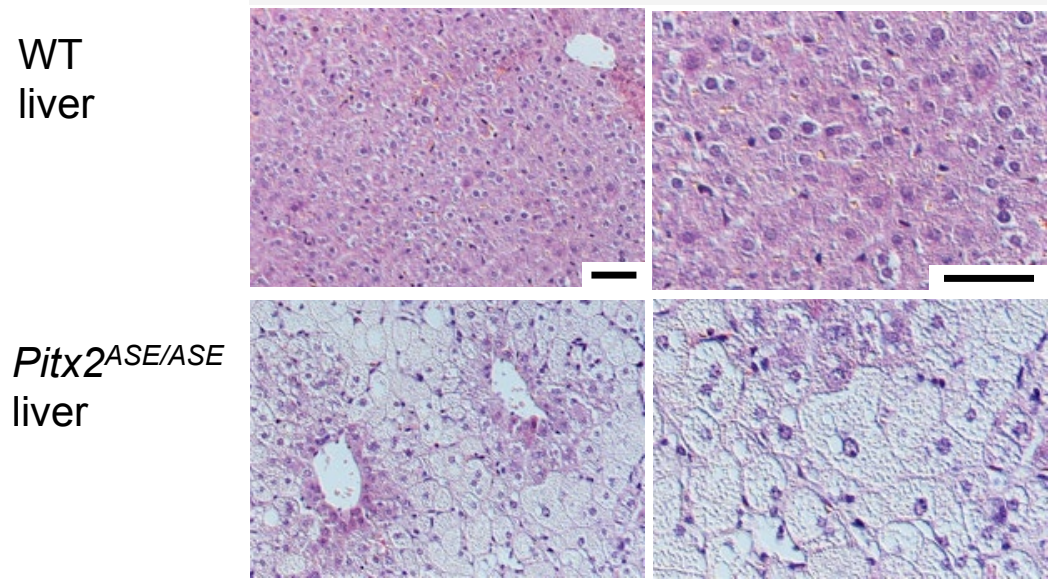

Weaned cubs >P21

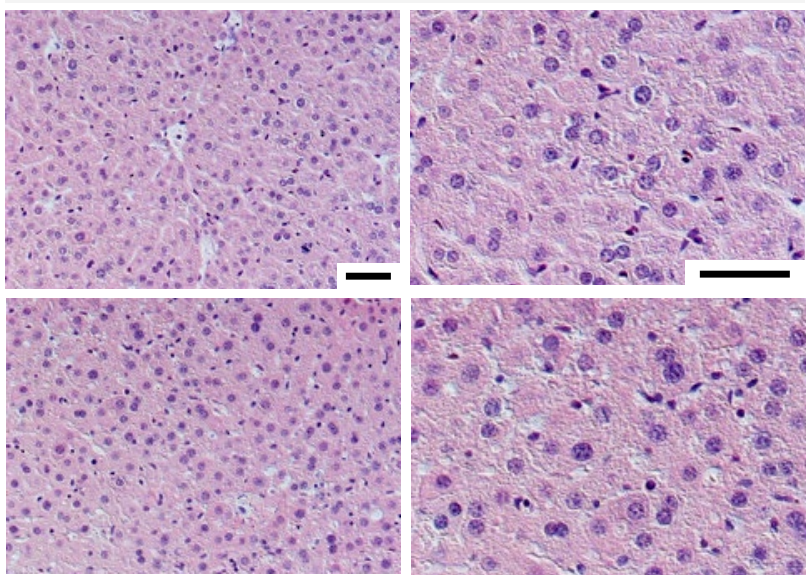

C Structural lacteal defects remain in post-weaning Pitx2 $2^{\text {ASE/ASE }}$ cubs (P21-26)

Pitx2 $2^{\text {ASE } /+}$

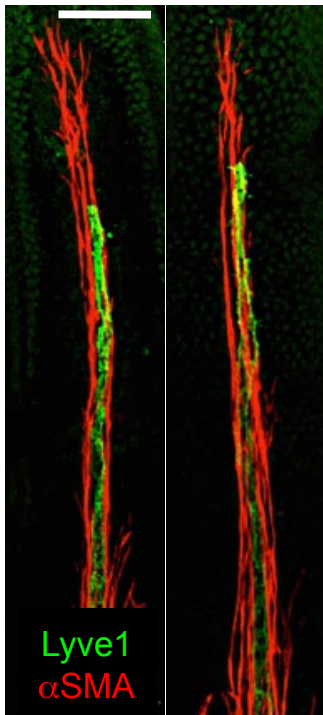

Pitx2 $2^{\text {ASE/ASE }}$

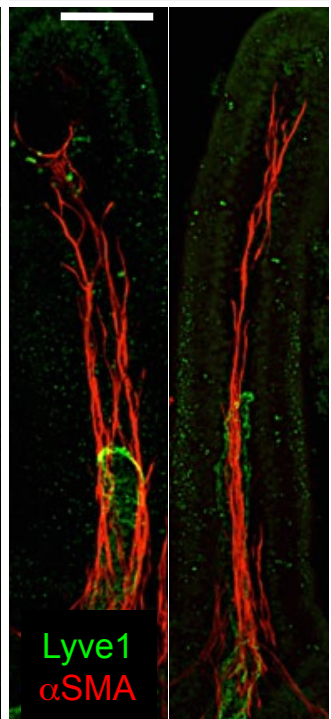

\% lacteal with filopodia

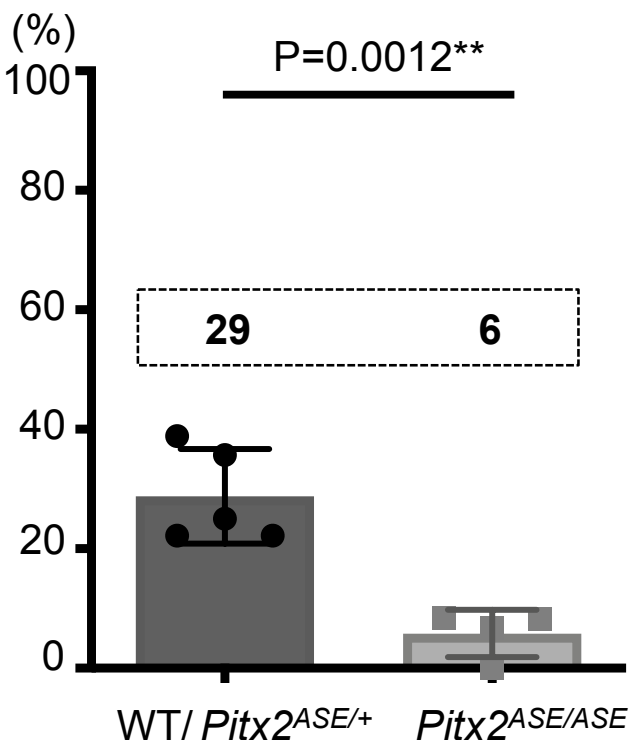

$\%$ lacteal with open bundles

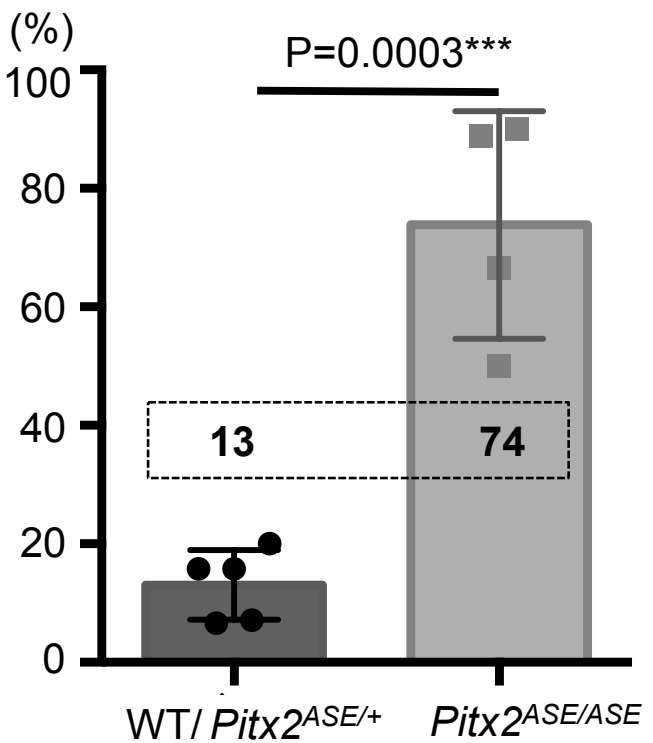




\section{FIGURE 8 Model for the role of ASE during gut lymphatic development and function}

\section{WT}

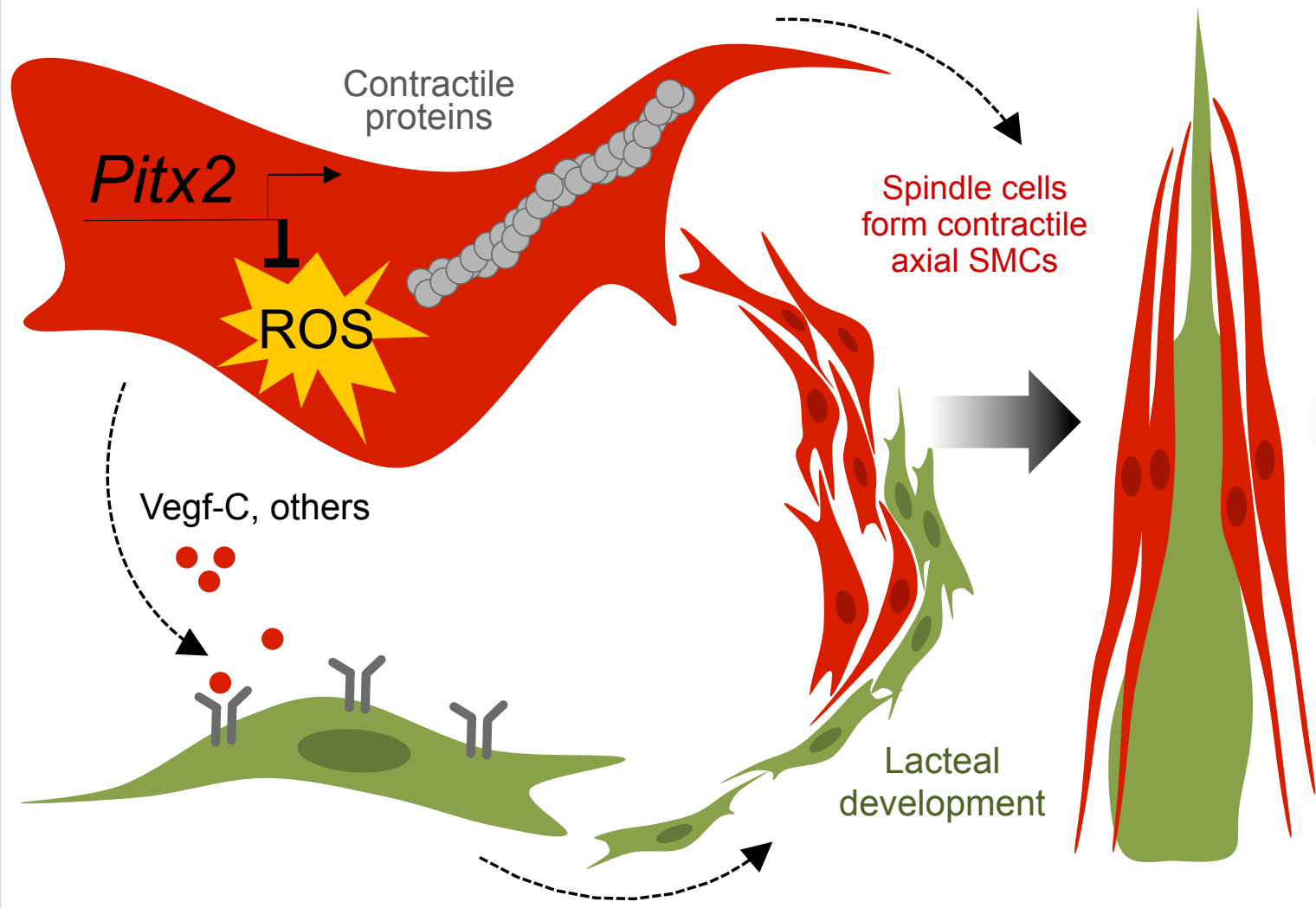

HEALTHY

LIVER

\section{Lymphatic} dependent lipid trafficking

\section{Pitx2ASE/ASE}

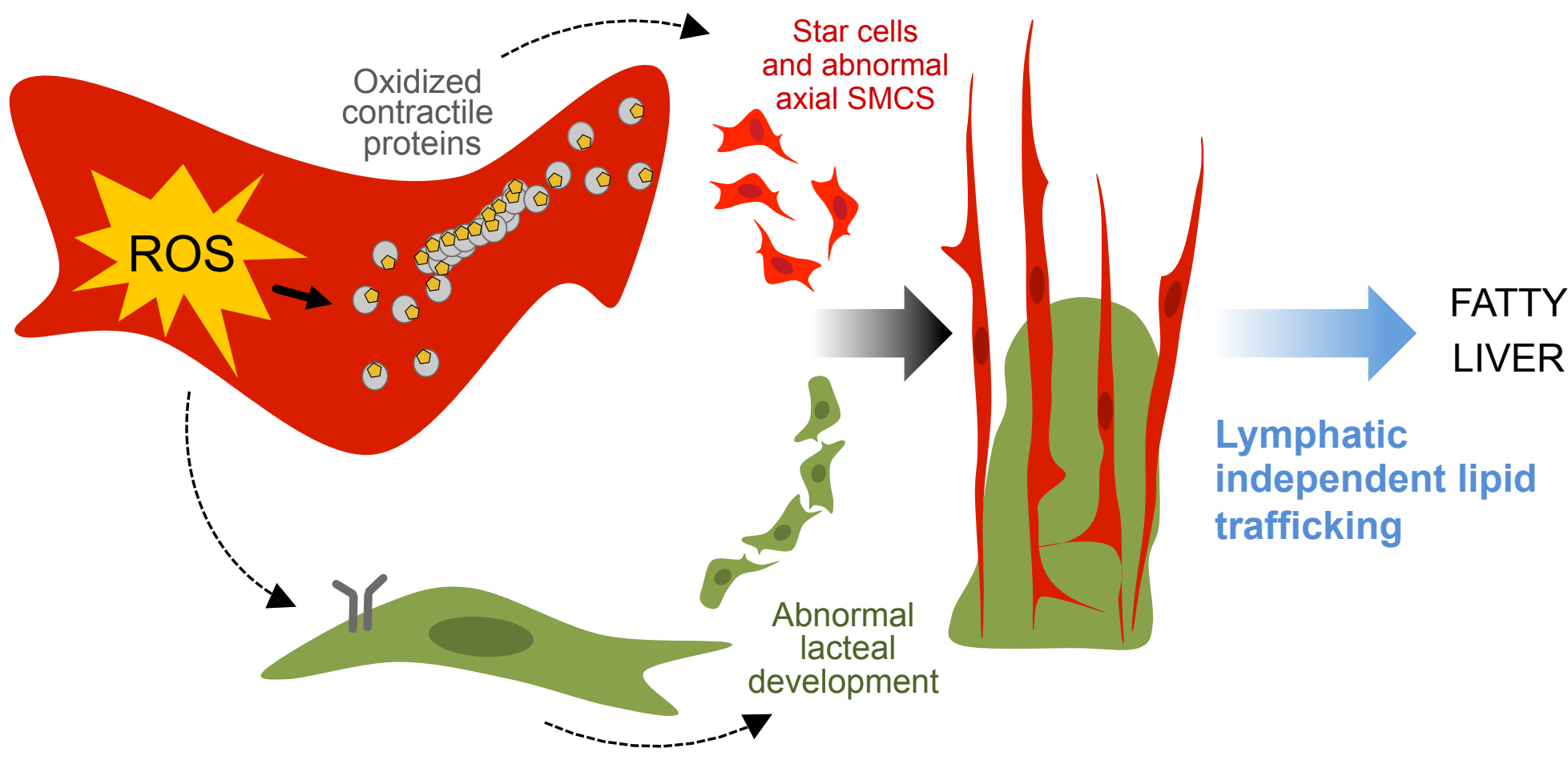


bioRxiv preprint doi: https://doi.org/10.1101/2021.06.11.447753; this version posted June 11, 2021. The copyright holder for this preprint (which was not certified by peer review) is the author/funder, who has granted bioRxiv a license to display the preprint in perpetuity. It is made available under aCC-BY 4.0 International license.

\section{FIGURE S 1}

Failure to properly gain weight in Pitx $2^{\text {ASE/ASE newborns }}$

A

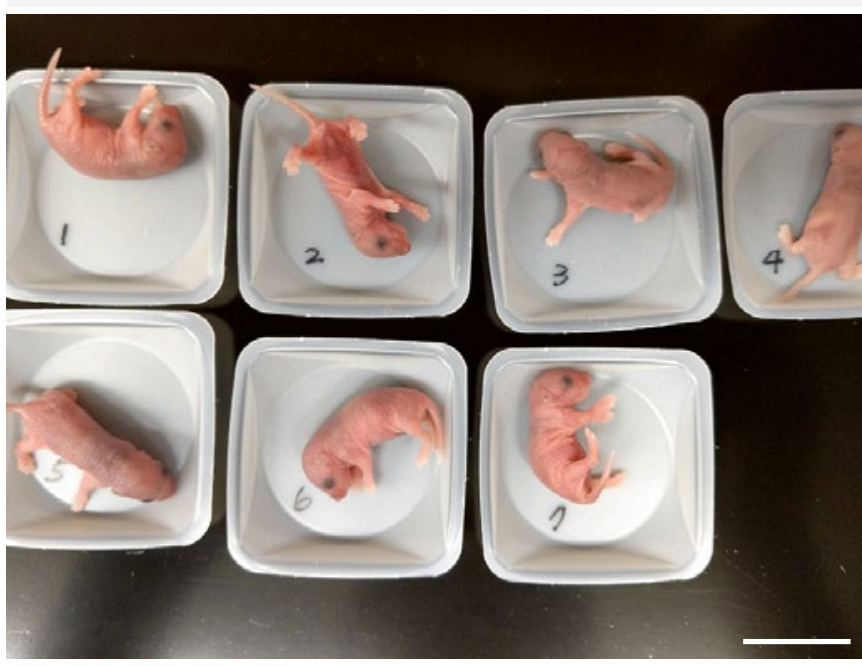

B

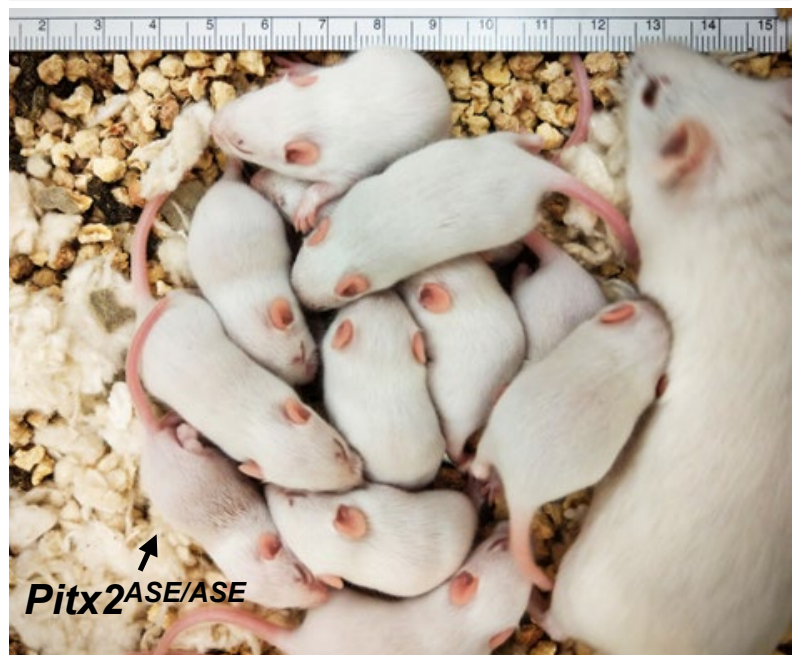




\section{FIGURE S2}

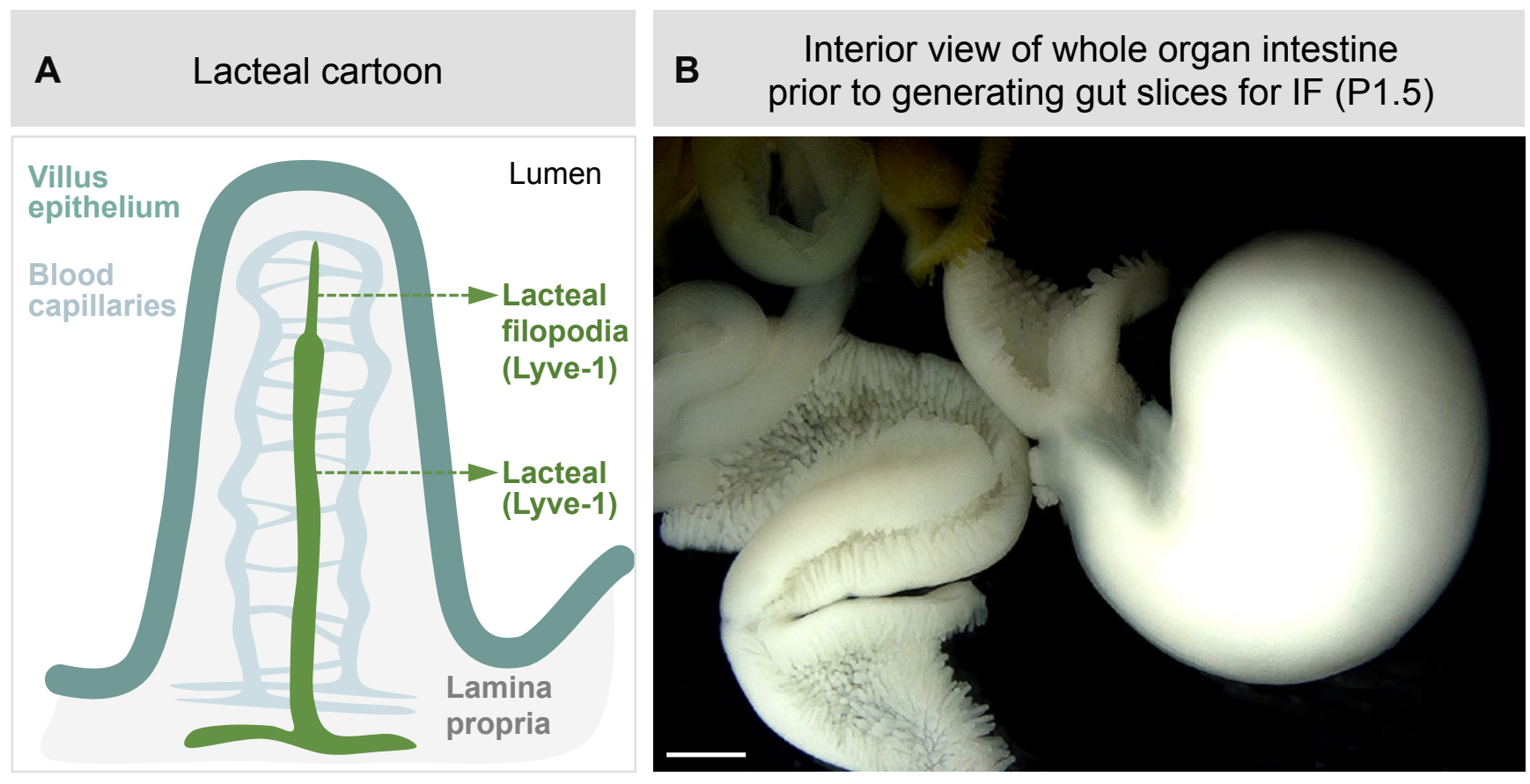

C

Reduced number of lacteals in Pitx2 $2^{\text {ASE/ASE }}$ intestine

E18.5 \% villus with lacteal

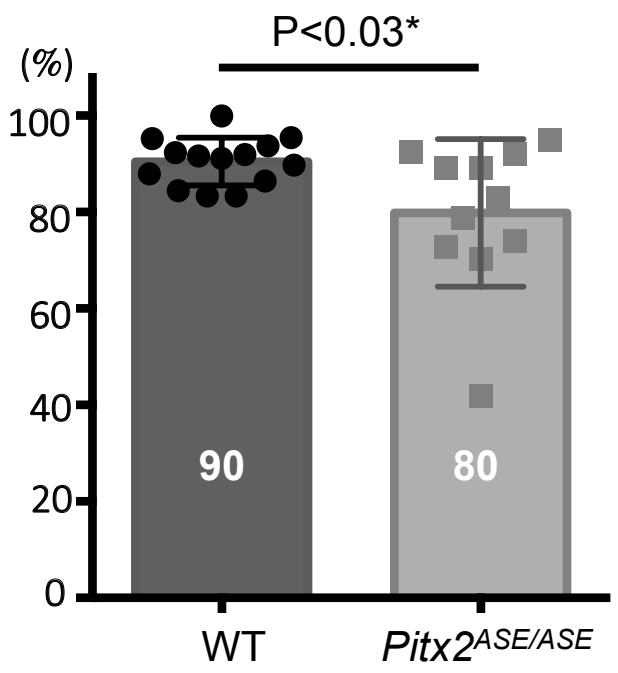

P9 \% villus with lacteal

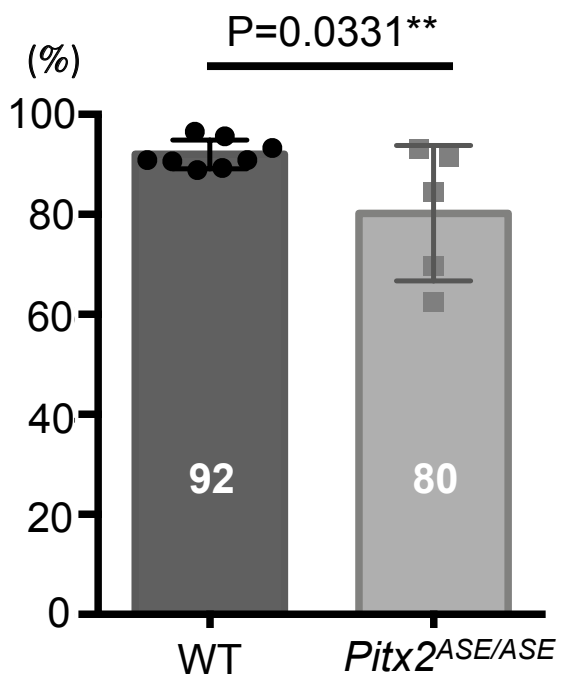




\section{FIGURE S3}

A Pitx2 lineage tracing in the gut using Pitx2-Cre mice
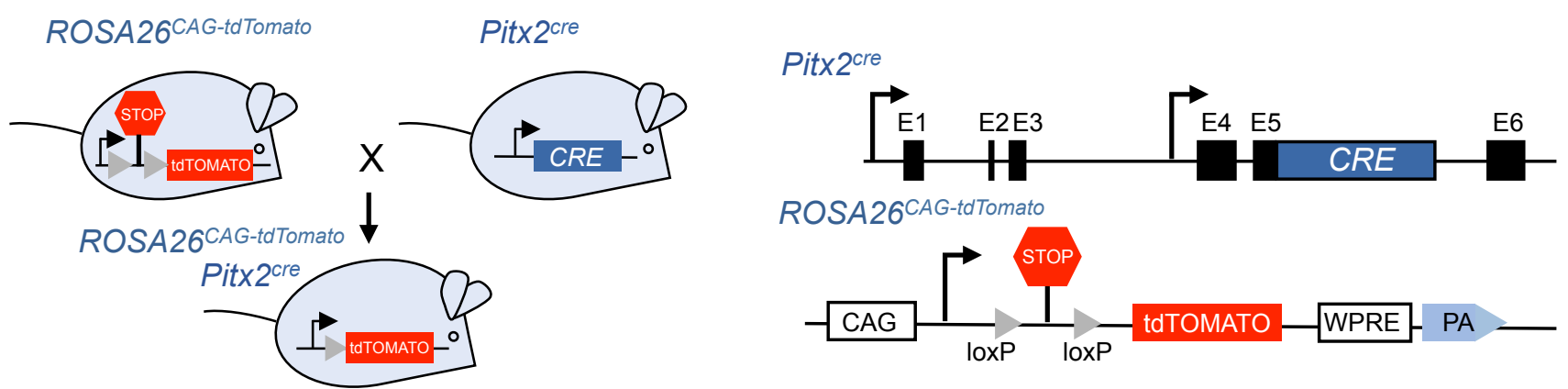

\section{A' P1.5}

digestive tract
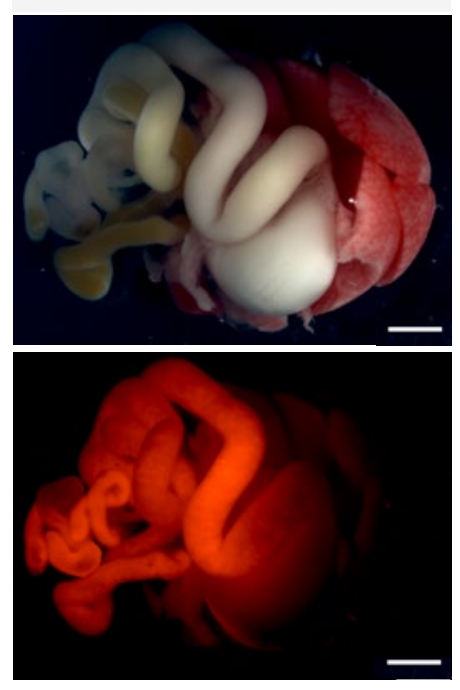

A"

P9 villous whole mount immunofluorescence tdTomato outside of LECs
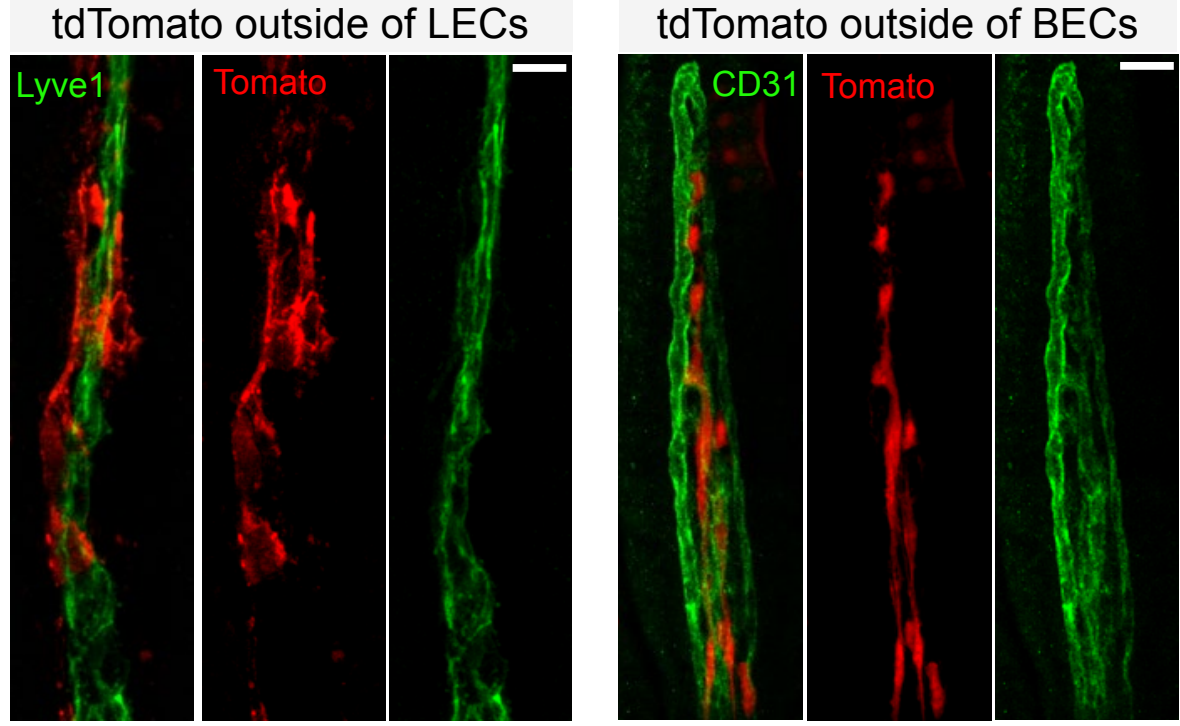

B Villus smooth muscle hypotrophy within the lamina propria (P26)

\section{Pitx2 ${ }^{\text {ASE } /+}$}

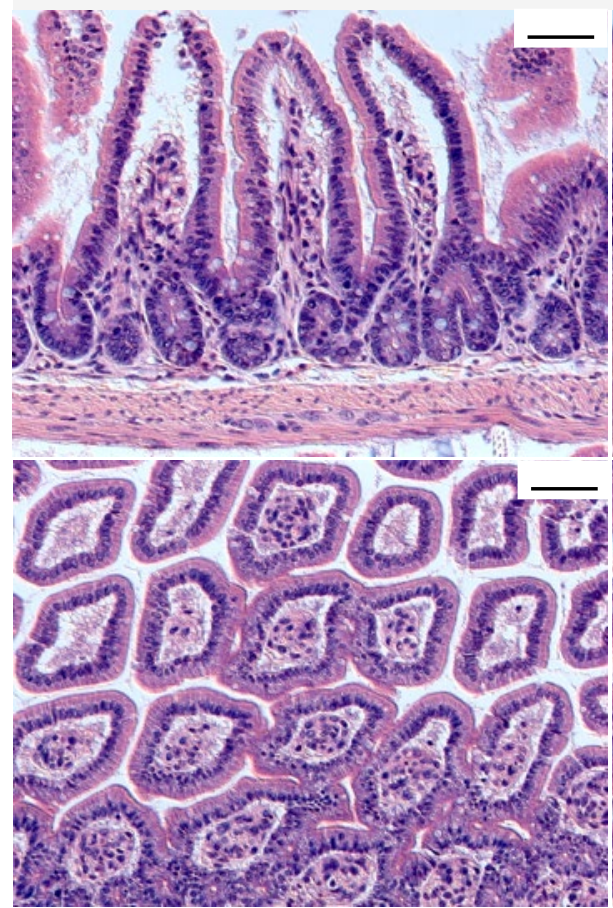

Pitx2ASE/ASE
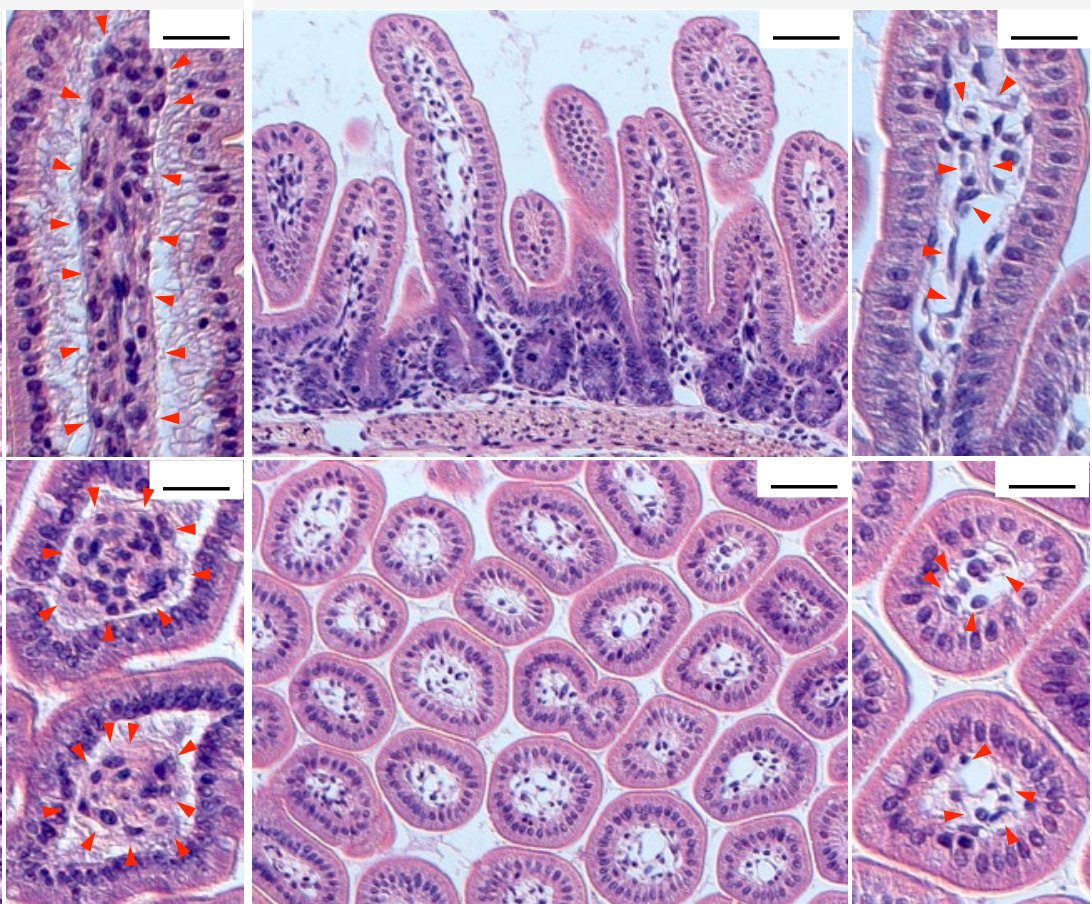
bioRxiv preprint doi: https://doi.org/10.1101/2021.06.11.447753; this version posted June 11, 2021. The copyright holder for this preprint

(which was not certified by peer review) is the author/funder, who has granted bioRxiv a license to display the preprint in perpetuity. It is made available under aCC-BY 4.0 International license.

\section{FIGURE S4}

A Villus SMA+ star cells associate with CD31+ vascular plexus during early development

E16.5

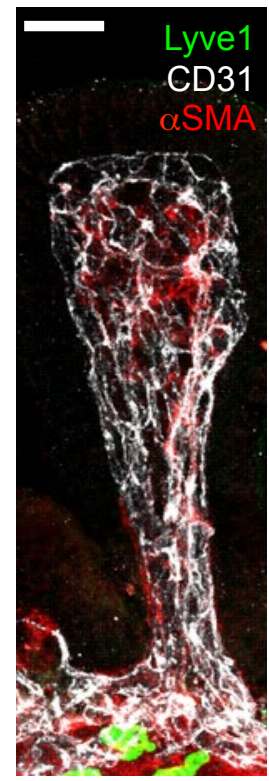

B

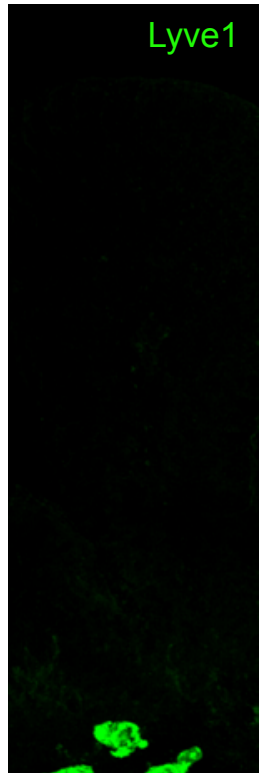

E18.5

P1.5

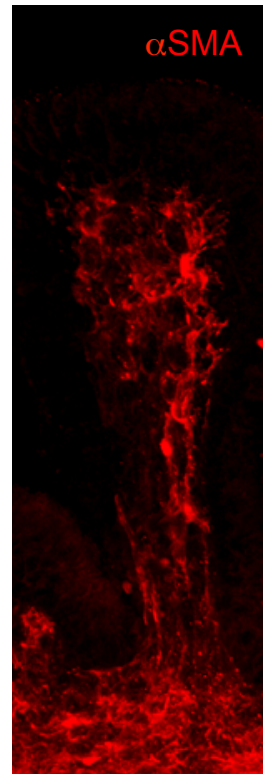

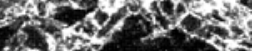

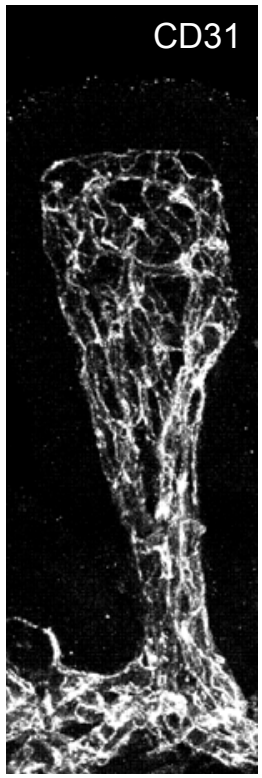

Star cells, but not spindle cells, are proliferative (E18.5)

Prophase

Metaphase

Anaphase

Telophase

Spindle cell
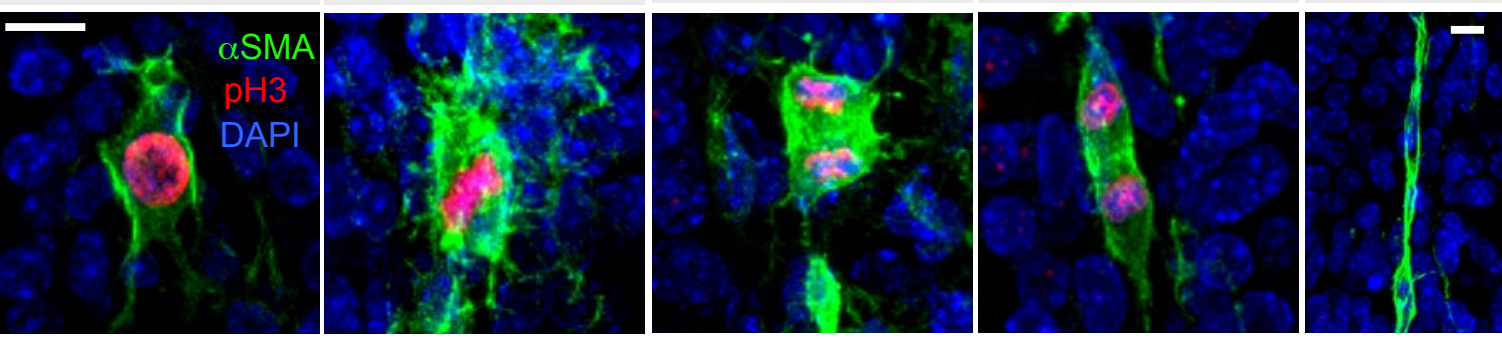

C SMC/lacteal

D Contractile protein expression in star cells versus bundle cells (P9)
E

TUNEL of villus axial SMCs at P9

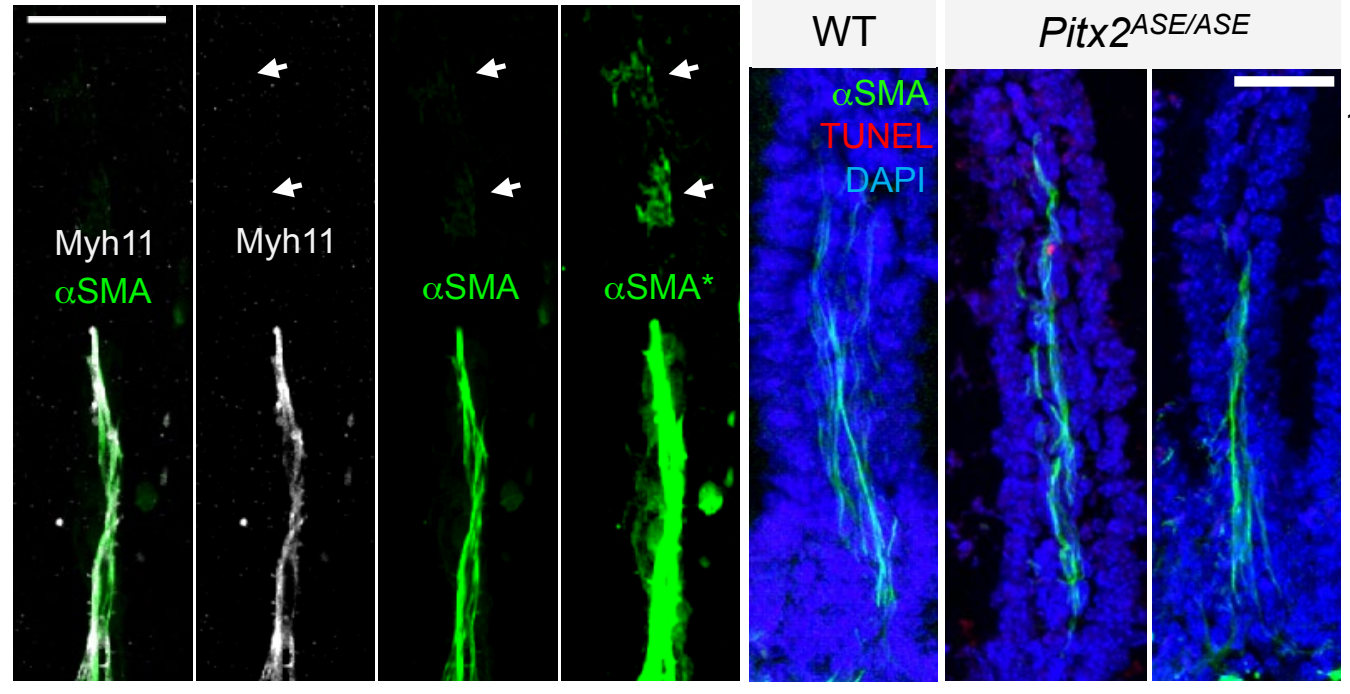

(\%)

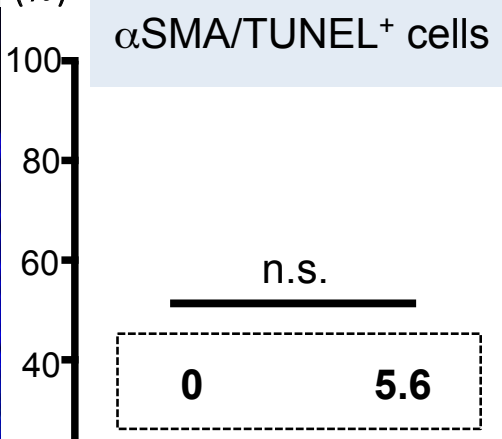

20

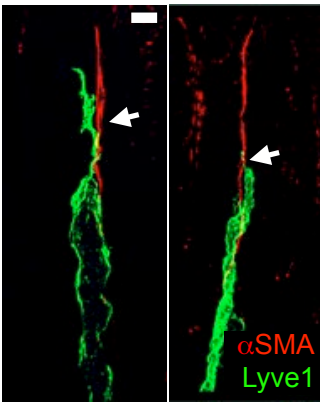


bioRxiv preprint doi: https://doi.org/10.1101/2021.06.11.447753; this version posted June 11, 2021. The copyright holder for this preprint (which was not certified by peer review) is the author/funder, who has granted bioRxiv a license to display the preprint in perpetuity. It is made available under aCC-BY 4.0 International license.

\section{FIGURE S5}

\section{A In vivo binding of Pitx2 to glutamate cysteine ligase (Gc/c)}

\section{$\stackrel{\text { Pitx2 }}{\longrightarrow}$ Gclc}

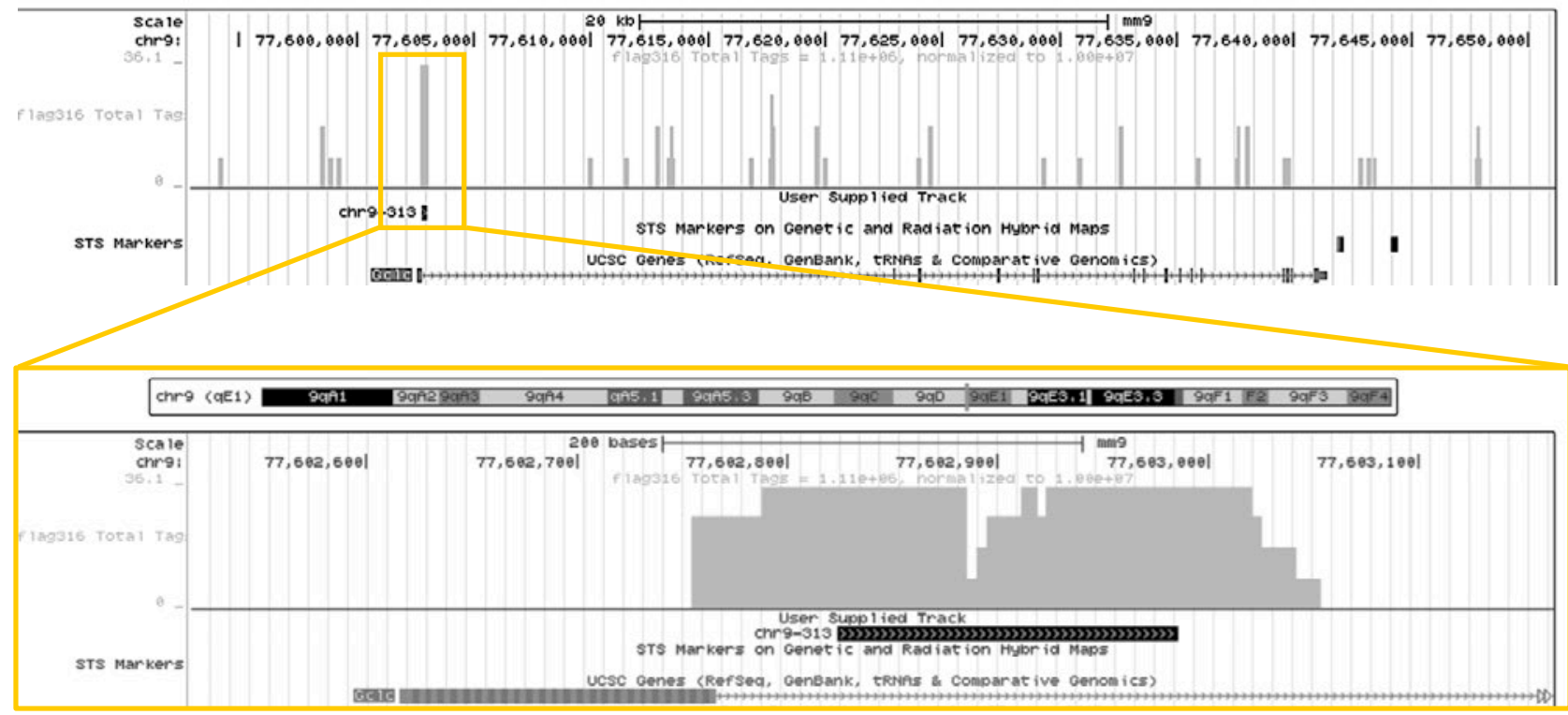

B

Fragmented $\alpha$ SMA expression pattern in Pitx2 $2^{A S E / A S E}$ mice (P21)

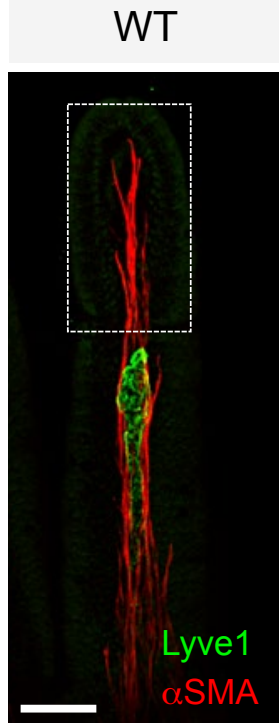

$$
\text { Pitx2 }{ }^{\text {ASE} / A S E}
$$

WT

Pitx2 ${ }^{\text {ASE/ASE }}$
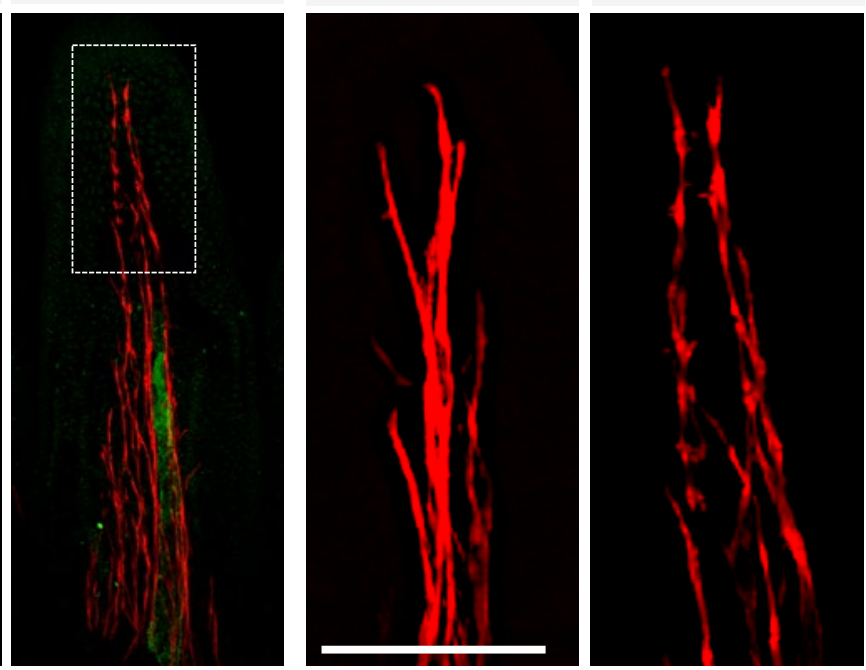
bioRxiv preprint doi: https://doi.org/10.1101/2021.06.11.447753; this version posted June 11, 2021. The copyright holder for this preprint (which was not certified by peer review) is the author/funder, who has granted bioRxiv a license to display the preprint in perpetuity. It is made available under aCC-BY 4.0 International license.

\section{FIGURE S6}

BODIPY C16 is detectable in the mesenteric collecting vessels of Pitx2 ${ }^{\text {ASE/ASE }}$ pups

\section{Brightfield}

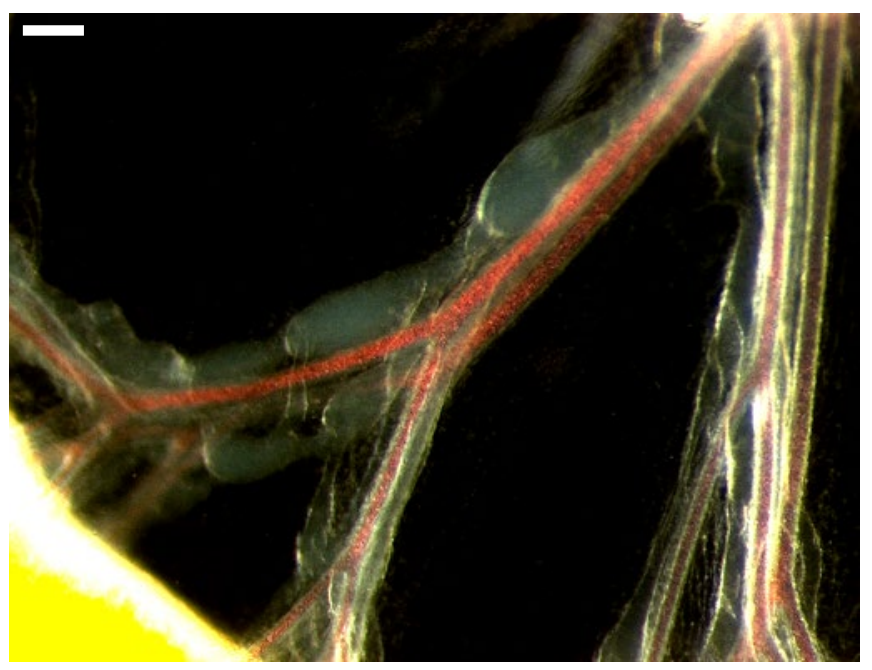

BODIPY C16

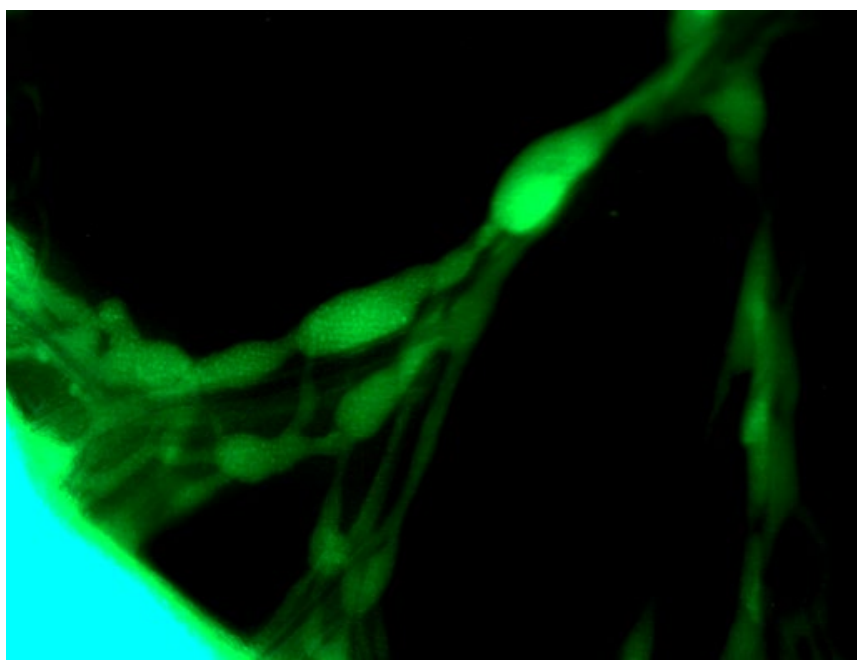


bioRxiv preprint doi: https://doi.org/10.1101/2021.06.11.447753; this version posted June 11, 2021. The copyright holder for this preprint (which was not certified by peer review) is the author/funder, who has granted bioRxiv a license to display the preprint in perpetuity. It is made available under aCC-BY 4.0 International license.

\section{FIGURE S7}

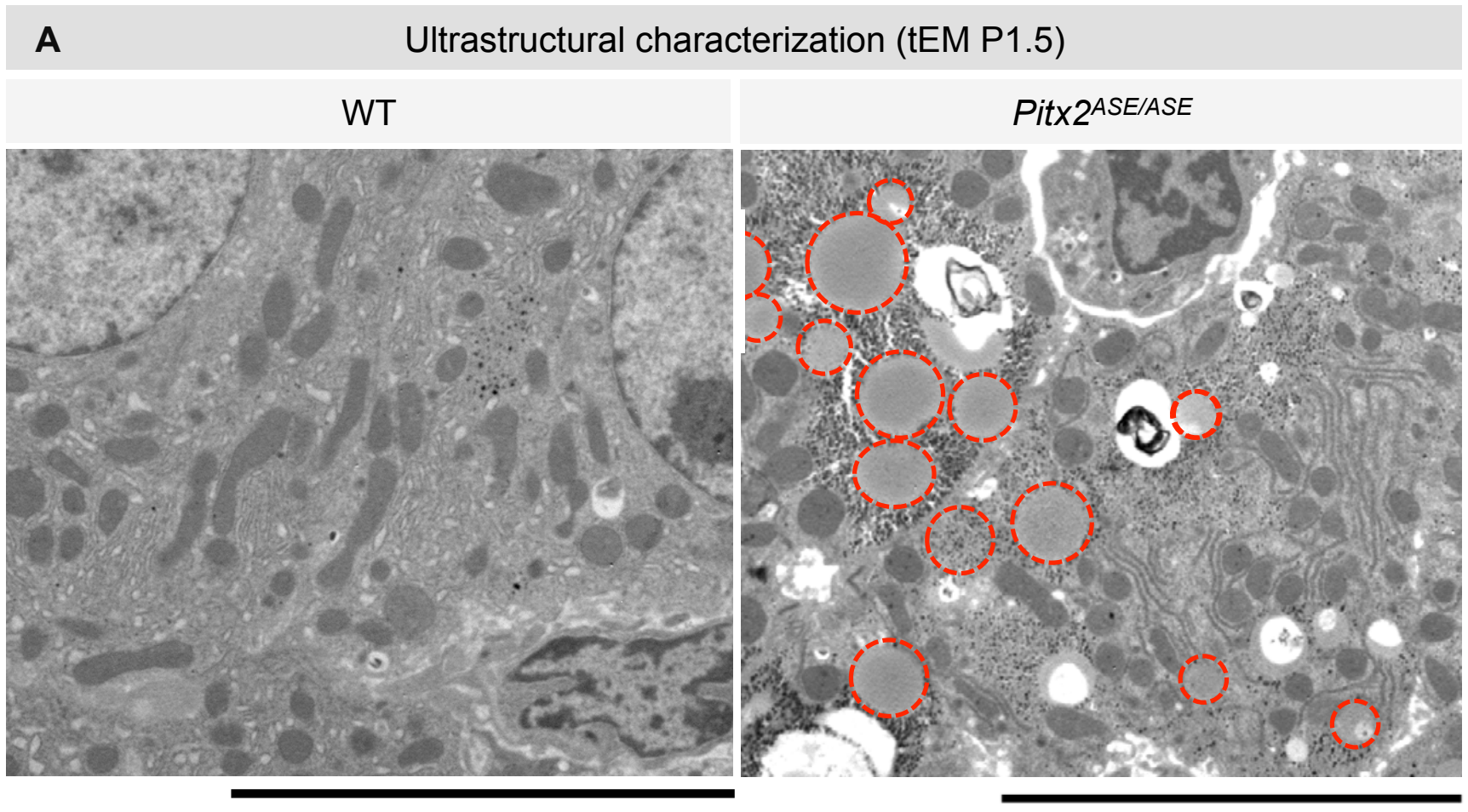

\section{B Fatty liver disease prevalence in Pitx2 ${ }^{\text {ASE } / A S E}$ mice}

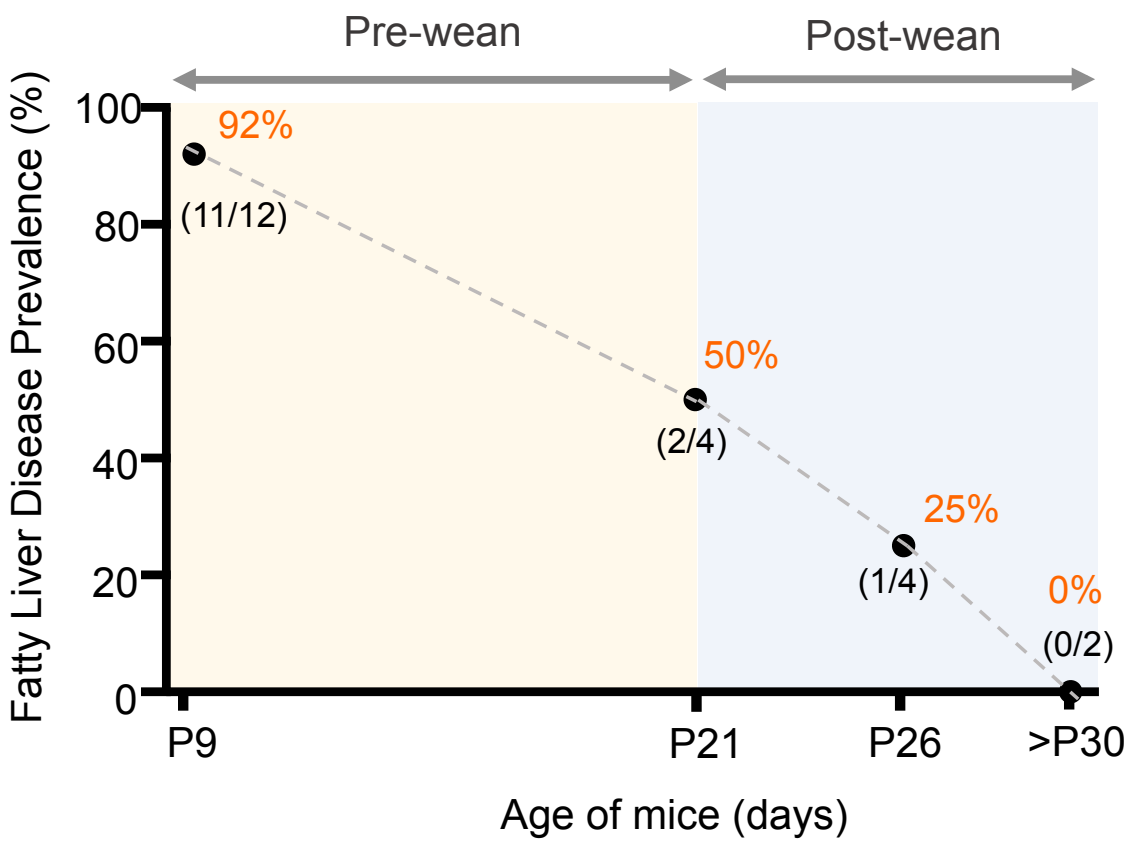

